\title{
A RENDA DA TERRA NO SISTEMA ECONÔMICO SRAFFIANO
}

PAULO REGIS VENTER

Engenheiro Agrôniomo

Orientador: Prof. Dr. Rodolfo Hof fmann

Dissertação apresentada à Escola Superior de Agricultura "Luiz de Queiröz", da Universidade de São Paulo, para obtenção do título de Mestre em Agronomia, Area de concentração: Economia Agräria.

P I R A C I C A B A

Estado de São Faulo - Brasil

Agosto - 1990 
Ficha catalográfica preparada pela Seção de Livros da Divisão de Biblioteca e Documentação - PCAP/USP

Venter, Paulo Régis

V465r A renda da terra no sistema econômico Sraffiano. Piracicaba, 1990.

$167 p$.

Diss.(Mestre) - ESALQ

Bibliografia.

1. Renda - Distribuição 2. Teoria\$ de Piero Sraffra 3. Terras-Renda I. Escola Superior de Agricultura Luiz de Queiroz, Piracicaba 


\section{A RENDA DA TERRA NO SISTEMA ECONÔMICO SRAFFIANO}

PAULO REGIS VENTER

Aprovada em: 03.08.1990

Comissão julgadora:

Prof. Dr. Rodolfo Hoffmann

ESALQ NSP

Prof. Dr. Carlos José Caetano Bacha

ESALQ/USP

Prof. Dr. José Eli da Veiga

FEA/USP

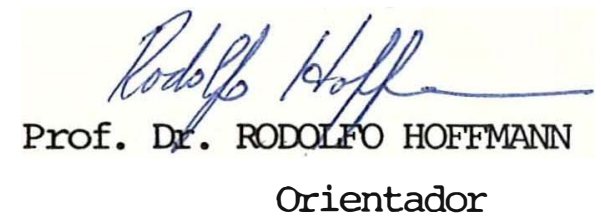


A meus pais, Guido e Valdomira, pelo carinho e apoio, OFEREÇO.

A Karen e Giuliana, pelo amor que tenho por elas, DEDICO. 


\section{A RENDA DA TERRA NO SISTEMA ECONÔMICO SRAFFIANO}

Autor: PAULO REGIS VENTER

orientador: PROF. DR. RODOLFO HOFFMANN

RESUMO

o objetivo central desse trabalho e a apresentação da teoria econômica da renda da terra, considerando sistemas econômicos sraffianos. Para atingir esse objetivo, foram analisados o trabalho de Piero Sraffa (Producão de mercadorias por meio de mercadorias) e os trabalhos que desenvolveram as considerações originais de Sraffa, sobre a renda da terra. Em seguida, procurou-se realizar uma dissertação didatica sobre o tema, de forma que os leitores pudessem acompanhar o desenvolvimento teorico sem consultar os trabalhos originais.

Inicialmente e apresentado um resumo dos principais aspectos das teorias antecedentes (ricardiana, marxista e marinalista) que trataram do mesmo tema, a fim de introduzir-se o contexto no qual a teoria sraffiana se desenvolve. Tambem discorreu-se sobre os aspectos teoricos do sistema econômico sraffiano, necessarios à compreensão da exposicão da teoria da renda da terra neste sistema. 
- trabalho conclui com uma pequena sintese comparativa entre a teoria sraffiana e as que a precederam, argumentando que a grande novidade daquela teoria refere-se à constatação de que a determinação da renda da terra e, portanto, da escassez da terra, tambem esta condicionada à previa distribuição do excedente econômico de um sistema entre lucros e salarios.

Conclui-se, tambem, que o modelo sraffiano es superior, quanto à sua consistência logica, às teorias precedentes no que se refere à explicação da renda da terra quando ha um unica qualidade de terra e quanto à andlise do progresso tecnologico na agricultura. Em virtude de sua formalizacão matematica, a teoria sraffiana da renda da terra tambem serviu para constatar deficiências das teorias anteriores, principalmente quanto à variacão das ordens de eficiência e de rentabilidade das terras frente a mudanças na distribuição da renda.

Finalmente, cabe ressaltar que as conclusões da teoria sraffiana da renda da terra estão condicionadas à hipotese de retornos constantes à escala nos diferentes processos produtivos da economia, e notar que essa teoria não tem sido utilizada como base para andlises de dados observados. 


\section{LAND RENT IN THE SRAFFIAN ECONOMIC SYSTEM}

Author: PAULO REGIS VENTER

Adviser: PROF. DR. RODOLFO HOFFMANN

SUMMARY

The central objective of this work is the presentation of the economic theory of land rent in the sraffian economic system. The book of Piero sraffa, Production of Commodities by Means of Commodities, was studied, as well as the papers of the other authors that developed the original analysis of sraffa on land rent. This dissertation tries to present the results of this literature in such a way that the reader does not need to go back to the original papers.

Inicially, the main aspects of the theories that preceded sraffa (ricardian, marxist and marginalist) are presented, in order to show the context in which the sraffian theory was developed. The principal caracteristics of Sraffa's work are also analysed.

The dissertation concludes with a comparison among sraffa's theory on land rent and the others, showing 
that the main novelty is the fact that in sraffa's theory the determination of rent and, therefore, land scarcity, depend on the previous distribution of the economic surplus between profits and wages.

It is shown that the sraffian model is superior, in terms of its logical consistency, to the preceding theories in the explanation of rent when all land is of the same quality and also in the analysis of technical progress in agriculture. The greater formalization of the sraffian model allowed to show some weaknesses of the preceding theories, mainly in relation with the change in the order of efficiency and rentability of different types of land with changes in income distribution.

$$
\text { Finally, it is recognized that the }
$$
conclusions of the sraffian theory on land rent depend on the assumption of constant returns to scale in the production process, and that this theory has not been used to analyse empirical data. 
SUMARIO

Pàgina

RESUMO

vi



1. O TEMA E SUA IMPORTANCIA ................... 1

1.1. Introducão .......................... 1

1.2. Os objetivos do trabalho ................ 5

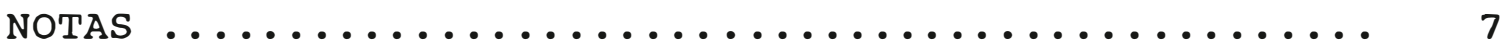

2. A EVOLUCAO DO PENSAMENTO ECONOMICO SOBRE A RENDA DA TERRA

2.1. o pensamento de David Ricardo .............. 8

2.2. o pensamento de $\operatorname{Karl} \operatorname{Marx} \ldots \ldots \ldots \ldots \ldots \ldots \ldots \ldots$

2.3. Os desenvolvimentos marginalistas .......... 28

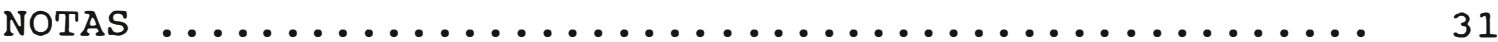

3. O SISTEMA ECONOMICO SRAFFIANO ............... 36

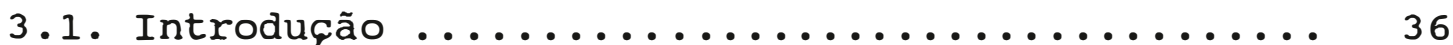

3.2. O sistema de precos 40

3.3. Mercadorias bdsicas e não-bdsicas ........... 44

3.4. Reducão a quantidades de trabalho "datadas" ... 47

3.5. Escolha da tecnologia de producão ........... 51

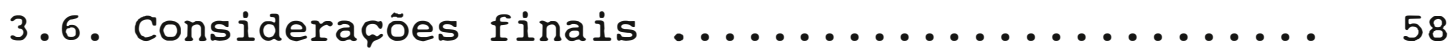

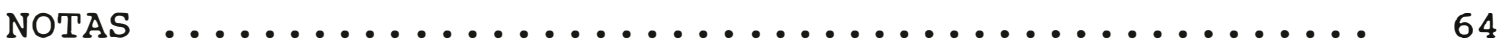

4. A RENDA DA TERRA NO SISTEMA ECONOMICO SRAFFIANO ... 67



4.2. A renda diferencial extensiva ............. 69 
4.2.1. Hipoteses e definicões

4.2.2. A ordem de eficiência das terras e o processo de crescimento extensivo da producão agricola

4.2.3. As mudanças autônomas na distribuição e a renda diferencial extensiva ......... 78

4.2.4. A não coincidência das ordens de eficiência e de rentabilidade das terras ......... 85

4.2.5. Um ultimo exemplo ilustrativo ....... 92

4.3. A renda intensiva 97

4.3.1. Introducão 97

4.3.2. Hipoteses e definições ............. 99

4.3.3. A soluqão do sistema de preços ........ 100

4.3.4. O crescimento intensivo da producão agricola

4.3.5. As mudanças autônomas na distribuicão e a renda intensiva ............... 112

4.3.5.1. Introdução ............... 112

4.3.5.2. Relações entre taxas de lucro, salario e renda da terra .............. 117

4.3.5.3. A possibilidade de uma relą̧ão w-r crescente: a indeterminação para uma dada taxa de salario ................... 122

4.3.5.4. Um outro tipo de indeterminacão ..... 127

4.3.5.5. A indeterminação e a inexistência de uma solucão para uma dada taxa de lucro 130 
4.4. Alguns desenvolvimentos do modelo sraffiano da renda da terra ........................... 138 4.4.1. Introducão .................... 138 4.4.2. A renda singular ............... 139 4.4.3. A renda intensiva externa .......... 142 NOTAS 145 APENDICE - Sobre o calculo das quantidades ......... 152 V- UMA SINTESE ........................ 156 REFERENCIAS BIBLIOGRAFICAS ................ 162 
1. O TEMA E SUA IMPORTANCIA

\subsection{Introdução}

"O produto da terra - tudo o que se obtem de sua superflcie pela aplicacão combinada de trabalho, maquinaria e capital - se divide entre três classes da sociedade, a saber: o proprietario da terra, o dono do capital necessario para seu cultivo e os trabalhadores cujos esforcos são empregados no seu cultivo.

Em diferentes estagios da sociedade, no entanto, as proporcões do produto total da terra destinadas a cada uma dessas classes, sob os nomes de renda, lucro e salario, serão essencialmente diferentes, o que dependerd, principalmente, da fertilidade do solo, da acumulação de capital e de população, e da habilidade, a engenhosidade e dos instrumentos empregados na agricultura.

Determinar as leis que regulam essa distribuicão e a principal questão da economia pol1tica". E desta forma, no prefacio de sua principal obra (PRINCIPIOS DE ECONOMIA POLITICA E TRIBUTACAO), que David Ricardo coloca a renda da terra como assunto da maior 
relevância para o estudo da Economia Polltica.

Neste contexto, o estudo da renda da terra tornou-se questão obrigatoria a ser tratada pelos economistas classicos, a ponto de RICARDo(1982, Prefacio) afirmar que, "não tendo examinado corretamente os princlpios da renda, Adam Smith e outros (*) competentes autores a que fiz alusão, não apreenderam muitas verdades importantes, que so podem ser descobertas apos uma perfeita compreensão do problema da renda". Para Ricardo, a teoria da renda constitula-se parte integrante e essencial de sua teoria geral da distribuicão e do desenvolvimento .

Se, por outro lado, voltarmo-nos à obra de Marx, observaremos que o autor trata do tema em todo um volume de sua obra principal ("O CAPITAL" - livro 3, vol. 6). Argumentando que seu proposito, nesse volume, era "sobretudo, examinar as relações espec1ficas de produção e de circulação, oriundas da aplicação do capital na agricultura", o autor prossegue, logo a seguir, afirmando que "sem isso seria incompleta a andlise do capital" MARX (1985, p.706).

Alem de Ricardo e Marx, outros autores cldssicos tambem analisaram o tema, como Smith, Malthus, Torrens, Sismondi, etc.

Com $\circ$ advento da andlise marginalista, (*) Os numeros superescritos correspondem a NOTAS que se encontram ao final do cap1tulo. 
entretanto, o tema perdeu a importância que teve no nascimento da Economia Pol1tica, sendo levado a uma posicão secundaria e subordinada, pelo desenvolvimento das teorias do comportamento do consumidor e das trocas em mercados competitivos - Como afirma Blaug, " a economia moderna abandonou quase totalmente a noção de que seja necessâria uma teoria especial sobre a renda da terra" ".

Tomando como o "problema econômico fundamental" o da alocação de recursos escassos frente a natureza ilimitada dos desejos e necessidades sociais, os neoclassicos desenvolveram, a partir da andlise da renda intensiva ricardiana, uma teoria da distribuição da renda baseada na produtividade marginal de fatores escassos. Desta forma, a explicação para a repartição funcional da renda era a mesma para qualquer fator de produção, o que contrastava com a teoria classica. E assim sendo, o termo renda da terra perdeu qualquer relevância básica, segundo as crlticas de Jevons e Wicksteed. Para Marshall, a renda da terra era apenas "the leading species of a large genus" $^{5}$

Segundo FLICHMAN(1977, p.29), "esta perda de importância, vistvel mesmo atraves de observação superficial, e um reflexo da perda de especificidade do agrârio nas concepcões teoricas dominantes". O fato de um meio de producão (a terra) ser ou não produto do trabalho, não the traz nenhuma especificidade dentro do enfoque 
marginalista ${ }^{6}$

No entanto, o surgimento do trabalho de sraffa

("PRODUCAO DE MERCADORIAS POR MEIO DE MERCADORIAS"), em 1960, renovou o interesse por teorias da producão que retomassem o enfoque classico dos problemas do desenvolvimento capitalista a longo prazo. o trabalho de Sraffa deu origem à famosa CONTROVRRSIA DE CAMBRIDGE sobre a teoria neoclássica do capital e da distribuicão.

Esta controversia, ao mostrar as deficiências daquela teoria, recolocou o enfoque clássico de volta à discussão dos problemas econômicos referentes à producão capitalista e à distribuicão do excedente econômico. Desta maneira, como assinala PASINETTI(1977, p.168), na teoria sraffiana discutem-se os problemas emergidos de "a theoretical world of production of commodities by means of commodities, which is different from the traditional world of given scarce resources".

Não se pode argumentar, finalmente, que o fato de a separação de classes (entre o proprietario da terra e - capitalista que nela emprega seu capital) não ser muito frequente na agricultura de hoje retira a relevância do tema renda da terra. Isso porque, mesmo que não haja tal separacão, e importante separarmos lucro de renda, principalmente para entendermos 0 conflito que pode estabelecer-se entre o capitalista agricola e o industrial, como veremos adiante. 
1.2. Objetivos do trabalho

o sistema econômico sraffiano renova o interesse pelo estudo teorico da renda da terra. Embora Sraffa destine poucas paginas de seu conciso livro ao tema, resumindo-se às principais conclusões que seu modelo oferece, outros autores trataram de desenvolvê-lo.

o objetivo central deste trabalho e apresentar uma dissertação sobre a renda da terra no sistema econômico sraffiano, contemplando os trabalhos que desenvolveram 0 tema a partir da obra de sraffa. Tentaremos apresentar o tema de maneira didatica, de forma que o leitor possa acompanht-lo sem recorrer aos trabalhos originais, pelo menos em seus principais aspectos.

Porem, antes de procedermos à dissertação sobre a teoria sraffiana da renda da terra propriamente dita, faremos uma breve exposição a respeito do desenvolvimento do pensamento econômico sobre a renda da terra, abrangendo, principalmente, o pensamento de Ricardo e Marx e concluindo com uma breve andlise dos desenvolvimentos marginalistas do tema. Estas considerações compõem o capltulo 2 deste trabalho. 0 capltulo 3 versard sobre o sistema econômico sraffiano, cuja exposicão se faz necessaria para a compreensão do capltulo central - o cap1tulo 4, sobre a renda da terra no sistema econômico sraffiano. Finalmente, o capltulo 5 
procurara, de maneira resumida, contrapor as principais diferencas entre a teoria sraffiana e as que a precederam, ressaltando o que há de novo na teoria sraffiana. Gostarlamos de ressaltar, finalmente, que o presente trabalho vem cobrir uma lacuna na literatura nacional sobre o tema, no sentido de que, ate então, os trabalhos têm se resumido à uma apresentacão e confronto das teorias ricardiana e marxista, com a poss1vel excecão do trabalho de PINHEIRO(1980), embora o mesmo não tratasse do desenvolvimento da teoria sraffiana da renda da terra, limitando-se às sua principais conclusões. 
NOTAS

Obs.: A menos que haja alguma observacão, em todas as transcrições de cítacões de autores (ao longo de todo este texto), os grifos são dos proprios autores.

(1) Ricardo refere-se, no Prefacio de seu livro, a Turgot, stuart, sismondi, Say e Malthus.

(2) Na verdade, a renda $e$ analisada logo apos a apresentacão de sua teoria do valor, antes de tratar dos demais temas do livro, como lucros, salários, impostos, comercio, maquinaria, etc.

(3) Cf. PASINETTI (1977, Prefácio).

(4) BLAUG, M. La teoria economica em retros eccion. Ed. Miracle, 1968 . ci a o por FLICHMAN 1977, p.29.

(5) Cf. BIRD(1975, p.69-70).

(6) Hd que se ressaltar que os fundadores da escola neoclassica ainda, de certa forma, destinavam um tratamento especlfico para a terra, em separado do capital.

(7) Cf. PINHEIRO(1980), LENZ(1980) e SILVA(1981) para uma discussão mais aprofundada sobre as teorias ricardiana e marxista, principalmente, no que concerne a um confronto entre ambas.

(8) Como em LENZ(1980) e SILVA(1981). 
2. A EVOLUÇA DO PENSAMENTO ECONOMICO SOBRE A RENDA DA TERRA

2.1. O Pensamento de David Ricardo

O interesse de David Ricardo sobre a renda da terra aparece em uma carta enviada à Malthus em 1813, onde Ricardo manifesta sua preocupacão com a acumulacão capitalista e sua relacão com a agricultura. Ate então os estudos de Ricardo ligavam-se, principalmente, a questões referentes à moeda.

Apos a publicação dos trabalhos de Malthus e West em fevereiro de 1815, que levantaram as primeiras proposicões a respeito da teoria da renda diferencial, Ricardo - dias apos - manifestou-se publicamente a respeito do tema, atraves da publicąão do "ENSAIO ACERCA DA INFLUENCIA DO BAIXO PRECOO DO CEREAL SOBRE OS LUCROS DO CAPITAL" " Nesse ensaio, Ricardo não so propõe os fundamentos da teoria da renda diferencial, em acordo com os trabalhos anteriores, como tambem assume posicão polıtica frente às polêmicas "Corn Laws", que restringiam as importações de trigo pela Inglaterra. Posteriormente, 
por insistência de James $\mathrm{Mill}^{3}$, Ricardo produz o seu mais famoso trabalho ("PRINCIPIOS DE ECONOMIA POLITICA E TRIBUTACAO"), onde o tema renda da terra assume papel relevante, como ja haviamos comentado.

Logo de intcio, Ricardo afirma que a renda da terra e a "compensação paga ao seu proprietário pelo uso das forcas originais e indestrut1veis da terra" (RICARDO, $1982, \mathrm{p} .66)^{4}$. Uma vez que houvesse investimentos que melhorassem a qualidade da terra, parte da renda serviria para remunerar o capital empregado. E, segundo Ricardo, esta distincão e muito importante, pois as leis que regulam os lucros são muito diferentes das leis que regulam a renda, "raramente operando na mesma diręão" (p.66) 5

Ricardo passa, então, a analisar a origem da renda em um pals fictlcio bem dotado de terras ferteis. Nesse pals, a demanda por alimentos e de tal grandeza, que apenas o cultivo de terras ferteis atenderia essa demanda. A renda al não existiria porque, como afirma RICARDO(1982, p.66), "nada se da em troca do uso do ar e da agua, ou de quaisquer outros bens naturais existentes em quantidades ilimitadas".

Com o crescimento populacional que acompanharia a acumulação capitalista, a demanda por alimentos só poderd ser atendida com a incorporação de novas terras de piores qualidades . Quando isto ocorre, na terra de melhor qualidade serd posstvel obter-se renda, uma 
vez que a menor lucratividade da terra recentemente incorporada reduzira os lucros obtidos pelos capitalistas que exploram a terra de melhor qualidade, assumido-se competicão entre os capitalistas. o excedente obtido na terra de melhor qualidade constituird a renda da terra paga ao proprietário da terra ${ }^{7}$.

Um novo aumento na demanda, devido ao crescimento populacional, fard com que terras de uma terceira qualidade sejam incorporadas. Segundo Ricardo, imediatamente aparece renda na terra de segunda qualidade, devido ao mesmo motivo que descrevemos acima. "Ao mesmo tempo, aumenta a renda da terra de primeira qualidade, pois esta deve ser sempre superior à renda da segunda, de acordo com a diferenca entre as producões obtidas numa e noutra,

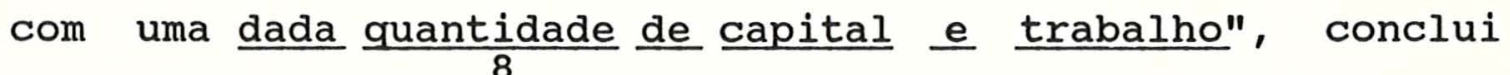
RICARDO (1982, p.66) .

Ricardo ressalta, tambem, que este processo de aumento da producão agricola pode se dar atraves de uma maior aplicacão de capital nas terras jâ cultivadas. Assim, ao inves de se aplicar capital em uma terra nova de pior qualidade, pode ocorrer que este capital seja aplicado, com rendimentos decrescentes, em uma terra ja cultivada. Assim, segundo Ricardo, o capital inicialmente aplicado produzird uma renda, "pois esta e sempre a diferenca entre produtos obtidos com o emprego de duas quantidades iguais de capital e trabalho"(p.67) . 
Portanto, tanto na margem extensiva (a terra de pior qualidade) quanto na margem intensiva (a ultima e menos produtiva "dose" de capital aplicada), não hà o pagamento de uma renda. E Ricardo, então, conclui que "se, portanto, existisse terra fertil em quantidade muito maior do que a requerida para a produção de alimentos para uma população crescente, ou se o capital pudesse ser aplicado indefinidamente na terra antiga sem retornos decrescentes, não poderia haver elevação da renda, pois esta procede, invariavelmente, do emprego de uma quantidade adicional de trabalho com um retorno proporcionalmente menor" (p.67).

Em seguida, Ricardo se põe a responder a questão posta por ele proprio no in1cio do cap1tulo "Sobre a renda da terra", qual seja, se a apropriacão da renda alteraria a regra segundo a qual o valor das mercadorias e determinado, essencialmente, pelo tempo de trabalho necessărio à sua producão. Esta questão surge, para Ricardo, devido à leiturà da obra de Adam Smith,-- onde constata-se a inclusão da renda da terra no prę̧o da mercadoria agricola. Dessa forma, Smith conclui que o cereal e caro porque a renda e paga.

Ricardo, então, argumenta que o valor de troca das mercadorias agricolas e obtido, em essência, pelo tempo de trabalho necessario à sua producão, nas condiç̃es mais desfavoráveis de cultivo (ou seja, na margem de cultivo). Como na margem de cultivo não hâ o pagamento de 
uma renda, a lei do valor de Ricardo não se altera com a existência da renda da terra. "Portanto, a razão pela qual ha um aumento no valor comparativo dos produtos agricolas e - emprego de mais trabalho para produzir a ultima porcão obtida e não o pagamento de renda ao proprietårio da terra", conclui RICARDo(1982, p.69). Em oposição à Smith, Ricardo conclui que a renda e paga porque o cereal e caro, e não o contrário.

Quanto à essa questão da relação entre a renda da terra e o valor do cereal ${ }^{9}$, SAMUELSON(1959) apresenta uma objęão ao argumentar que esse "artif1cio" ricardiano de determinar o valor de troca do cereal na margem de cultivo (para "salvar" sua teoria do valor) não tem validade, "for the extensive margin is itself a variable, to be determined like any other equilibrium variable as a part of the theorist's explicit task"(p.2). E 0 mesmo vale, segundo o autor, para a margem intensiva. o argumento de Samuelson e de que a determinacão do valor depende tanto da determinação da margem quanto essa depende daquele ${ }^{10}$.

Outra questão levantada por Ricardo, novamente refletindo o seu posicionamento pol1tico mais expl1cito no "ENSAIO", refere-se à relação entre a riqueza e a renda. Quanto a esta questão, Ricardo se opõe à posicão de Malthus em defesa das "Corn Laws". Malthus acredita que a riqueza dos proprietários da terra traria reflexos positivos sobre 
a riqueza do pa1s. Assim sendo, o autor advoga a permanência das "Corn Laws", restringindo a importação de cereal, o que faria aumentar a renda da terra, como vimos, e enriquecer os proprietários de terras.

Para Ricardo, a riqueza de um pals não corresponde, necessariamente, ao aumento da renda da terra. Ricardo, então, argumenta que quando a terra e muito fertil e abundante, quando hà muita riqueza natural, não haverd renda alguma (ou serd de grandeza muito pequena). A renda surgird apenas quando terras menos ferteis forem usadas. Assim, ele considera que o crescimento da renda e apenas um reflexo da riqueza (acumulação de capital), e nunca a sua causa. "Se o produto excedente proporcionado pela terra sob a forma de renda fosse uma vantagem, seria desejavel que, a cada ano, a maquinaria recentemente fabricada fosse menos eficiente que a mais antiga", conclui RICARDo(1982, p.69) •

A teoria ricardiana prevê, assim, um conflito entre a acumulação capitalista e a produção de produtos agricolas. Dentro da teoria da distribuição, Ricardo considera que os salărios são regulados por um fundo proveniente da acumulação capitalista. Se se admite que a populacão e o capital crescem à mesma taxa, os salários reais manter-se-iam constantes. A taxa de lucro e obtida na margem de cultivo, e nas terras intramarginais o que sobrar após o pagamento de lucros e salários e apropriado como 
renda pelos proprietarios de terras. A acumulação capitalista e o crescimento da populaqão levaria a uma redução da taxa de lucro (devido aos retornos decrescentes obtidos na agricultura) e ao aumento da renda da terra. Isto, segundo Ricardo, poderia levar a economia a um estado estacionário, onde não mais haveria acumulacão e desenvolvimento capitalista. o lucro industrial reduzirse-ia, devido ao encarecimento dos salarios (que Ricardo assume como sendo gastos, essencialmente, em produtos agrlcolas, alem de rlgidos ao nlvel de subsistência). Assim concluindo, Ricardo posiciona-se pela liberacão das importações de cereal, a fim de conter a queda na taxa de lucro.

NAPOLEONI(1978), por ourto lado, pretendendo sustentar a teoria marxista da queda na taxa de lucro, critica a teoria ricardiana quanto à regulacão da taxa de lucro da economia pela produção agricola. o autor sustenta a tese marxista de que a taxa de lucro da economia \& regulada pelo setor industrial, criticando os pressupostos ricardianos para a determinacão, em termos "flsicos" (independente de precos), da taxa de lucro no setor agricola.

Segundo Napoleoni, Ricardo viu-se na
necessidade de desenvolver sua teoria do valor, a fim de
sustentar sua tese de que a taxa de lucro da economia era
regulada pela producão agrıcola, ao constatar a irrealidade


dos pressupostos do modelo do "ENSAIO". Para o autor, entretanto, os mesmos pressupostos irrealistas (quanto à homogeneidade do capital e do produto agricola e à constituicão da cesta de consumo dos trabalhadores) serão necessarios para a sua tese manter-se, sob a sua teoria do valor. O autor conclui (p.91), então, que "nessas condições, o fato de que a taxa de lucro na agricultura tenda a diminuir, pode ser demonstrado, unicamente, atraves de referência ao processo que se desenrola na industria" ${ }^{11}$. Quanto aos melhoramentos na agricultura, Ricardo argumenta que estes, ao reduzirem o preço relativo dos produtos agrlcolas, provocariam um aumento na acumulação devido à reducão dos salărios nominais e, tambèm, provocariam uma diminuição na renda, pois aumentaria a produtividade da dose menos produtiva de capital, e a renda origina-se, como vimos, pela diferença de produtividade dos capitais aplicados. o aumento na acumulação, entretanto, levaria a uma maior demanda por trabalho e, por conseguinte, um aumento nos salärios reais. A isto seguiria, segundo Ricardo, um acrescimo populacional, que levaria a uma maior procura por alimentos, redundando em uma nova intensificação do cultivo do produto agricola, o que acarretaria, finalmente, numa queda na acumulação. No entanto, como diz RICARDo(1982, p.71), "um tempo considerável teria transcorrido, acompanhado por uma positiva diminuição da renda". 
Ricardo considera, então, dois tipos de melhoramentos: os que aumentam a capacidade produtiva da terra e os que permitem obter o mesmo produto utilizandose menos trabalho, devido a aperfeicoamentos na maquinaria. Os melhoramentos que aumentam a capacidade produtiva da terra, como o uso mais adequado de fertilizantes, reduzem a renda em termos flsicos (unidades de produto) e em termos monetários (ja que, por serem melhoramentos, reduzem 0 preço do cereal). Ricardo, então, mostra um exemplo numerico onde se pode constatar que um melhoramento que aumenta a capacidade produtiva das terras fard com que, para uma mesma demanda, a terra menos produtiva poderia ser utilizada para outro fim (ou deixada de lado) reduzindo a renda da terra, devido à maior produtividade da terra marginal.

Se, por outro lado, ocorresse um melhoramento que tornasse possivel a obtencão do mesmo produto utilizando menos trabalho, poderlamos verificar que tal melhoramento, apesar de reduzir a renda em termos monetários (devido à queda do prę̧o do cereal), pode não reduzir a renda em termos flsicos se as reducões dos capitais aplicados forem iguais em todas as terras, conforme mostra Ricardo, novamente, atraves de exemplo numerico.

$\mathrm{Na}$ verdade, quanto a esse segundo tipo de melhoramento, como observa JoHNSON(1948), e posstvel mostrar que a renda em trigo eleva-se, nesse processo. 0 
cálculo de Ricardo está incorreto porque ele inclui a renda da terra no capital sobre o qual são calculados os lucros.

Em resumo, sempre que os melhoramentos agirem no sentido de aumentar a diferenca de produtividade entre as terras, a renda auferida pelos proprietários de terras aumentará. Finalmente, \& preciso salientar que os proprietărios de terras beneficiam-se duplamente do aumento na dificuldade de producão do cereal, porque recebem uma maior parcela em termos flsicos e o valor de cada unidade e acrescido devido ao aumento no preço do cereal.

\subsection{O pensamento de Karl Marx}

Como jd havlamos comentado, o pensamento de Marx sobre renda da terra insere-se no contexto de todo o seu trabalho de busca das leis do desenvolvimento capitalista. O tema renda da terra tratado no livro III de "O CAPITAL" (vol. 6), que foi publicado apos a morte de Marx, num trabalho fidedigno de interpretação e reunião de manuscritos, feito por Engels. Em "TEORIAS SOBRE A MAISVALIA" tambèm encontram-se dezenas de páginas sobre o assunto. Vamos nos limitar à exposição das ideias contidas em "O CAPITAL", uma vez que não e nosso objetivo o aprofundamento do tema em Marx. Alem disso, o texto de "O CAPITAL" representa a palavra final, pois e posterior às "TEORIAS ..." ${ }^{12}$. 
- trabalho de Marx, alem de acrescentar aspectos referentes à renda diferencial ricardiana, considera um tipo de renda não considerado por Ricardo: a renda absoluta. Alem desse tipo de renda (uma renda de monopolio, como veremos) Marx define dois tipos de renda diferencial: renda diferencial I e renda diferencial II.

Antes de conceituarmos esses tipos de renda, gostarlamos de salientar que Marx considera que a renda fundiaria seria a forma com que se realiza economicamente a moderna propriedade fundiaria, onde o proprietario da terra não corresponde ao capitalista que nela emprega o seu capital.

Ao enfatizar a diferenca entre a renda fundiária e o juro sobre o capital aplicado na produção agricola, Marx argumenta que a propriedade fundiăria seria uma barreira imposta ao modo capitalista de producão, ao incentivar menores aplicacões de capital por parte do arrendatário $^{13}$. Isto porque o arrendatårio capitalista, ao final do contrato, "devolve" a terra, melhorada por suas aplicąões de capital, ao proprietårio. Estaria al um "dos segredos - se abstralmos do movimento da renda fundiária propriamente dita - do enriquecimento ascendente dos proprietarios de terras, do aumento cont1nuo de suas rendas e do valor monetario crescente de suas propriedades com o progresso do desenvolvimento econômico", conclui MARX(1985, p.712) . 
Ainda, quanto à renda fundiăria de forma geral, Marx argumenta que "toda renda fundiária e mais-valia, produto de trabalho excedente"(p.728). A renda fundiaria e sempre sobra acima do lucro. A fertilidade da natureza forneceria um limite, uma base. Com o desenvolvimento da produtividade social do trabalho, a producão de mais-valia aumenta e na mesma medida aumenta a capacidade da propriedade fundiaria de apoderar-se - em virtude do monopolio sobre a terra - de parte crescente da mais-valia. A renda diferencial I surgiria, segundo Marx, devido a resultados desiguais oriundos da aplicąão de idênticas massas de capitais em terras de qualidades diferentes, por unidade de àrea.

Quanto a essa definição (que coincide como o conceito ricardiano de renda diferencial), FLICHMAN(1977) adverte que a "dose" otima de capital e trabalho aplicada em terras de qualidades diferentes não \&, necessariamente, a mesma. FLICHMAN(1977) sugere, - então, que se amplie-a definição de renda diferencial I considerando-a, simplesmente, oriunda do resultado diferente que aplicações de capital geram quando aplicadas em terras de qualidades diferentes. Essa diferença dever-se-ia, meramente, às diferencas de qualidades das terras ${ }^{14}$.

Marx, no entanto, amplia a andlise ricardiana ao considerar que a ordem de incorporação das terras não se daria, necessariamente, das terras melhores às terras 
piores. Marx considera que o desenvolvimento tecnologico poderia alterar a fertilidade natural de algumas terras, tornando mais produtiva uma terra que era ate então menos produtiva (atraves de uma drenagem, por exemplo). Assim tambem poderia ocorrer com o desenvolvimento da infraestrutura, possibilitando 0 acesso ao mercado da produção oriunda de uma terra de otima fertilidade, que ate então não estava sendo cultivada.

Nesse sentido, Marx mostra como a renda pode formar-se com a incorporacão de terras cada vez melhores ou, cada vez piores ou, ainda, de terras melhores para piores e dessas para melhores . Marx deseja mostrar que a andlise ricardiana e por demais particularizada, rejeitando a explicacão ricardiana para a queda na taxa de lucro da economia, baseada nos rendimentos decrescentes na agricultura. Marx sustenta que a taxa de lucro do setor industrial regula a taxa de lucro da economia.

Marx considera, então, um segundo tipo de renda diferencial, ao questionar: "Qual a diferenca se quantidades de capital de produtividade diversa se aplicarem sucessivamente no mesmo terreno, em vez de serem empregadas, paralelamente em terrenos diferentes, supostos invariaveis os resultados?"(MARX, 1985, p.771). E sobre essa possibilidade que Marx desenvolve o estudo da" renda diferencial II, uma renda derivada da desigualdade de aplicacão de capital em terrenos de mesmo tipo. 
Na verdade, como adverte FLICHMAN(1977), a renda diferencial II só surgiria devido à desigualdade de acesso ao capital e/ou à tecnologia. Numa abordagem teorica de longo prazo, assumindo competicão entre capitalistas e mobilidade dos capitais (como faz Marx ao pressupor que 0 modo capitalista de produção opera na agricultura tanto quanto na industria), a renda diferencial II deixaria de existir. "Numa situação de equillbrio, os capitalistas investirão atહ $\circ$ ponto em que seus lucros marginais igualem à taxa media de lucro, e não poderá haver renda diferencial II", conclui FLICHMAN(1977, p.39). O autor constata, ainda, que nos vários exemplos que Marx desenvolve, "os investimentos por unidade de terra não atingem o ponto no qual não convem investir mais pelo fato e a produtividade marginal dos investimentos igualar-se à taxa media de lucro" (p.35) ${ }^{16}$.

- estudo da renda diferencial II pretende desenvolver aspectos pouco desenvolvidos por Ricardo, uma vez que esse não aprofundou a análise da renda diferencial devida a aplicąões de quantidades de capitais diferentes em um terreno de mesma qualidade . Marx desenvolve toda uma gama de possibilidades ao considerar esses dois tipos de rendas diferenciais, quando Ricardo, em sua teoria da renda diferencial, "faz dela um exame de todo unilateral, tratando-a como coisa simples"(MARX, 1985, p.778) ${ }^{18}$.

$$
\text { A renda diferencial I, adverte Marx, e } O
$$


fundamento historico donde se parte. A renda diferencial II desenvolver-se-ia sob a hipotese da renda diferencial I, no sentido de que a intensificacão do cultivo dá-se, inicialmente, a partir da incorporação de novas terras para, posteriormente, ocorrer atraves do uso de tecnicas mais intensivas em capital, nos terrenos ja em cultivo. Marx mostra, ainda, que à diferença da renda diferencial I, no caso da renda diferencial II o montante de renda por area pode subir, mesmo que permaneçam constantes o preço regulador e as diferencas de fertilidades dos terrenos. Isto porque, a renda por ârea variard conforme a "dose" de capital aplicada. MARX(p.792) conclui, então, que "quanto mais se desenvolve o modo capitalista de producão, tanto mais acresce a concentracão do capital na mesma área, tanto mais se eleva, portanto, a renda calculada por acre".

Uma outra diferença em relação à renda diferencial I, refere-se ao fato de que e mais diflcil a transformação do lucro suplementar (referente à renda diferencial II) para o proprietario da terra, uma vez que o arrendatărio apropria-se desse excedente, ate que finde 0 contrato de arrendamento, momento no qual o proprietario poderia elevar o valor das rendas.

De qualquer forma, quanto à renda diferencial II, para os lucros suplementares converterem-se em renda fundiåria, transferindo-se para os proprietarios de terras, "' mister, antes, que os diversos preços de produção 
individuais reais (que não dependem do prę̧o de producão geral regulador do mercado) das parcelas produzidas pelos diversos investimentos sucessivos se nivelem num preqo de produção individual medio" ${ }^{19}$, conclui $\operatorname{MARX}(p .837)$. Enquanto isso não ocorrer, o arrendatărio adiantado (que detem a melhor tecnica ou que tem mais acesso ao credito) "embolsard" a renda diferencial II.

Afora os casos comentados por Marx sobre a geração de renda diferencial tambem no pior solo cultivado, Marx pretende explicar a formação de uma renda na terra marginal que justifique a cessão da terra pelo proprietário para o capitalista arrendatário, cessão esta que deve ocorrer apenas atraves do pagamento de uma renda. ou seja, jâ que o proprietârio da terra marginal não e quem vai cultiva-la, como se explica o cultivo na terra marginal sem o pagamento de uma renda ? Marx, então, desenvolve, ao longo de um capltulo de seu livro, a teoria da renda fundiăria absoluta. Uma renda que não tem $\circ$ caratter diferencial, mas um carater de renda de monopolio, evidenciando uma nova barreira que a propriedade fundiaria impõe ao capital.

Segundo MARX(p. 863), "o monopolio da propriedade fundiária, erigida em barreira ao capital, \& condicão da renda diferencial pois, sem esse monopolio, o lucro suplementar não se converteria em renda e caberia ao arrendatário e não ao proprietário da terra. E a 
propriedade fundiâria continua a constituir a barreira, mesmo quando a renda desaparece como renda diferencial", isto e, na terra marginal. Marx identifica, então, a propriedade fundiaria como geradora da renda absoluta, ao requerer que o preço de mercado seja superior ao preço de produção. O que não ocorria com a renda diferencial, onde os fatores geradores da renda seriam elementos naturais, locacionais e/ou de distribuição e acesso ao capital e às melhores tecnicas, ficando a propriedade fundiaria com $\circ$ papel exclusivo de transferência do lucro suplementar aos proprietarios de terras.

Ao argumentar que a renda absoluta aumentaria - preq̧o de produção em todas as terras, Marx conclui que "a lei da renda diferencial não depende da circunstância de haver ou não renda nos terrenos menos ferteis, e que a unica maneira de apreender o caráter da renda diferencial e supondo-se que a renda do terreno $A=0 "(p .862)^{21}$. Essa renda gerada pelo monopolio da propriedade privada da terra, faz com que $\circ$ preco de mercado do produto agricola torne-se um preco de monopolio, cujos limites econômicos estariam definidos, segundo Marx, pelas aplicações de capital nos velhos arrendamentos, pela concorrência de produtos estrangeiros (quando hà livre importacão), pela concorrência entre proprietârios de terras e, finalmente, pelas necessidades e pela capacidade de pagar dos consumidores. 
Marx adverte, entretanto, que não e necessårio supor que a renda absoluta caracterize um preco de monopolio "no sentido corrente", como "um imposto que não e coletado pelo Estado mas pelo proprietârio da terra"( $p$. 871). Isso porque, a renda absoluta seria compat1vel (consistentemente com a teoria de Marx sobre as leis do desenvolvimento capitalista descritas em "O CAPITAL") com o fato de o valor das mercadorias agrlcolas ser superior ao seu respectivo preço de produção.

A teoria da renda absoluta baseia-se na explicacão de Marx para a transformacão de valores em preços de produção - Segundo Marx, no momento de realização do capital (venda das mercadorias) no processo de circulação, a mais-valia produzida nos diferentes ramos da economia não e distribulda na proporção em que e produzida em cada ramo, mas na proporcão da magnitude dos capitais adiantados. Dessa forma, Marx mostra que, no ramo onde a composição orgânica do capital e menor que a composição media da economia, o valor da produção será superior ao preco de produção.

A agricultura, por utilizar mais capital variảvel que capital constante, teria, segundo Marx, uma menor composicão orgânica do capital do que a composicão media da economia. Dessa forma, o valor do produto agricola seria superior ao prę̧o de produção, sendo que a renda absoluta poderia absorver essa diferenca ${ }^{23}$. 
- fato de a composicão orgânica do capital aplicado na agricultura ser inferior à composiç̃o media revelaria que, nos palses industrializados, "a agricultura não progrediu no mesmo ritmo da indústria de transformąão"(MARX, p. 873). A composi६ão orgânica do capital refletiria, segundo Marx, a produtividade social do trabalho, "pois o grau de produtividade atingido se expressa pela preponderância relativa da parte constante sobre a variâvel do capital"(p.872). O autor prossegue, então, desconsiderando a importância da constatacão emplrica dessa pressuposição, afirmando que "so admitida esta condicão pode existir a forma de renda fundiaria que estamos considerando e, por isso, basta para analisa-la, estabelecer essa suposicão"(p.873). Termina por afirmar que "se eliminamos esse pressuposto, desaparece tambem a forma de renda que the corresponde" (p.873).

Contudo, prossegue o autor, o fato de o valor superar o preço de produção do produto agricola não e condição suficiente para que surja a renda absoluta. Esta surgiria, segundo Marx, pelo fato de a propriedade fundiåria impedir que esse lucro suplementar (correspondente à maior producão de mais-valia na producão agrlcola, por usar mais capital variàvel) seja transferido para os ramos de maior composição orgânica do capital. Este impedimento correspoderia à cobrança pelo uso de qualquer tipo de terra por parte dos proprietarios de 
terras. A propriedade da terra atuaria, novamente, como uma barreira ao capital ao cobrar um tributo para que o capital al se aplique. Marx estaria, dessa forma, cobrindo uma lacuna da teoria ricardiana, ao considerar a explicacão para o pagamento de uma renda, inclusive na terra $\operatorname{marginal}^{24}$.

A renda absoluta poderia, então, abranger, total ou parcialmente, a diferenca entre o valor e o preqo de producão do cereal, na medida em que se estabelecessem as relacões de oferta e procura do produto agricola, e na medida em que se dispusesse de terras ainda incultas. Ressalta Marx que "os produtos agrlcolas, contudo, venderse-ão sempre a preco de monopolio, não por estar o preco acima do valor, e sim por ser igual ao valor, ou estar abaixo do valor, mas acima do preqo de producão"(p.876) . Afora isso, ele admite que a renda agricola possa ser superior às rendas normais (diferencial e absoluta) num caso de monopólio propriamente dito, onde o preco de mercado superaria o valor da mercadoria agricola ${ }^{25}$. Conclui MARX(p. 878) que "cabe estudar esta materia na teoria da concorrência. Investiga-se a1 o movimento real de preços de mercado".

Finalmente, Marx assinala que o preco da terra corresponderia à mera capitalizafão das rendas a serem obtidas no cultivo da terra. E partir dessa constatacão que o autor explica que a terra, embora não tendo valor (jł 
que não e produto do trabalho), tem preço.

Assim, se o capitalista compra por 4.000 libras uma terra que the rende 200 libras esterlinas, receberd, por ano, o juro medio de 5\% sobre 4.000 libras, como se tivesse empregado esse capital em papeis rentaveis ou o tivesse emprestado diretamente a juros de $5 \% \quad \ldots$ nessa hipotese terá reposto em 20 anos o preqo de compra da propriedade, por meio de receitas que esta proporciona", explica MARX(1985, p.715). Como, segundo a teoria marxista, a taxa de juros tende a cair com o desenvolvimento capitalista, o preço da terra tenderia a subir independentemente do movimento da renda.

2.3. Os desenvolvimentos marginalistas ${ }^{26}$

A principal crltica marginalista à teoria ricardiana refere-se ao fato de que a mesma não explicava a alocąão de recursos escassos, uma vez que considerava apenas um produto agricola . Os marginalistas basearam-se nas considerações de J.S.Mill sobre os usos competitivos da terra e na teoria ricardiana da renda diferencial, para propor sua teoria da produtividade marginal da terra (generalizada para qualquer tipo de recurso). Dessa forma, como argumenta LACKMAN(1977, p.51), "the modern rent theory evolved considerably from rent's classical definition as un unearned increment and rests today on the classical footing 
that part of rent enters price" ${ }^{28}$.

$$
\text { Antes disso lou seja, antes do }
$$

desenvolvimento da teoria neoclassica da produtividade marginal dos recursos), Marshall considerava que a renda diferencial ricardiana era um caso particular de renda devido à "habilidade". Assim, artesãos, profissionais liberais e empresarios tambem poderiam auferir uma renda devido a "habilidades" maiores que a media.

Alem desse enfoque, Marshall procurou explicar a renda como o resultado de um ajuste inadequado (ou lento) na oferta de fatores frente a alteracões nas condiçoes de mercado. Marshall ressaltava, assim, o conceito de renda aliado a condições de escassez, o que não era tratado na teoria ricardiana. A esse tipo de renda Marshall denominou de "quasi-renda".

Finalmente, Marshall mostrou que não e necessario que exista uma terra de qualidade inferior para que possa existir a renda diferencial. Isso porque, uma comparação diferencial pode ser feita atraves do uso mais vantajoso da terra melhor em relacão com a utilizacão marginal da mesma terra.

Seguindo essa linha, Wicksteed e J.B. Clark, pri ncipalmente, des envolveram a teoria neoclássica da pro dutividade marginal de recursos. Nesse caso, a renda da terra cor responderia ao produto marginal da terra, assumindo-se substituicão contınua entre os fatores de 
produção e competicão perfeita no mercado de fatores. Se a funcão de producão for homogênea de primeiro grau, è possivel mostrar que a totalidade do valor do produto serd esgotada pelo valor dos produtos marginais dos fatores de producão $^{29}$

Sob competicão perfeita, a renda da terra determinard a alocação eficiente das varias terras ordenadas pelos seus respectivos produtos marginais. Evidentemente que condicões de imperfeição no mercado de terras poderão fazer com que a renda da terra seja maior que o valor do produto marginal da terra.

Como o valor do produto marginal da terra varia conforme o produto que esta sendo produzido, este produto marginal serd̂ a variável relevante que ird determinar qual o uso mais eficiente da terra. Nesse sentido, a teoria marginalista explica a alocacão eficiente do recurso terra, fornecendo uma perspectiva microeconômica para o problema da renda, o que não era considerado atહ então ${ }^{30}$. 
NOTAS

(1) Cf. SRAFFA, P. Pamphlets and papers-1815/1823. In:The Works and Correspondence of David Ricardo, Cambridge, Cambriage University press for The Royal Economic society, 1951, Vol 4, p.3. Citado por LENZ(1980, p.15).

(2) Esse trabalho encontra-se reproduzido em NAPOLEONI (1978, p. 195-225) .

(3) Cf. Introdução de Sraffa em RICARDO(1982).

(4) Veremos, quando tratarmos da renda da terra no sistema econômico sraffiano, que esta assertativa de Ricardo serâ alvo de criticas, no sentido de que a determinacão da renda da terra estard, tambem, condicionada à prêvia distribuicão do excedente econômico.

(5) Novamente, quanto a esse aspecto, veremos que na teoria sraffiana da renda da terra, e plenamente possivel obtermos um crescimento (ou decrescimo) simultâneo da renda da terra e da taxa de lucro. Alids, como veremos logo a seguir, a propria teoria marxista irá salientar esse aspecto.

(6) Quando nos referirmos ao termo "qualidade" da terra, estamos incluindo as condicões edafoclímaticas, bem como a localização da terra em relação ao mercado. Comentaremos, essa questão, mais adiante, com um pouco mais de detalhes.

(7) Na Inglaterra do tempo de Ricardo havia uma nitida separacão de classes entre capitalistas e proprietarios de terras ("landlords"). Estes ultimos constitulam uma classe que vivia, exclusivamente, a custa da renda obtida pelos arrendamentos das terras que possulam. $\mathbf{E}$ preciso salientar, entretanto, que se não houvesse tal separacão de classes os capitalistas embolsariam a renda "como se fosse lucro". No entanto, como salientamos anteriormente, as leis que regulam os lucros são diferentes das leis que regulam a renda, sendo portanto necessario distingui-los mesmo que não exista separacão de classes. Voltaremos a essa questão da pressuposição de separaça das classes, quando nos referirmos à teoria sraffiana. Embora a palavra "landlord" tenha sido largamente utilizada na literatura para se referir aos proprietdrios de terras (ressaltando a especificidade que caracterizava essa classe na epoca de Ricardo e Marx), preferimos utilizar a traducão portuguesa da palavra, como em RICARDO(1982).

(8) Grifos nossos. Apresentaremos, tambem nesse caso, uma critica baseada na teoria sraffiana, adiante.

(9) No contexto ricardiano, o termo "cereal" refere-se à producão agricola agregada. Ricardo toma o produto agricola mais importante ("corn", que corresponde à "trigo", no inglês britânico) para representar o setor agricolá.

(10) Quanto a esse aspecto, \& oportuno reproduzirmos uma 
citacão de Marx contra os "adversarios de Ricardo": "São deliciosas as ideias de todos os adversários de Ricardo que combatem a determinação do valor apenas pelo trabalho: alegam, no tocante à renda diferencial oriunda das diferencas entre os terrenos, que a natureza a1, e não o trabalho, se converte em agente determinante do valor; mas, ao mesmo tempo reinvidicam esse papel determinante para a localizacão e, ainda mais, para o juro do capital incorporado ao solo com cultivo", afirma MARX(1985, p.859). $\mathrm{E}$ prossegue, logo em seguida, argumentando que "o mesmo trabalho gera o mesmo valor para o produto criado num dado lapso de tempo; mas, a grandeza ou a quantidade desse produto, e portanto a fração de valor configurada em parte allquota desse produto, depende, para dada quantidade de trabalho, unicamente do volume da producão e este, por sua vez, da produtividade de dada quantidade de trabaiho e não da magnitude dessa quantidade. Tanto faz que essa produtividade derive da natureza ou da sociedade. A produtividade so acresce o custo de producão com novo componente quando custa trabalho, capital portanto, o que não se dá quando se trata apenas da natureza".

(11) Consideramos invalida a crltica de Napoleoni, uma vez que pode ser demonstrado (Cf. NICOL(1984) e HOFFMÁNN(1985)) que a queda na produtividade do setor agrtcola redundard na queda da taxa de lucro de toda a economia, independentemente de posslveis aumentos de produtividade no setor industrial.

(12) SILVA(198i), por outro lado, argumenta que, principalmente com relaça à renda ab́soluta, o tema é melhor tratado em "TEORIAS SOBRE A MAIS-VALIA".

(13) Cf. MURRAY(1978) para uma discussão sobre os caminhos que o capital busca para superar essa barreira.

(14) Quanto a isso, veremos que a teoria sraffiana explica a renda diferencial (em terras de diferentes qualidades) sem requerer que iguais capitais sejam empregados em terras desiguais.

(15) Pensamos que cabe, aqui, uma correção quanto à afirmativa de Marx de que, na sequência ascendente de incorporacão de terras (cada vez melhores), "o preco do trigo produzido no melhor solo e regulador, na medida em que a quantidade nele produzida permite ou não que o solo $A$ continue sendo regulador" (MARX, 1985, p.754). Na verdade, e a quantidade produzida no melhor solo que permite que a producáo do pior solo seja necessaria. Em PINHEIRo(1980, p.32-3) e SILVA (1981) encontramos equivocos quanto à essa questão. SILVA(1981) confere à Marx a superacão da ideia de que o preco regulador e dado na terra pior, devido, em particular, ao "seus notdveis desenvolvimentos sobre a renda diférencial II" (p. 58). Adiante comentaremos as ressalvas com que devem ser analisados os "notâveis desenvolvimentos" de Marx sobre a renda diferencial II. O 
preco regulador serd sempre o preço da produção na terra marginal, em condicões de equilibrio.

(16) Cf. ROBINSON \& EATWELL(1979, pp.89-90) para demostração de que, em equilibrio, a produtividade marginal do capital e igual em qualquer tipo de terra.

(17) Segundo SRAFFA(1989), Ricardo preferia evidenciar a diminuição de produtividade decorrente da incorporação de terras de pior qualidade, relegando para um plano secundário a diminuição de produtividade decorrente da aplicacão de doses sucessivas de capital e trabalho sobre um mesmo terreno porque, enquanto "a produtividade de um dado terreno e, em larga medida, independente do fato de ser ou não cultivado um outro terreno, .... a produtividade de uma certa quantia de capital aplicada num terreno e, em grau muito menor, independente do fato de uma outra quantia determinada de capital ser ou não aplicada, ao mesmo tempo, no mesmo terreno", conclui SRAFFA(p.37) .

(18) Cf. MURRAY'(1977) para um quadro sintetico desses movimentos. No entanto, como argumenta FLICHMAN(1977, p.41), embora Marx abra um enorme leque de provaveís desenvolvimentos, "não assinala qual deles e 0 mais congruente com o desenvolvimento do capitalismo".

(19) Pela teoria marxista, preço de producão = capital constante + capital varidvel + mais-valia realizada. Cf. SWEEZY(1983) para uma apresentąão dos conceitos fundamentais da teoria marxista como capital constante, capital variável, taxa de mais-valia, composição orgânica do capital, etc.

(20) Cf. MARX (1985, cap. XLIV) • Na verdade, novamente, esses casos são incompatlveis com uma situação de equillbrio.

(21) No caso, o terreno A corresponde, pelos exemplos de Marx, ao terreno menos fertil. SILVÁ(1981), por outro lado, argumenta que a inclusão da renda absoluta como uma mera adição à renda diferencial, faria com que a renda absoluta variasse com a qualidade de terra. Considerando estranho esse fenômeno e constatando outras contradiçóes e incorrecões quanto ao tratamento da renda absoluta em "O CAPITAL", Silva propõe um modelo de determinação conjunta das rendas diferencial e absoluta, fazendo com que a renda absoluta se forme no mesmo movimento de formacão da renda diferencial. E necessario afirmarmos, entretanto, que pode-se constatar facilmente (Cf.SILVA, 1980, p.73), que a renda absoluta que se obtem no esquema proposto por silva so ocorre porque o autor parte do pressuposto de que os proprietarios da terra marginal so cedem suas terras em troca de uma renda. ou seja, para explicar a origem da renda absoluta, Silva parte do fato de que ela deve existir. Claramente um ciclo vicioso que invalida o modelo proposto por silva para explicar a formacão da renda absoluta. Silva, inclusive, contradiz-se quando afirma que 
a inexistência de lucro suplementar em uma dada terra (que se converteria em renda) determina "a não exploração da terra, dentro da situacão geral considerada, a saber, onde os capitalistas condicionam os seus investimentos à realização da taxa geral de lucro" (p.78). Grifo nosso. Se não bastasse isso, se o autor trabalhasse (como convem a um esquema teorico) com doses contlnuas de aplicacão de capitais, a renda absoluta obtida seria insignificantemente pequena, de forma que não deveria ser objeto de tantas påginas de discussão. o proprio Marx ja salientava que a renda absoluta, "em condicões normais, e necessariamente exlgua, por mais que a sobra do valor do produto ultrapasse o preço de produçã̃o" (MARX, 1985, p. 885).

(22) Tambem em SWEEZY(1983), e poss1vel encontrar uma boa explicacão para o problema (e uma das solucões propostas) da transformação de valores em precos de producão. Quanto a esse "problema", cf. POSSAS(1982) para uma proposta de solucão utilizando-se do esquema teorico sraffiano.

(23) Não hâ um consenso quanto a essa questão. Flichman argumenta que "são bem fortes os pressupostos que se devem cumprir para que, efetivamente, toda a renda seja maisvalia produzida no setor agrário"(p.45). Nesse sentido, a renda absoluta (ou qualquer renda, como adverte Flichman) poderia conter mais-valia produzida na industria, não simplesmente por ser o preço de producão maior que o valor (o monopolio propriamente dito), mas "porque o preqo comercial e igual ao preco de producão na terra pior, o qual e superior ao preqo medio de producão" (FLICHMAN, 1977, p. 45).

(24) Cf. SILVA(1981, cap. 3) para uma andlise critica quanto à determinação do valor (trabalho) da produção agricola, no sentido de acrescentar elementos à teoria marxista.

(25) Nesse caso, a renda agricola conteria mais-valia produzida na industria.

(26) Esse resumo dos desenvolvimentos marginalistas baseia-se em LACKMAN(1977), BIRD(1975) e QUADRIOCURZIO (1987) .

(27) Cf. BIRD(1975, p.70). Idem, pp.71-2, para uma ressalva quanto a uma melhor interpretacão do pensamento ricardiano, no sentido de o mesmo não contemplar aspectos microeconômicos.

(28) O termo "unearned increment" (ou "unearned surplus", conforme QUADRIO-CURZIO, 1987) refere-se ao fato de a renda não ter uma contrapartida na produção, no sentido de que não e algo pago em troca de um trabalho, não constituindo, assim, o preqo da mercadoria agrlcola. Na verdade, isso justificaria o carater peculiar do meio de produção terra (peculiaridade essa ressaltada pelas teorias ricardiana, marxista e sraffiana). Por outro lado, da parte dos economistas marginalistas, a renda da terra corresponderia 
à remuneracão devida a um serviço prestado por um fator de producão (como outro qualquer). Nesse caso, a renda e parte constituinte do preco da mercadoria agricola.

(29) Pelo teorema de Euler. Se a função de produção tem essa caracterlstica ou não, \& uma questão que fica em aberto. Se assim não for, o produto não se esgotará pela soma dos valores dos produtos marginais dos fatores de produção, e a teoria perde seu poder explicativo da distribuicão da renda. Veremos, no próximo cap1tulo, que essa teoria assumiu papel central na CONTROVERSIA DE CAMBRIDGE, que concluiu pela rejeição dessa teoria, como uma teoria da distribuicão da renda. Como afirma BLAUG(1978, p.449-50), "estritamente falando, ela e apenas uma teoria da demanda por fator". In: Economic theory in retrospect, terceira edicão, Cambridge, Cambridge University Press, 1978. Citado por PINHEIRO(1980, p.66). (30) Cf. SAMUELSON(1959) para um tratamento analitico da renda diferencial, valendo-se de modelos de programação linear (enfatizando o aspecto de alocação da terra nos seus usos alternativos). 
3- O SISTEMA ECONOMICO SRAFFIANO

\section{1) Introdução}

A obra de Piero Sraffa representou, sem duvida alguma, uma nova revoluqão no pensamento econômico do seculo XX. Aposs a revolucão keynesiana, parece ser legitimo rotular o impacto da obra de sraffa como uma revolucão sraffiana, como sugere RONCAGLIA(1978) • No sentido kuhniano ${ }^{1}$ do termo, a revoluqão sraffiana representou a superacão do paradigma neoclássico da teoria da distribuicão baseada no conceito de funcão de producão agregada, um dos pilares da teoria microeconômica marginalista. No entanto, muitos economistas neoclassicos decidiram fazer "vista grossa" ao fato.

$\mathrm{Na}$ verdade, muito antes da publicação de "PRODUCTION OF COMMODITIES BY MEANS OF COMMODITIES" (1960) e do debate gerado em torno da teoria neoclássica do capital e da distribuiqão, sraffa ja contestava os preceitos da microeconomia marginalista. Foi assim em dois artigos(1925 e 1926), publicados em revistas europeias ', onde sraffa ja questionava a viabilidade da andlise de 
equillbrio parcial de Marshall, quanto à curva de oferta da firma. Para Sraffa, a andlise de Marshall so seria vảlida na hipotese restritiva de retornos constantes à escala, uma vez que só assim seria posslvel determinar a curva de oferta da firma (baseada em rendimentos marginais decrescentes). Nestes trabalhos, Sraffa tambem questionava a realidade da pressuposição de concorrência na economia, entre outras coisas, incompativel com os retornos crescentes à escala derivados das vantagens da divisão do trabalho, gerando a concentração do mercado (neste sentido, a livre entrada no mercado não eliminaria os lucros anormais) $^{3}$. Como produto do questionamento de sraffa, nascem os primeiros trabalhos incorporando modelos de concorrência imperfeita (Chamberlin e Robinson,1933).

Apos isto, Sraffa dedicou-se ao estudo das obras de David Ricardo, o que originou a edicão completa dessas obras com uma importante introducão de sraffa . Estes estudos fizeram com que Sraffa retomasse o enfoque clássico da economia politica no seu trabalho posterior, tratando de questões como a teoria do valor-trabalho, determinacão dos preços de producão e distribuicão do excedente econômico.

Foi então, em 1960, que o mundo acadêmico veio conhecer o trabalho revolucionario de sraffa. o subtitulo do livro "PRODUCTION OF COMMODITIES BY MEANS OF COMMODItIEs", "Prelude to a critique of economic theory", 
sugere uma critica à teoria econômica atê então estabelecida, em coerência com os primeiros trabalhos publicados por sraffa . De fato, a crltica mais forte do livro se refere à medida do capital como independente da distribuicão do excedente entre lucros e salários.

Durante a decada de 60 travou-se um debate entre os economistas de Cambridge (nos EUA) e de Cambridge (na Inglaterra) em torno da teoria neoclássica do capital e da distribuiqão, motivado pelo trabalho de Sraffa. Neste debate (denominado CONTROVERSIA DE CAMBRIGE sobre a teoria neocldssica do capital e da distribuicão), foram evidenciadas as deficiências desta teoria e do conceito marginalista de função de producão para este fim ${ }^{6}$.

Apesar de o objetivo central do livro de Sraffa ser "essentially an investigation of the system of prices of production, and the influence of the distributive variables (the rate of profits and the wage) on these prices" (RONCAGLIA,1978,p. 117), o produto desta investigação abrange um amplo conjunto de questões de teoria econômica, como a citada critica à medida do capital, a solucão para uma medida invariâvel do valor (a mercadoria-padrão), o problema da escolha de tecnicas (tambem central na CONTROVERSIA DE CAMBRIDGE), o tratamento da formacão de precos de producão com producão conjunta e capital fixo, a distincão entre mercadorias bâsicas e não-básicas (em confronto com a and̆lise clássica 
entre "necessaries" e "luxuries"), a aplicąão do modelo de Sraffa para o problema marxista da transformaça de valores em precos, ate a formalização matematica da teoria ricardiana da renda diferencial, que e o que mais nos interessa no momento.

Os trabalhos de Sraffa e de seus seguidores têm originado a denominação de escola neo-ricardiana para engloba-los em uma linha de pensamento que não se incorporaria nem à escola neocldssica nem, tampouco, à escola marxista. No entanto, como adverte Roncaglia, embora Sraffa represente, sem duvida, um retorno à economia polltica clássica, as similaridades devem ser buscadas em alguns aspectos, mas não em todos. Assim sendo, Roncaglia ressalta que "the identification of similarities between Sraffa and the classical economists is too often derived from reading the classical economists through marginalist glasses"(p.XVI), o que leva a creditar ao modelo de sraffa a pressuposicão de retornos constantes à escala e o consequente aspecto de um modelo de equilibrio geral. Neste sentido, ha que se restringir a amplitude do termo neo-ricardiano aplicado à obra de sraffa e seus seguidores, uma vez que "ha algo de novo no ar".

Apos esta breve introducão da obra de Sraffa dentro da evolucão do pensamento econômico, pretendemos detalhar os aspectos do sistema econômico sraffiano contido em "PRODUCTION OF ..." no que for util para a compreensão 
da teoria sraffiana da renda da terra, objetivo ultimo deste trabalho.

\section{2) O sistema de precos}

Sraffa comeqa o seu livro tratando de uma economia simplificada, onde as mercadorias são produzidas por meio de outras mercadorias e de trabalho, sem a producão de um excedente. Desta forma, anualmente o sistema econômico se repete tal como e. Admitindo-se que não ha capital fixo e que cada industria produz um so produto, teremos, na terminologia de sraffa, o seguinte sistema de preços de producão:

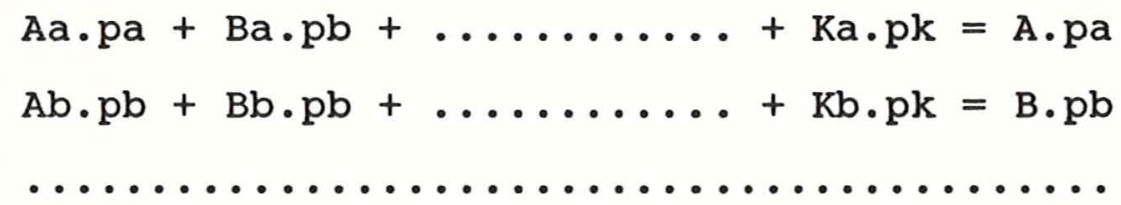

$\mathrm{Ak} \cdot \mathrm{pk}+\mathrm{Bk} \cdot \mathrm{pk}+\ldots \ldots \ldots \ldots+\mathrm{Kk} \cdot \mathrm{pk}=\mathrm{K} \cdot \mathrm{pk}$

Onde:

Aa e a quantidade da mercadoria "a" necessdria para a produção de A unidades da mercadoria "a", e assim por diante. Por exemplo, $\mathrm{Kb}$ representa a quantidade da mercadoria "k" necessåria para a producão de B unidades da mercadoria "b".

$\mathrm{pa}, \mathrm{pb}, \ldots . ., \mathrm{pk}$ serão os preqos (necessariamente 
estabelecidos para que o sistema reproduza-se anualmente) das mercadorias "a","b", ..., "k".

A, B,...K representam as quantidades produzidas das respectivas mercadorias.

Deve-se observar que Sraffa parte de quantidades conhecidas das mercadorias produzidas e das respectivas quantidades necessarias de insumos. No final desse cap1tulo detalharemos um pouco esse aspecto.

Tomando-se uma das mercadorias como medida de valor (doravante chamada de numerario), tem-se k-1 incognitas a resolver, que são os preços das demais mercadorias. Agora, o sistema de $\mathrm{k}$ equacões pode ser escrito da seguinte forma :

$(A a-A) \cdot p a+B a \cdot p b+\ldots \ldots \ldots+\cdots+K a \cdot p k=A \cdot p a$

$\mathrm{Ab} \cdot \mathrm{pb}+(\mathrm{Bb}-\mathrm{B}) \cdot \mathrm{pb}+\ldots \ldots \ldots \ldots+\mathrm{Kb} \cdot \mathrm{pk}=\mathrm{B} \cdot \mathrm{pb}$

$\mathrm{Ak} \cdot \mathrm{pk}+\mathrm{Bk} \cdot \mathrm{pk}+\ldots \ldots \ldots+\ldots+(\mathrm{Kk}-\mathrm{K}) \cdot \mathrm{pk}=\mathrm{K} \cdot \mathrm{pk}$

Verifica-se que a soma dos coeficientes de qualquer preqo e sempre zero, se não houver excedente. Portanto, $k$ equações são linearmente dependentes. Abandonando uma das equações ficamos com $k-1$ equacões que permitem determinar, em geral, os k - 1 precos.

No entanto, se passarmos a admitir que a economia e capaz de produzir mais do que o necessario para recomecar o ciclo anual, o sistema torna-se 
"autocontraditorio" (nas palavras de Sraffa). Isto porque passaremos a ter $\mathrm{k}$ equações linearmente independentes (e não mais $\mathrm{k}-1$ ) para obtermos $\mathrm{k}-1$ incognitas.

A distribuicão do excedente deverd, agora, ser determinada atraves do mesmo mecanismo e ao mesmo tempo que se determinam os preços das mercadorias. Há uma mutua dependência entre os preços e a taxa de lucro. Quando acrescentamos uma nova incognita ao nosso sistema de equações tal sistema volta a se tornar determinado, pois as $\mathrm{k}$ equações linearmente independentes (salvo acaso) determinarão os k-1 preços e a taxa de lucro.

Sraffa passa a considerar, então, a possibilidade de $\circ$ salário tomar parte do excedente produzido $^{11}$. Ate então, o salário consistia de bens de subsistência que participavam do sistema como qualquer outro meio de producão. Sraffa considera razodvel manter a parte do salário correspondente aos bens de subsistência como meio de producão e a parte correspondente ao excedente produzido na economia como "bens de luxo". Apenas esta parte seria, então, variâvel. No entanto, o autor pretende seguir " a prática usual de tratar todo o salário como variável".

Sraffa supõe, ainda, que os salårios são pagos ao final do perlodo de produção, em oposição à ideia clássica dos salários adiantados por um fundo capitalista. Desta forma, chamando-se de $\mathrm{La}, \mathrm{Lb}, \ldots, \mathrm{Lk}$ as quantidades 
anuais de trabalho necessarias como insumos, e anulando-se as diferencas na qualidade do trabalho atraves de diferencas equivalentes na quantidade (de forma que cada unidade receba a mesma taxa de salario(w)), teremos o seguinte sistema de preços:

$$
\begin{aligned}
& (\mathrm{Aa} \cdot \mathrm{pa}+\mathrm{Ba} \cdot \mathrm{pb}+\ldots \ldots+\mathrm{Ka} \cdot \mathrm{pk}) \cdot(1+\mathrm{r})+\mathrm{La} \cdot \mathrm{W}=\mathrm{A} \cdot \mathrm{pa} \\
& (\mathrm{Ab} \cdot \mathrm{pa}+\mathrm{Bb} \cdot \mathrm{pb}+\ldots \ldots+\mathrm{Kb} \cdot \mathrm{pk}) \cdot(1+\mathrm{C})+\mathrm{Lb} \cdot \mathrm{w}=\mathrm{B} \cdot \mathrm{pb}
\end{aligned}
$$$$
(\mathrm{Ak} \cdot \mathrm{pa}+\mathrm{Bk} \cdot \mathrm{pb}+\ldots \ldots+\mathrm{Kk} \cdot \mathrm{pk}) \cdot(1+\mathrm{r})+\mathrm{Lk} \cdot \mathrm{W}=\mathrm{K} \cdot \mathrm{pk}
$$

o valor monetario do excedente (renda nacional) e [ A $(\mathrm{Aa}+\mathrm{Ab}+\ldots+\mathrm{Ak})] \cdot \mathrm{pa}+[\mathrm{B}-(\mathrm{Ba}+\mathrm{Bb}+\ldots \ldots+$ $\mathrm{Bk})] \cdot \mathrm{pb}+\ldots \ldots+\ldots+[\mathrm{K}-(\mathrm{Ka}+\mathrm{Kb}+\ldots+\mathrm{Kk})] \cdot \mathrm{pk}$. Acrescentando-se, agora, uma equação que define o numerăio (que pode ser a propria renda nacional, uma mercadoria composta), teremos $k+1$ equações linearmente independentes e $k+2$ incognitas a serem determinadas.

"O resultado de acrescentar o salario como uma das variáveis e que o numero destas excede em um, agora, o numero de equações, e que o sistema pode mover-se com um grau de liberdade; e se uma das varidaveis e fixada, as demais tambem estarão fixadas", conclui SRAFFA(1983, p. 185) .

A solução do sistema será, então, representada pela relação entre a taxa de lucro e a taxa de 
salário (relaqão, ou curva, w-r). E os demais precos serão funcões de uma das duas varidveis distributivas. A relação $\mathrm{w}-\mathrm{r}$ determinard, portanto, o maior valor posstvel que uma das varidveis distributivas pode assumir, apos imputarmos o valor da outra. Representa o conflito distributivo entre capitalistas e trabalhadores, quando for uma relação decrescente ${ }^{12}$.

Na verdade, Sraffa opta por considerar a taxa de lucro como o dado exogeno pois, " como uma razão, tem significado que e independente de qualquer preqo e pode ser, portanto, ' dada ' antes que os precos sejam fixados" (SRAFFA, 1983, p. 202) ${ }^{13}$.

3.3) Mercadorias básicas e não-båsicas

Tão logo se admite a possibilidade de um excedente, criam-se condições para que uma mercadoria que compareqa no excedente não conste dos meios de producão. Esses "bens de luxo" que "não são utilizados, nem como instrumentos de producão nem como artigos de subsistência, na produção de outras mercadorias" (SRAFFA, 1983, p.182), não desempenham papel algum na determinação do sistema. Como adverte SRAFFA(1983, p.182), " se uma inovąão vier a reduzir à metade a quantidade de cada um dos meios de producão que são necessarios para produzir uma unidade do 
"bem de luxo" deste tipo, o preqo dessa mercadoria cairia pela metade, mas não se registrariam consequências posteriores; as relacões de preqos dos outros produtos e a taxa de lucro permaneceriam inalteradas".

De outra parte, as mercadorias que fazem parte dos meios de producão de outras mercadorias que, por sua vez, são meios de producão de outras, afetam todos os preqos e as variáveis distributivas (taxas de lucro e de salario). A estas mercadorias sraffa denominou mercadorias båsicas, e ao equivalente aos bens de luxo sraffa denominou mercadorias não-básicas. Deve-se acrescentar que entre as mercadorias não-bd́sicas estão incluldas aquelas que são apenas meios de producão de sua própria producão, assim como da producão de outras mercadorias não-básicas ${ }^{14}$.

Neste ponto, Sraffa volta a advertir para uma questão de terminologia. Assim, o autor pretende denominar as relacões de troca que solucionam o sistema por "valores" ou "preqos" (sendo apropriados os termos clássicos "preqo necessario","preqo natural","preco de producão") e não por "custo de producão". Esta ultima terminologia seria apenas adequada às mercadorias não-basicas, uma vez que os seus preq̧os não afetam os demais. No caso das mercadorias básicas, entretanto, o termo torna-se inadequado, uma vez que "os preqos de seus meios de producão dependem de seu proprio preqo não menos do que este ultimo depende daqueles"(SRAFFA, p.183) . E o mesmo vale, segundo o autor, 
para o termo "capital", termos esses "ligados, inseparavelmente, à suposicão de que representam quantidades que podem ser medidas independentemente e antes da determinacão dos preqos dos produtos", afirma SRAFFA (1983, p.183).

Uma outra questão, importante neste contexto, refere-se ao tratamento do salario que, por opqão de Sraffa, e inteiramente varidvel. Neste caso, os bens necessarios à subsistência do trabalhador seriam relegados "ao limbo dos produtos não-básicos", uma vez que não aparecem mais entre os meios de producão e, sendo assim, uma melhora nos metodos de producão dos bens necessários para a vida não mais afetard diretamente a taxa de lucro e o preço dos demais produtos. Sraffa, entretanto, argumenta que, sendo os bens de subsistência essencialmente básicos, e preciso que se permita uma influência destes por outras maneiras, como impondo um limite minimo para o salário que se modificaria se melhorassem as tecnicas de producão dos bens de subsistência, fazendo aumentar a taxa de lucro do sistema 15

Finalmente, o efeito de um imposto sobre mercadorias båsicas e não-básicas ilustra, mais uma vez, a importância dessa diferenciaqão. Assim, se um imposto recair sobre uma mercadoria básica, a curva de saláriolucro desloca-se em direcão à origem dos eixos, e os preqos relativos das mercadorias alterar-se-ão se esta mercadoria 
(a que esta sendo taxada) for utilizada em diferentes proporqões nos diversos processos produtivos. Se, entretanto, o imposto recair sobre uma mercadoria nãobásica, a curva saldrio-lucro não se altera (evidentemente, se a mercadoria utilizada como numerario for básica). Como observa RONCAGLIA $(1978, \mathrm{p} .62)$, em oposição à concepqão de Ricardo em que um imposto sobre os bens-salario afeta apenas os lucros,"within the framework of sraffa's system, on the contrary, a tax levied on a wage good falls, in the first instance, on the worker".

3.4) Reducão a quantidades de trabalho "datadas"

No cap1tulo destinado ao tema acima, sraffa pretende mostrar como se decompõem os precos das mercadorias em salarios e lucros, considerando, então, os precos a partir de seu aspecto de "custo de producão" (uma vez que não mais se considerarão os preqos dos meios de producão). Entenderemos assim, dois importantes aspectos da teoria sraffiana, quais sejam: o movimento complexo dos preços frente a mudanças na distribuicão da renda e a relação inversa entre taxa de salário e taxa de lucro.

Para efetuarmos a reducão dos preqos a quantidades de trabalho "datadas", partiremos da equação de producão de uma mercadoria e substituiremos o valor das diferentes mercadorias que compõem os meios de producão da 
mercadoria que escolhemos, por uma serie de quantidades de trabalho com "datas" adequadas.

Desta forma, se tomarmos a mercadoria "a", a sua equacão de produção serâ representada por:

$$
(\mathrm{Aa} \cdot \mathrm{pa}+\mathrm{Ba} \cdot \mathrm{pb}+\ldots+\mathrm{Ka} \cdot \mathrm{pk}) \cdot(1+\mathrm{r})+\mathrm{La} \cdot \mathrm{W}=\mathrm{A} \cdot \mathrm{pa}
$$

E tomamos o termo Aa.pa para substitu1-lo pela equação de producão deste meio de producão. E fazemos isto para os demais termos da equacão. Como a producão dos meios de producão ocorreu no perlodo anterior, devemos multiplicar cada equacão substitulda por $(1+r)$. Agora fazemos o mesmo para os termos correspondentes aos meios de producão dos meios de produção de "a". Se assim prosseguirmos "ad infinitum", obteremos a seguinte equacão de reducão ${ }^{16}$ :

$$
\begin{aligned}
& \mathrm{A} \cdot \mathrm{pa}=\mathrm{La} \cdot \mathrm{w}+\mathrm{La}_{1} \cdot \mathrm{w} \cdot(1+\mathrm{r})+\mathrm{La}_{2} \cdot \mathrm{w} \cdot(1+r)^{2}+\ldots+ \\
& +\ldots \ldots+\mathrm{La}_{\mathrm{n}} \cdot \mathrm{w} \cdot(1+r)^{\mathrm{n}}+\ldots \ldots \ldots
\end{aligned}
$$

Onde La e quantidade de trabalho direto total recolhida a cada data n. Desta forma, o valor da mercadoria dependerá do trabalho direto e indireto que foi necessario à sua produção e da taxa de lucro.

Admitindo-se que haja pelo menos uma mercadoria bł́sica (como Sraffa pressupõe), sempre haverd um residuo na expressão (correspondente à presença da 
mercadoria basica como meio de producão em todos os pertodos) e o "custo de producão" não poderá ser exaurido por lucros e salarios. No entanto, o reslduo torna-se cada vez menos significante quanto mais avancarmos na operacão de reducão. Apenas quando a taxa de lucro atinge o seu valor máximo e que o residuo torna-se importante como determinante unico do valor da mercadoria (uma vez que a1 w $=0$, e restard apenas o res1duo. E claro que, quanto mais proxima a taxa de lucro estiver de seu valor máximo, tanto mais deve-se avancar na reducão, para tornar o residuo insignificante).

Se supusermos, agora, uma elevação cont1nua da taxa de lucro, partindo-se do zero ate o seu valor maximo, observaremos um movimento complexo dos termos de cada parcela da soma da reducão, fruto do movimento oposto das taxas de lucro e de saldrio e da "data" do termo. Sraffa faz um exerclcio numerico e grafico para ilustrar a questão. Expressando o salario (e os precos, obviamente) em termos do produto I1quido padrão ${ }^{17}$, Sraffa mostra que os termos de "datas" recentes apresentam queda contınua à medida que a taxa de lucro aumenta (uma vez que nestes a taxa de lucro est elevada a expoentes menores e o efeito de w e maior), e os termos de datas mais remotas aumentam de valor inicialmente, atingem um máximo e caem rapidamente quando a taxa de lucro aproxima-se de seu valor måximo. 
Este comportamento dos termos de trabalho da reducão faz com que os precos das diferentes mercadorias tenham um comportamento imprevisivel à medida que muda a distribuicão do excedente entre lucros e salarios ${ }^{19}$. Sraffa mostra, então, atraves de um exemplo numerico, que a diferença de precos de duas mercadorias pode ser positiva, negativa ou nula, à medida que a taxa de lucro aumenta. A partir deste exemplo, Sraffa conclui que "as inversões na direqão do movimento dos preqos relativos, frente aos metodos invariáveis de producão, não podem ser reconciliados com nenhuma nocão de capital como uma quantidade mensurâvel independentemente da distribuição e dos preqos"(SRAFFA, 1983,p.206) 20 .

Finalmente, Sraffa usa do artiflcio da reducão a quantidades de trabalho "datadas" para provar a relacão inversa entre taxa de lucro e de salario. Se tomarmos, por exemplo, a equacão de producão da mercadoria "a" e passarmos o termo pa dividindo todos os membros do outro lado da equacão, obteremos a seguinte equação:

$\mathrm{A}=\mathrm{La} \cdot(\mathrm{w} / \mathrm{pa})+\mathrm{La}_{1} \cdot(\mathrm{w} / \mathrm{pa}) \cdot(1+r)+\mathrm{La}_{2} \cdot(\mathrm{w} / \mathrm{pa}) \cdot(1+r) \mathrm{n}+\ldots$

Portanto, se a taxa de lucro aumentar, a taxa de salario em termos da mercadoria "a" deverd reduzir-se. Como isso pode ser feito para qualquer mercadoria ${ }^{21}$, segue-se que, se a taxa de lucro aumentar, a taxa de salario devera reduzirse, e vice-versa. 
3.5) Escolha da tecnologia de producão ${ }^{22}$

\begin{abstract}
Simultaneamente com $\circ$ problema de determinação dos preços, temos que resolver o problema da escolha dos metodos de produção. Ate então esta questão não foi comentada pois supunhamos que havia um unico metodo de producão para cada mercadoria produzida.

Conceituemos, então, a tecnologia de produção
\end{abstract} como o conjunto de tecnicas (ou metodos) de producão das diferentes mercadorias de um sistema econômico. Veremos, agora, que, embora possam haver metodos alternativos de produção, em cada faixa de variação da taxa de lucro, um (e apenas um) metodo serd utilizado (exceto nos pontos de mudanca de tecnica). o metodo que representar o menor custo serd o mais eficiente e serd o escolhido. Quanto ao criterio de eficiência " " is usually maintained that this is precisely the criterion which is automatically imposed upon producers who operate within a competitive system", como afirma PASINETTI(1977, p. 151). Este criterio, entretanto, claramente não depende apenas das condições tecnicas de produção, mas, tambem, da distribuição de renda entre lucros e salårios, como veremos a seguir $^{24}$.

Para as mercadorias não-bdsicas, a escolha do metodo mais eficiente de produzi-las (quando hà alternativas de produzi-las) pode ser resolvido a nfvel da 
propria industria (processo, ou equação) ${ }^{25}$. Assim, como os preqos dos seus meios de producão e das varidveis distributivas são tomados do sistema de mercadorias básicas, basta compararmos os preqos da mercadoria nãobásica em cada metodo, e escolhermos o metodo cujo preco e menor. E possivel, entretanto, que haja um deslocamento dos metodos de producão, quando varia a taxa de lucro, como mostra a Figura 3.1 , a seguir ${ }^{26}$.

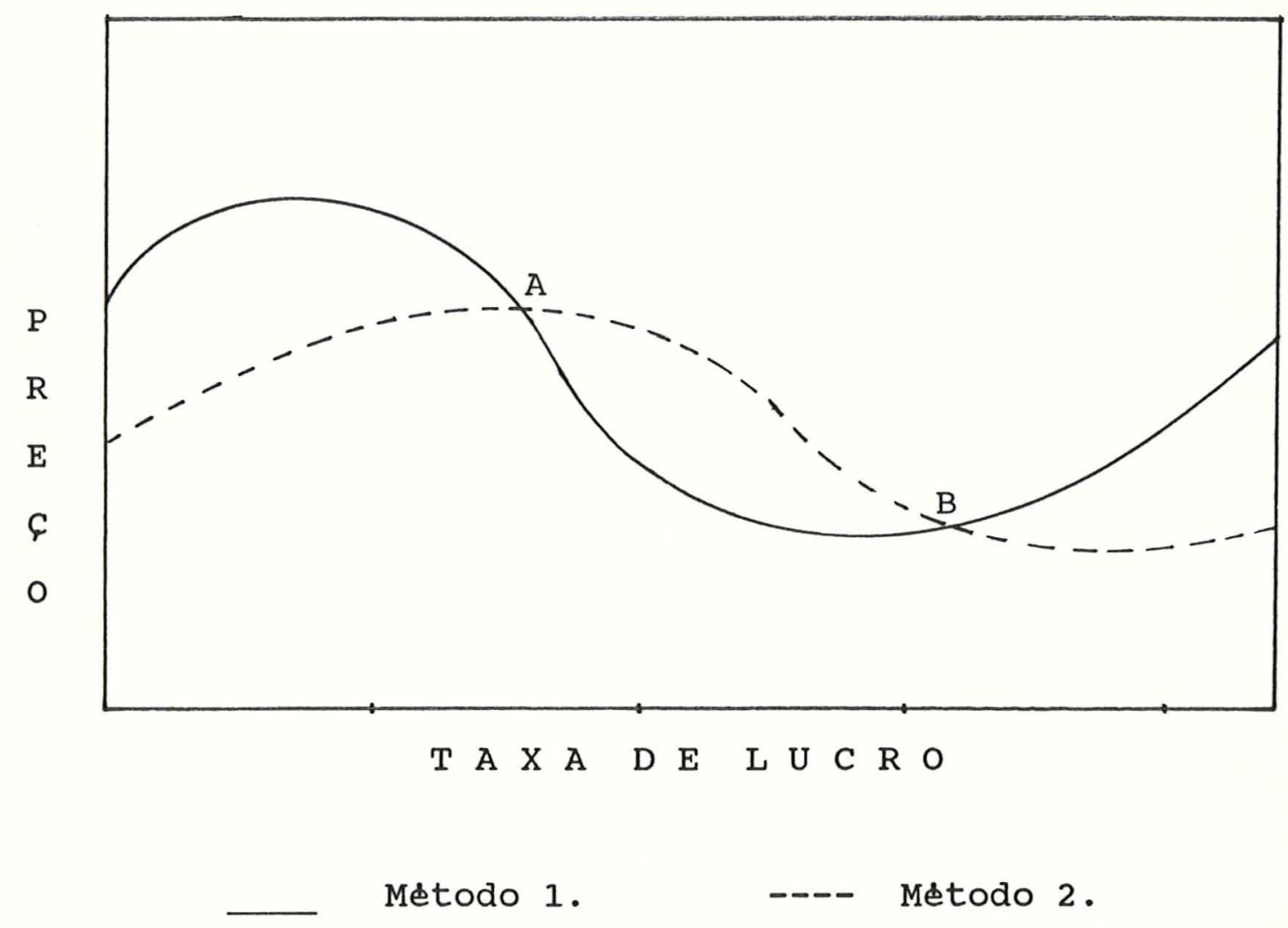

Figura 3.1 - Escolha da técnica para mercadoria não-básica. 
Nos pontos de interseção $(A, B)$, entretanto, ambos os metodos poderão coexistir, devido à mesma eficiência. E evidente, por fim, que os efeitos da alteracão dos metodos de producão de uma mercadoria nãobásica so afetarão o preq̧o desta mercadoria (ou os preqos de outras mercadorias não-básicas que utilizam esta mercadoria como meio de produção).

A escolha da tecnica (metodo de produção) para uma mercadoria básica, envolverá, entretanto, o sistema como um todo. Suponhamos, agora, que existam três metodos para produzir a mercadoria bảsica "h" ${ }^{27}$ (metodos "a","b" e "c"). Como o preço desta mercadoria "h" afeta os demais preços e a taxa de lucro ( se fixarmos a taxa de salário), deveremos pensar no sistema como um todo para escolhermos a tecnologia mais eficiente (o progresso tecnico afeta todas as demais mercadorias).

Para isso, suporemos, inicialmente, que hd um so metodo de producão para cada uma das demais mercadorias. A escolha da tecnologia (para o sistema econômico como um todo) resumir-se-à, portanto, à escolha entre as três tecnicas alternativas de producão da mercadoria "h". Desta forma, cada uma das três tecnicas compõem três diferentes sistemas de preços, e pode parecer, à primeira vista, que elas não podem ser comparadas uma com a outra. Se, entretanto, escolhermos uma mercadoria qualquer como numerărio, podemos obter três curvas $w-r$ e, desde que a 
taxa de salario esteja expressa na mesma mercadoria, as três relações podem ser comparadas. Um exemplo poss1vel e mostrado pela Figura 3.2 , abaixo ${ }^{28}$.

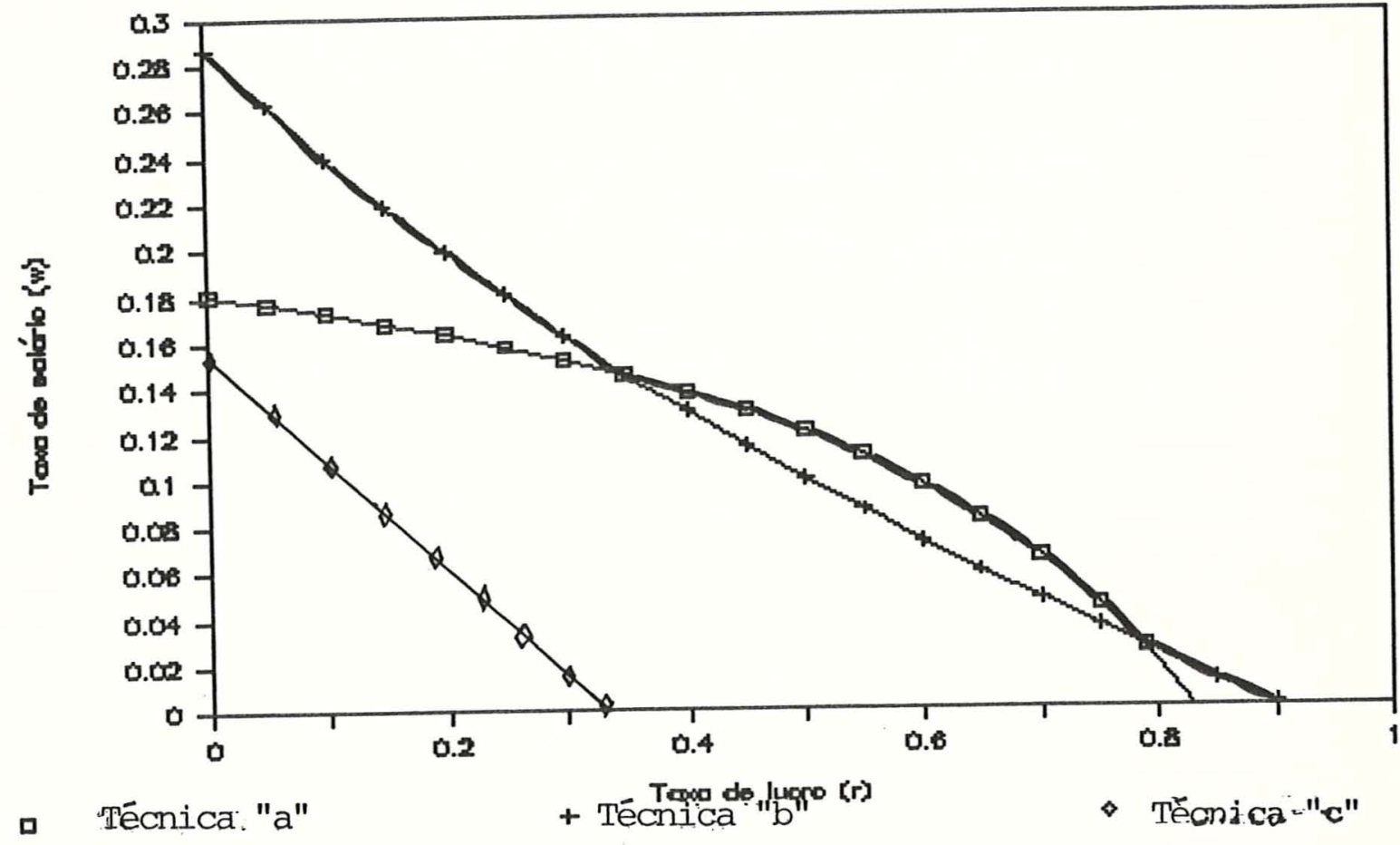

Figura 3.2 - Escolha da tecnica para mercadoria básica.

Neste caso, a tecnica "c" serd, claramente, obsoleta, uma vez que, para qualquer taxa de lucro, ela fornece uma taxa de saldrio menor que as outras duas ${ }^{29}$.

Observando-se a Figura 3.2, verifica-se que, para $0<r<0,35$, a tecnica "a" \& a mais eficiente (pelo mesmo raciocinio anterior), enquanto que, para $0,35<r<$ 0,80, a tẹcnica "b" torna-se a mais eficiente, e deverâ ser 
adotada. Finalmente, para $r>0,8$ a tecnica "a" volta a ser a mais eficiente.

E importante observar que o criterio de eficiência implica em minimizacão de custos a nlvel de cada industria, e obtenção de uma maior taxa de lucro (para uma taxa de salario fixa) a ntvel do sistema como um todo. E, tambem, em cada ponto de mudanca de tecnica, tanto as duas tecnicas são igualmente eficientes, como qualquer combinação destas. Nesse caso, as duas equações juntam-se às demais equações do sistema de preços, para formar um sistema determinado, sem qualquer grau de liberdade.

Podemos denominar a curva envolvente, externa às curvas $w-r$ das diferentes tecnicas alternativas, como a fronteira tecnologica das posslveis distribuições da renda entre lucros e salários ou, a fronteira tecnologica das possibilidades de distribuição de renda ou, simplesmente, fronteira tecnologica (em negrito na Fig. 3.2).

Pode-se demonstrar as seguintes propriedades anal1ticas da curva envolvente: 31

(i) em um ponto de mudança, os sistemas de preços das duas tecnicas (ou de qualquer combinação linear destas) serão os mesmos.

(ii) quando uma tecnica e superior a outra (ou seja, quando não estamos nos pontos de mudança) esta gera preços, em termos da taxa de salario, estritamente menores que aqueles precos gerados por outra tecnica, para todas as mercadorias 
(e não apenas para a mercadoria "h").

(iii) se mudarmos o numerário, as relacões w-r alterar-seão, mas os pontos de mudança ocorrerão às mesmas taxas de lucro, e a ordem de eficiência não se alterará.

(iv) a fronteira tecnologica e estritamente decrescente para valores crescentes da taxa de lucro ${ }^{32}$.

Vale observar que hat uma prioridade lógica para a escolha de tecnicas para mercadorias basicas em relacão às não-básicas, uma vez que apenas após escolhermos a tecnologia mais apropriada para a producão das básicas e que teremos os valores dos preços e da taxa de lucro para substituirmos nas equações de producão das mercadorias não-básicas.

Agora mostraremos que as propriedades analfticas da fronteira tecnologica, vallidas para o caso em que havia tecnicas alternativas apenas para uma mercadoria, podem ser estendidas para o caso geral onde hâ tecnicas alternativas para todas as mercadorias. Faremos esta "demonstracão", em vez de simplesmente deixd-la ao leitor interessado, porque mostrard, na verdade, uma nova propriedade anal1tica da fronteira tecnologica.

Suponhamos que todas as tecnicas alternativas que fazem parte da fronteira tecnologica envolvam a producão das mesmas mercadorias. Se uma tecnica estâ na fronteira tecnologica, nenhum preço associado a ela pode ser maior (em termos da taxa de salário) do que qualquer 
preco obtido por qualquer outra tecnica e, ainda, em cada ponto de mudanca, os preqos associados às duas tecnicas serão iguais para todas as mercadorias, qualquer que seja o numerărio escolhido. Agora, num ponto de mudança, os valores das incognitas de um sistema podem ser determinados (sem qualquer grau de liberdade) se acrescentarmos uma equacão do outro sistema, que está no ponto de mudança. Isto implica que, no ponto de mudanca, os dois sistemas que geram as mesmas solucões podem, em geral ${ }^{33}$, diferir por apenas uma equacão. "The conclusion to be drawn is that, on the technological frontier, although the various techniques may differ in more than one method of production (..), those techniques which are adjacente at a switch point will differ, in general, in only one method of production", conclui PASINETTI (1977, p. 163). Ou seja, se "descermos" gradualmente a fronteira tecnologica, apenas um metodo de produção (uma equação) será alterado em cada ponto de mudanca.

Portanto, na fronteira tecnologica está-se comparando duas tecnologias que diferem, em geral, por apenas um metodo de producão. E, sendo assim, as propriedades anal1ticas da fronteira tecnologica podem ser demonstradas para o caso geral.

Pode ser demonstrado que as mesmas conclusões aplicam-se ao caso em que todas as tecnicas alternativas não produzem, exatamente, as mesmas 
mercadorias, como foi suposto inicialmente ${ }^{34}$. Isto porque, para compararmos as tecnologias, so necessitamos que a taxa de salário seja expressa em termos de uma mercadoria que e comum às duas tecnologias. E, e claro, apenas os precos das mercadorias comuns às duas tecnologias poderão ser comparados $^{35}$.

Estas conclusões, finalmente, são vâlidas apenas sob a hipotese de retornos constantes à escala e para producão simples. Caso contrdrio a andlise torna-se mais complexa e aqui não trataremos do assunto.

\section{6) Considerạões finais}

Consideramos necessario que se façam alguns comentarios finais a respeito do sistema econômico sraffiano, a fim de completarmos o contexto, antes de incluirmos o meio de producão terra no sistema. Isto porque, como diz RONCAGLIA(1978,p.XV), " an appreciation of the revolutionary impact of sraffian analysis has, perhaps, been impeled by the fact that in the Production of commodities by means of commodities the conceptual frame of reference for the study of prices of production is not made explicit."

Não pretendemos tornar explicito tudo que esta implicito no trabalho de $\operatorname{sraffa}^{36}$. o que pretendemos e levantar alguns pontos importantes da metodologia de 
Sraffa ao determinar os precos relativos da economia. Principalmente, no sentido de não tomar o sistema de preços de Sraffa, como parte do contexto da andlise tradicional de equillbrio de preqos. Assim, Sraffa, diferentemente dos economistas classicos, exclui qualquer tratamento que relacione os preqos resultantes de seu sistema econômico com os precos de mercado ${ }^{37}$. Desta forma, não e leg1timo tratar o sistema de preqos de sraffa como um dos lados do equillbrio geral, restando acrescentar equações de demanda.

Isto leva-nos a um outro aspecto importante, ja que implica em uma diferenciacão de sraffa dos clássicos. Assim, se o tratamento acima serviu de argumento de uma continuidade da teoria econômica dos clássicos aos neoclássicos, pois a hipotese de retornos constantes estava presente entre os clássicos, o mesmo não se aplica ao sistema teorico de sraffa.

No seu prefâcio (p. 175) de "PRODUCÁ DE MERCADORIAS ... ", Sraffa usa quatro parägrafos para comentar este aspecto, seguindo um conselho de Keynes. Sraffa sugere, então, que, apenas para auxllio de compreensão, pode-se supor rendimentos constantes à escala em seu modelo . Mas, de fato, esta hipotese não e feita, porque o que se pretende estudar não depende das variacões na escala ou na proporcão dos "fatores". Não se considera, portanto, variações nas quantidades produzidas. Isto sim, representa um retorno aos clássicos e um abandono do metodo 
marginalista que requer variações (na escala ou na proporcão de fatores) para determinar os valores de equiltbrio do modelo ${ }^{39}$.

outro aspecto importante se refere ao cardter de reprodutibilidade do sistema econômico de Sraffa. Novamente, aqui hả um claro retorno as clássicos, como o proprio sraffa assume:" a concepఢão original do processo de producão e de consumo como um processo circular, se encontra, naturalmente, no Tableau Economique de Quesnay, e aparece em agudo contraste com a visão apresentada pela moderna teoria de uma avenida unidirecional que leva dos "fatores de producão" aos "bens de consumo" " (p. 257). Neste sentido, podemos aludir a POSSAS(1982) e denominar os preços do esquema teorico de sraffa como precos de reproducão.

Metodologicamente, enfim, a teoria de Sraffa afasta-se, completamente, do metodo marginalista de andlise econômica. De modo que, se não e apropriado tratar o sistema econômico de sraffa como um caso de equilibrio geral $^{41}$, tampouco o e trata-lo como uma andlise de equillbrio parcial, no sentido neoclássico. Isto porque a andlise não se limita a qualquer parte particular do sistema econômico, a fim de fornecer uma solucão aproximada a um problema cuja solução completa requer andlises a nivel geral. Como afirma RONCAGLIA(1978, P.119) "Sraffa takes into account all and only those elements necessary to 
the problem under consideration".

Desta forma, Sraffa escolhe as variáveis precos, taxas de lucro e de salário (e, depois, renda da terra), para estudar a relação entre os precos relativos e a distribuição de renda. Tudo o mais (tecnologia, nlveis de produção) e assumido como dado para a andlise do problema particular escolhido. Isto implica, apenas, em analisar cada problema de uma vez, isolando um problema do outro, e não em uma recusa "a priori" da possibilidade de analisar os problemas de mudanca tecnologica, determinacão dos nlveis de producão, etc. Como diz RONCAGLIA(1978,p. 22) "from this point of view sraffa's abstraction from movements in the level of activity can be compared to the abstraction from movements in the relative prices in the keynesian theory of effective demand".

De outra parte, os marginalistas pretendem "explicar" a determinação simultânea de preços, quantidades e distribuição de renda, sem, portanto, isolar um problema de cada vez. Hd uma pretensão dos economistas marginalistas de "buscar" uma teoria geral capaz de resolver "o problema econômico geral" (da alocą̧ão de recursos escassos), "that they believe to be identified with the science of economics" (RONCAGLIA,p. 119).

Com respeito à teoria da distribuição, e ilustrativo citarmos as palavras de DOBB (1973a,p.326) de que a teoria de Sraffa não faz "qualquer tentativa de 
dedução de uma teoria da repartição a partir do interior do clrculo de trocas; e, no abandono desta tentativa, verificamos uma inversão da ordem ou esquema de determinação pre-jevoniana: os preços derivam (ou dependem em parte) das condicões da reparticão, em vez de esta derivar da estrutura de precos, tratada, por sua vez, como resultante da procura".

Quanto ao papel da demanda na determinação dos precos relativos e oportuno citarmos ROBINSON (1973,p. 202). Segundo a autora " when we are provided with a set of technical equations for production and a real wage rate which is uniform throughout the economy, there is no room for demand equations in the determination of equilibrium prices". E mais, "in a market economy, either there may be a tendency towards uniformity of wages and the rate of profit in different lines of production, or prices may be governed by supply and demand, but not both", continua a autora (p. 202).

o sistema econômico sraffiano, enfim, deve ser encarado como uma abstracão teorica do funcionamento do sistema capitalista. "Evidently we are in a capitalist economy, but to avoid the ambiguities which have clustered around the word, capital is never mentioned. There is profit, but no enterprises; wages, but no paypackets; prices, but no markets. Nothing is mentioned but the equations of production and the necessary conditions of 
exchange", conclui ROBINSON (1973, p.197).

NOTAS

(1) Cf. RONCAGLIA (1978, pp.124-126).

(2) Cf. SRAFFA (1989) E SRAFFA(1982).

(3) Cf. RONCAGLIA(1978, pp.9-12) e Introdução de Possas em SRAFFA (1983, pp.156-58).

(4) Cf. RICÁRD (1982, pp.3-35) .

(5) Cf. ROBINSON (1973) e prefácio do livro de SRAFFA(1983).

(6) Cf. DOBB (1973a,1973b) e ROBINSON(1973). Cf. tambem METCALFE \& STEEDMAN(1972), para um modelo sraffiano que contesta as conclusôes do modelo neoclássico de equilibrio geral.

(7) Veremos, adiante, que não se trata de uma mera formalização matematica do pensamento ricardiano.

(8) Por exemplo, quanto ao tratamento do conceito de concorrência no sentido de livre mobilidade de recursos, originando uma mesma taxa de lucro entre os diferentes setores da economia, em contraste com a noção de agentes econômicos atomizados que não influenciam prę̧os. Tambem, quanto à determinação dos preços pelo nlvel objetivo da produção, sem considerar o nlvel subjetivo da demanda. Alem disso, a ênfase no aspecto da reprodutibilidade do sistema econômico (uma abordagem de fluxo), contra a ênfase em escassez de recursos (uma abordagem de estoque). Cf. RONCAGLIA (1978, p.125) .

(9) Assume-se, por simplicidade, o mesmo pertodo de produção (ano) para todas as mercadorias. discussão sobre o assunto, veja RoNCAGLIA (1978, pp.29-31). (10) Esse sistema de precos e parecido com o sistema de Leontief. Na verdade, a j-esima coluna do sistema de Sraffa corresponde à j-ésima linha do sistema de Leontief. Por outro lado, enquanto o sistema de Leontief tem implicações mais emplricas de planejamento econômico, o sistema de Sraffa es mais destinado à andlise teorica.

(11) Sraffa rompe, aqui, com a tradição clássica de considerar o salário como rlgido no valor de subsistência. - autor abre a possibilidade para o conflito distributivo entre capitalistas e trabalhadores, aproximando-se mais da andlise marxista. Ricardo, por outro lado, so previa um conflito entre proprietarios de terras e capitalistas, embora jâ conclulsse pela relação inversa entre lucros e salärios, tendo os trabalhadores uma posicão passiva.

(12) Que e o caso mais comum. Tal relação poderá ser crescente quando houver produção conjunta ou no caso da 
renda intensiva, que veremos adiante.

(13) De qualquer forma, como argumenta DOBB(1973a, p.326), " o que aquí importa é que, entre as condicões dadas do problema, ou os dados postulados, um dado social e introduzido do exterior (ou, como alguns podem preferir que se diga, debaixo do processo de mercado). Assim, os limites da economia como materia são ipso facto traçados de forma diferente e mais ampla, de modo a incluir condicões sociais, institucionais, e historicamente relativas, em permanente modificacão e modificdveis, que eram excluldas da economia de tradição pos-jevoniana".

(14) Cf. PASINETTI(1977, pp. 104-110) para excelente exposicão do tema em termos de matrizes irredut1veis, alem de demonstração matematica da não influência das mercadorias não-básicas na solução do sistema de preços.

(15) $\mathrm{Na}$ verdade, não hâ porque não tratar como variâvel apenas a parte do salario acima dos gastos necessarios à subsistência do trabalhador e de sua famllia, o que evitaria esta e outras complicacões.

(16) Cf.PASINETTI(1977, pp. 89-91), para obtenção, em termos de algebra linear, dessa expressão. Inclusive com maior compreensão da operação de redução.

(17) Trata-se do produto Ilquido do sistema padrão. Não discutiremos o sistema padrão, aqui, por não ter implicacões quanto à compreensão do tema central do trabalho. Adiantamos apenas, que o sistema padrão e obtido do verdadeiro sistema, a partír de multiplicadores, para obter-se uma medida invariatvel de valor. Para o exemplo em questão, expressar o saldrio em produto l1quido padrão serve, apenas, para facilitar a and̆lise, mas não interfere nas conclusões essenciais.

(18) Sraffa mostra (p.204) a expressão que determina a "data" em que esse máximo ocorre. Na edicão que usamos (SRAFFA(1983)) ha um erro de grafia na expressão. A expressão correta e dada por La $n *[1-r / R] *(1+r)^{n}$. onde $\mathrm{R}$ e a taxa maxima de lucro.

(19) Ou, pelo menos, complexo. Seria previstvel se obtivessemos as verdadeiras equacões de reducão. 0 que se quer mostrar, teoricamente, e que a mudança na distribuicão altera os precos relativos, de uma maneira muito complexa. Essa, alids, e a chave para a busca de uma medida invariavel de valor, que sraffa busca no sistema padrão. Cf. PASINETTI(1977, pp. 91-2) e SRAFFA(1983, cap. 3, 4 e 5). Este comportamento dos precos possibilitou a compreensão de "anomalias" na teoria do capital e na teoria da renda da terra, como veremos.

(20) Este e o aspecto de maior alcance da sua crltica à teoria econômica. Ponto central da "CONTROVERSIA DE CAMBRIDGE", com jà comentamos.

(21) Não precisamos, para isto, de uma medida invariável de valor, visto que o que importa e a relacão de preços entre 
- trabalho e o produto escolhido (arbitrariamente) como numerărio (a relação e independente da mercadoria escolhida) :

(22) Aqui utilizaremos a exposicão de PASINETTI(1977, cap.6) por ser mais clara e desenvolvida. O metodo de Sraffa parece mais abstrato, alem de ser apenas uma introdução ao tema, mostrando a possibilidade de obter-se uma ordenação da eficiência dos metodos, para produtos båsicos e não-båsicos. Entretanto, e preciso, agora, assumirmos retornos constantes à escala, como adverte PASINETTI (1977) .

(23) Preferimos usar o termo "eficiência", ao inves de "lucratividade" (como em PASINETTI(1977)), por considerarmo-lo mais adequado. Assim, se tomarmos a taxa de lucro como um dado, a maior eficiência de um metodo corresponderd a uma maior taxa de saldrio (por isso achamos inadequado o termo "lucratividade").

(24) Como veremos no proximo capitulo, esta e uma das principais "novidades" da teoria da renda da terra, extralda do modelo sraffiano.

(25) Veremos, no proximo cap1tulo, um caso ilustrativo em que a escolha da tecnologia dependerd da equacão de uma mercadoria não-básica que es escolhida como numerârio. A escolha de um numerârio diferente não afeta os pontos de mudança nem a ordem de eficiência das terras, apenas altera o formato das curvas. Cf. PASINETTI(1977, pp.154-5).

(26) A figura e baseada em SRAFFA(1983, p.243).

(27) No proximo cap1tulo a mercadoria "h" tornar-se-d o cereal (produto agricola), e a teoria de escolha de tecnicas assumird papel da maior relevância.

(28) O exemplo e baseado em PASINETTI(1977, p.157).

(29) Elaro que podemos raciocinar com uma taxa de saldrio fixa, e procurar a maior taxa de lucro. De qualquer forma, quanto mais afastada da origem, maior a eficiêncía absoluta da tecnica.

(30) Para $\mathrm{k}$ mercadorias básicas, a relação $\mathrm{w}-\mathrm{r}$ serd um polinômio de grau k e, tomadas duas a duas, as curvas poderão interceptar-se k vezes. No entanto, apenas as interseç̧ões no quadrante positivo terão interesse econômico. Cf. PASINETTI (1977, pp.87-9 e p.157) .

(31) Cf. PASINETTI (1977, pp.159-60) .

(32) Como ja comentamos, no caso de producão conjunta e no caso de renda intensiva, a relacão $w-r$ pode ser crescente, e a fronteira tecnológica pode ser, alternativamente, crescente e decrescente. Comentaremos, detalhadamente, o caso em questão, no proximo capltulo, discutindo um trabalho que reforcard a andlise de escolha de tecnicas (em outro contexto), questão central na teoria sraffiana da renda da terra.

(33) PASINETTI(1977, pp.164) argumenta que, mesmo no caso em que mais de duas curvas interceptam-se nos pontos de 
mudanç, e possivel ordenar as tecnicas a fim de fazer apenas um metodo mudar entre as curvas adjacentes.

(34) Cf. PASINETTI (1977, pp. 164-6).

(35) Para maiores detalhes da escolha de tecnicas, veja PASINETTI(1977, pp. 167-77), principalmente para um resumo da CONTROVERSIA DE CAMBRIDGE sobre a teoria do capital.

(36) Consulte o livro de RONCAGLIA(1978), para este fim.

(37) Quanto a esse aspecto, cf. RONCAGLIA(1978, pp. XVIIXVIII e pp. 23-7). Cf. POSSAS(1982), tambem, sobre a interpretação dos precos no sistema econômico sraffiano.

(38) "Qualquer pessoa acostumada a pensar em termos de equilibrio de demanda e oferta pode inclinar-se a supor, ao ler estas pàginas, que a argumentacão repousa sobre a pressuposicão tácita de rendimentos constantes em todas as industrias. Se se achar util tal suposição, não hà incoveniente algum em que o leitor a adote como uma hipotese temporária de trabalho", afirma o autor (p.175). Com a restrição ja comentada no final da NOTA 22 .

(39) Sraffa adverte, no prefácio de seu livro (p.175), que - caso de renda extensiva (que trataremos no próximo capitulo) tem alguma similaridade com exemplos marginalistas, mas não contempla qualquer variacão requerida.

(40) Veja tambem o conceito de estatica envolvido no conceito de preços de reproducão, no artigo citado. cf. RONCAGLIA(1978, pp. 5-7 e 119) sobre o assunto.

(41) E nesse sentido que os neoclasssicos querem encarar 0 modelo de sraffa como uma continuidade à teoria neocldssica, conforme RONCAGLIA(1978, p.99) . 
4- A RENDA DA TERRA NO SISTEMA ECONOMICO SRAFFIANO

4.1. Introducão

Embora o trabalho de sraffa tenha se constituldo no pilar da "CONTROVERSIA DE CAMBRIDGE", suas implicações não se resumem a essa controversia. E neste ponto que se insere o presente cap1tulo. Pretendemos abordar um outro aspecto da obra de sraffa, qual seja, o tratamento da renda da terra em seu sistema econômico.

Dentro do objetivo do trabalho de Sraffa, houve oportunidade para inclusão do meio de produção terra e o consequente estudo do tema renda da terra. Esse estudo, por sua vez, tambem gerou crlticas à teoria econômica até então estabelecida. A principal delas refere-se à constatação de que a renda da terra, tal como os precos das mercadorias, tem sua determinacão condicionada à distribuição do excedente econômico entre lucros e salarios. Por isso, conforme argumenta SRAFFA(1983, p.238), a ordem de fertilidade", "não esta definida independentemente das rendas; tal ordem, assim como a magnitude das proprias rendas, pode oscilar com a 
variaqão de $r$ e de w". Um resultado ate então ausente na teoria da renda da terra.

A teoria da renda da terra em Sraffa pode ser entendida como uma formalização matematica do pensamento ricardiano sobre o assunto. No entanto, talvez pela propria existência de um modelo mais formalizado, dela extraem-se aspectos outros, não considerados na teoria ricardiana. Dentro do estilo abstrato de que o autor se

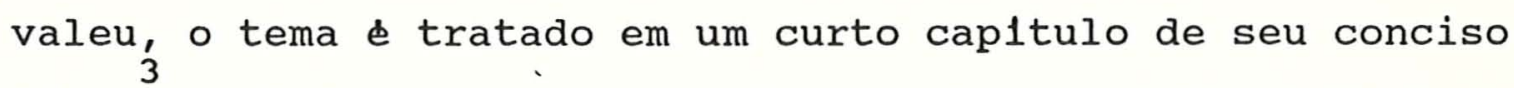
livro. Tal como os demais aspectos da obra, o tema

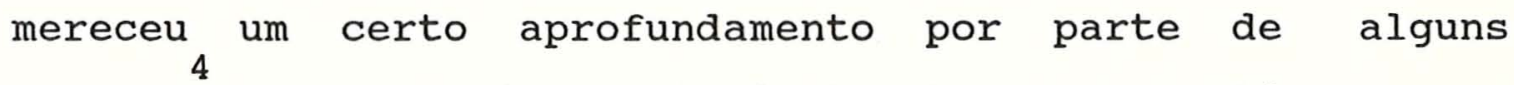
autores, que serviu, principalmente, para explicar o que Sraffa escreveu em poucas paginas. Entretanto, tal aprofundamento gerou, como era de se esperar, certos desenvolvimentos não considerados no curto texto de Sraffa.

o proposito deste cap1tulo resume-se a uma dissertacão sobre a teoria da renda da terra em um sistema econômico sraffiano, considerando os trabalhos subsequentes que tratam do assunto. De intcio, iremos expor o caso da renda extensiva (quando se consideram terras de diferentes qualidades), para depois tratarmos do caso da renda intensiva (quando se assume um unico tipo de terra). Finalmente, consideraremos os desenvolvimentos recentes da teoria sraffiana da renda da terra, principalmente quanto a dois novos tipos de renda: a renda singular e a renda 
intensiva externa. Na medida do possivel, tentaremos ressaltar as diferencas entre o modelo sraffiano e as teorias precedentes, deixando, no entanto, para um cap1tulo conclusivo da dissertação, a apresentação de um resumo que englobe as diferencas principais entre a teoria sraffiana e as que a precederam.

4.2. A renda diferencial extensiva

4.2.1. Hipoteses e definiçoes

Admitiremos, inicialmente, que existam k mercadorias industriais, produzidas, cada qual, por um unico metodo de producão. Cada metodo produz, por sua vez, uma unica mercadoria industrial, não havendo, portanto, producão conjunta. Hd uma só mercadoria agricola (que chamaremos de "cereal"), produzida em "H" diferentes qualidades de terras . Todas as mercadorias são båsicas, salvo certos casos que consideraremos adiante. A producão de todas as mercadorias envolve, obrigatoriamente, a utilizacão de trabalho. O salário e pago "pos-factum" e há apenas "capital circulante" . As quantidades produzidas são suficientes para repor os meios de producão necessarios para que os processos produtivos recomecem. Ha um excedente obtido no final de cada ciclo. Este excedente, o 
produto Ilquido do sistema, pode ser constituldo por uma ou mais mercadorias cuja producão excede os requisitos de insumos dos diferentes processos. O produto l1quido será distribuldo na forma de salário, lucros e, eventualmente, renda da terra.

Desta forma, 9 sistema econômico sraffiano passa a ser representado por :

$(\mathrm{Aa} \cdot \mathrm{pa}+\mathrm{Ba} \cdot \mathrm{pb}+\ldots+\mathrm{Ka} \cdot \mathrm{pk}+\mathrm{Za} \cdot \mathrm{pz}) \cdot(1+r)+\mathrm{La} \cdot \mathrm{W}=\mathrm{A} \cdot \mathrm{pa}$ $(\mathrm{Ab} \cdot \mathrm{pa}+\mathrm{Bb} \cdot \mathrm{pb}+\ldots+\mathrm{Kb} \cdot \mathrm{pk}+\mathrm{Zb} \cdot \mathrm{pz}) \cdot(1+r)+\mathrm{Lb} \cdot \mathrm{W}=\mathrm{B} \cdot \mathrm{pb}$ $(\mathrm{Ak} \cdot \mathrm{pa}+\mathrm{Bk} \cdot \mathrm{pb}+\ldots+\mathrm{Kk} \cdot \mathrm{pk}+\mathrm{Zk} \cdot \mathrm{pz}) \cdot(1+\mathrm{r})+\mathrm{Lk} \cdot \mathrm{W}=\mathrm{K} \cdot \mathrm{pk}$ $[\mathrm{Az}(\mathrm{i}) \cdot \mathrm{pa}+\mathrm{Bz}(\mathrm{i}) \cdot \mathrm{pb}+\ldots+\mathrm{Kz}(\mathrm{i}) \cdot \mathrm{pk}+\mathrm{zz}(\mathrm{i}) \cdot \mathrm{pz}] \cdot(1+\mathrm{r})+$ $\mathrm{Lz}(\mathrm{i}) \cdot \mathrm{w}+\mathrm{T}(\mathrm{i}) \cdot \mathrm{R}(\mathrm{i})=\mathrm{z}(\mathrm{i}) \cdot \mathrm{pz} \quad \mathrm{com} \mathrm{i}=1,2, \ldots . ., \mathrm{H}$.

As primeiras "k" equacões referem-se ao sistema industrial e correspondem ao sistema econômico discutido no cap1tulo anterior. As "H" equacões restantes referem-se ao sistema agricola, onde cada equação representa a tecnica de producão nas diferentes qualidades de terra (aqui ja fica claro que o modelo sraffiano da renda extensiva não requer que, nas diferentes qualidades de terras, sejam aplicados iguais "doses" de capital e trabalho, a fim de explicar a origem dessa renda, como era considerado nas teorias anteriores). A interpretação dos termos das equações e a mesma, restando comentarmos o termo referente ao meio de 
producão terra que, agora, faz parte do sistema econômico. Assim, R(i) representa a renda por unidade de àrea . T(i), por sua vez, representa a área total de terra utilizada com o metodo " $\mathrm{i}$ ", para produzir $\mathrm{z}(\mathrm{i})$ unidades de cereal ${ }^{10}$. Pronto: podemos analisar, então, o surgimento da renda extensiva e suas relações com a variação na distribuicão do excedente. Antes de procedermos a essa andlise discutiremos o processo de crescimento extensivo da producão agricola e os conceitos de ordem de eficiência e ordem de rentabilidade das terras.

4.2.2. A ordem de eficiência das terras e o processo de crescimento extensivo da producão agricola

Podemos observar que no sistema econômico acima, temos $\mathrm{k}+\mathrm{H}+3$ incognitas (os $\mathrm{k}$ preços das mercadorias industriais, as $\mathrm{H}$ taxas de renda das diferentes qualidades de terra, a taxa de lucro, a taxa de salário e o preco do cereal), e apenas $k+H$ equacões. Para obtermos os valores das demais incognitas escolheremos uma mercadoria como numerário, admitiremos, por ora, que a taxa de salário e um dado exógeno e, ainda assim, restará um grau de liberdade. Acrescentaremos, então, uma nova equação que determinard que a terra marginal (refere-se à terra menos eficiente) não pagard renda ${ }^{12}$. Nesse caso, a 
terra marginal não e escassa, sendo considerada redundante. o modelo sraffiano da renda extensiva, como em Ricardo, propõe-se a estudar a renda diferencial. Nesse sentido, haverd sempre uma terra redundante (não totalmente utilizada), para uma dada demanda por cereal ${ }^{13}$.

Qual sera a terra marginal e uma questão que deveremos responder dentro do contexto teorico. Veremos que a resposta dependerd, como não podia deixar de ser (dentro da teoria sraffiana), da previa distribuição do produto llquido entre lucros e salarios. Esse e tambem, um resultado não contemplado pelas teorias antecedentes que consideravam que a terra marginal era determinada, exclusivamente, pela demanda por cereal (dadas as disponibilidades e as produtividades das terras) - Para obtermos a ordem de eficiência das terras, juntaremos uma das equacões de producão do cereal ao conjunto de equacões de produção industrial, repetindo o procedimento para cada um das $\mathrm{H}$ equações. Na equacão de produção do cereal que for escolhida, admitiremos que $R(i)=0$, ou seja, que se trata da terra marginal. A ordem de eficiência das terras corresponderd, então, à ordem de taxas de lucros obtidas nas solucões dos diferentes sistemas ${ }^{14}$. Esta ordem indicard a sucessão hipotetica com que os diferentes tipos de terras serão incorporados ao cultivo, à medida que aumenta a demanda por cereal.

E bom ressaltarmos que estamos trabalhando 
com uma dada tecnologia (descrita pelos coeficientes tecnicos das equacões), que pode ser alterada, conforme o interesse em questão. Desta forma, melhoramentos tecnologicos e de infraestrutura podem ser considerados no modelo, podendo alterar a ordem de eficiência das terras.

Partindo-se do uso da terra mais eficiente, mostraremos que, conforme se passa a cultivar uma terra menos eficiente, surge, imediatamente, uma renda na terra mais eficiente, conforme Ricardo ja mostrara.

Se tomarmos o cereal como numerario, basta constatarmos que todos os precos industriais reduzir-se-ão à medida que terras menos eficientes vão sendo incorporadas. Demonstraremos isso por absurdo ${ }^{15}$. Suponhamos que, após a queda da taxa de lucro (devido à producão de cereal em terra de menor eficiência), os preços industriais permaneceram fixos. Como a taxa de saldrio estâ monetariamente fixada, verifica-se que nenhuma equacão do sistema industrial estard em equilfbrio apos a queda da taxa de lucro. Alguma variacão de preqos serd, então, necessaria. Suponhamos que pa aumente. Para que o equilfbrio da industria "a" volte a ocorrer, \& necessario que o valor dos meios de producão desta industria aumente o suficiente para que, compensada a queda na taxa de lucro, acompanhe o aumento do valor da produç̃o (A.pa). Para isso, e preciso que ao menos um dos meios de producão de "a" tenha seu preco aumentado mais que pa. Digamos que 
isso ocorra para pb (que entra na producão de "a") • Neste caso, novamente, \& preciso que pelo menos um de seus meios de produção (que não pode ser "a") tenha seu preqo aumentado mais que $\mathrm{pb}$. Se prosseguirmos neste raciocinio ate a ultima mercadoria, verificaremos que não e posstvel que seu preqo aumente, ja que todos os outros preqos aumentaram menos que seu preqo. Devemos concluir que a hipotese de aumento de qualquer preqo industrial, apos a queda da taxa de lucro, e absurda. Portanto, como $r$ diminuiu e nenhum outro preqo subiu, e preciso que os precos industriais reduzam-se para manter a igualdade das equações $^{16}$.

Agora, a estes novos precos industriais, e possivel obter uma renda na terra imediatamente mais eficiente (digamos, a terra $\mathrm{T}(1)$ ) que a terra marginal (digamos, a terra $\mathrm{T}(2)$ ). Basta reportarmo-nos à equacão de producão na terra $\mathrm{T}(1)$ :

$[\mathrm{Az}(1) \cdot \mathrm{pa}+\mathrm{Bz}(1) \cdot \mathrm{pb}+\ldots+\mathrm{Kz}(1) \cdot \mathrm{pk}+\mathrm{zz}(1)] \cdot(1+\mathrm{r})+$ $\mathrm{Lz}(1) \cdot \mathrm{W}+\mathrm{T}(1) \cdot \mathrm{R}(1)=\mathrm{Z}(1)$

Como $r$ diminuiu e todos os preqos industriais tambem diminuiram, com w fixo, e necesstrio que $R(1)$ passe a ser maior que zero para manter a igualdade da expressão ${ }^{17}$.

Uma nova incorporacão de terra ainda menos eficiente reduzird, novamente, a taxa de lucro e os precos 
industriais, aumentando a renda nas terras que $j \mathrm{~d}$ pagavam renda, e surgindo renda na terra de eficiência imediatamente superior à nova terra marginal.

Ate aqui tivemos uma mera formalizacão do pensamento ricardiano, em termos matematicos, com o preqo do cereal dado na terra marginal. No entanto, não podemos garantir que a incorporacão da terceira terra menos eficiente mantenha a ordem de rentabilidade das terras (a ordem de magnitudes das rendas por unidade de área). Um resultado que vai contra o pensamento de Ricardo e Marx.

Segundo Ricardo(1982, pp. 66-7), "quando uma terra de terceira qualidade comeca a ser cultivada, imediatamente aparece renda na de segunda, regulando-se, como no caso anterior, pela diferenca entre forcas produtivas de uma e de outra. Ao mesmo tempo, aumenta a renda da terra de primeira qualidade, pois essa deve ser sempre superior à renda da segunda, de acordo com a diferenca entre as produções obtidas numa e outra, com uma dada quantidade de capital e trabalho" (grifos nossos). Tambem Marx não considerava essa posslvel inversão na ordem de rentabilidade das terras, pois definia a renda diferencial I a partir de aplicacões de iguais capitais em terras diferentes (como vimos no capltulo 2 dessa dissertąão) e, portanto, essa questão não se colocava dentro da teoria marxista.

Se admitirmos que nas $\mathrm{H}$ diferentes qualidades 
de terra utilizam-se os mesmos meios de producão (e as mesmas quantidades destes) e a mesma quantidade de trabalho por área cultivada, haveremos de concordar com Ricardo e Marx. No entanto, se admitirmos que isto não ocorre (ou seja, que nas diferentes qualidades de terra os meios de producão e o trabalho empregados são de natureza e quantidades diferentes, o que e muito mais realista), então as conclusões de Ricardo e Marx ja não mais se aplicam. Vejamos, agora, porque isto ocorre.

Admitamos que duas qualidades de terra estão sendo exploradas $(T(1), T(2))$ e que $T(1)$ e mais eficiente que $\mathrm{T}(2)$, para uma dada taxa de saldrio. Admitamos, agora, que a crescente demanda por cereal torne necessario que se cultive uma terceira terra de inferior eficiência em relacão às anteriores. Atè então, t1nhamos $\mathrm{R}(1)>\mathrm{R}(2)=0$. A entrada em cultivo da terceira terra fez cair a taxa de lucro e os precos dos produtos industriais, assim como aumentar as rendas por hectare. Como os meios de produção são de natureza e quantidades diferentes para as diferentes qualidades de terras, \& factlvel que a queda dos precos industriais e da taxa de lucro afete diferentemente o valor dos meios de producão das terras, de forma que a maior parte dos precos dos meios de producão da terra $\mathrm{T}(2)$ caiam mais que os da terra $\mathrm{T}(1)$, - que poderd fazer com que, nesta nova situacão, $R(2)$ torne-se maior que $\mathrm{R}(1)$. Ja havlamos comentado no capltulo 
anterior, sobre esse comportamento imprevislvel dos preqos quando a taxa de lucro varia. Adiante, quando nos referirmos às curvas $w-r$, utilizaremos exemplos numericos para ilustrar essa questão.

Jd que estamos discutindo o processo de crescimento extensivo da produção agricola, cabe tecer alguns comentârios adicionais a respeito do impacto deste processo sobre as variàveis econômicas, a fim de ressaltar - importante papel do meio de producão terra como influenciador das variáveis econômicas, com o crescimento da atividade econômica ${ }^{18}$. As mudanças nas varidaveis distributivas causadas pelo crescimento da atividade econômica serão denominadas de mudanças induzidas, para diferenciarmos das mudanças autônomas, que serão analisadas a seguir.

Se, em primeiro lugar, com o crescimento do ntvel de atividade econômica, for aumentada a area cultivada da terra marginal, os efeitos sobre as varidveis econômicas são simples de prever. As soluções do sistema não se alteram (e como multiplicar a equacão de producão do cereal na terra marginal por um multiplo que seja suficiente para atender o crescimento da demanda). No entanto, salarios e lucros totais aumentam, uma vez que mais terras são usadas, mais trabalhadores são empregados, e maior e o volume de meios de producão utilizados (que, com a mesma taxa de lucro, faz crescer os lucros). No 
entanto, se o crescimento do nivel de atividade econômica requerer a incorporação de uma terra de menor eficiência, as consequências serão mais complexas. Vimos acima, que a taxa de lucro reduzir-se-â, com uma contrapartida no aumento da renda da terra, mantida fixa a taxa de salario. A renda (da terra) total tambem aumentará, evidentemente. Os lucros totais, entretanto, poderão aumentar, diminuir ou não se alterar, dependendo de a queda da taxa de lucro ser ou não compensada (ou mais que) por um aumento no volume dos meios de produção utilizados, fruto do crescimento da produção. Quanto à situação dos trabalhadores, essa dependerá de como serão alterados os preços das mercadorias que constituem a cesta básica de consumo, uma vez que a taxa de salário está fixada monetariamente.

\subsubsection{As mudanças autônomas na distribuição e a renda diferencial extensiva}

Agora consideraremos o problema da renda diferencial extensiva sob uma optica mais abrangente, quando se possibilita que haja uma mudanca na distribuicão do excedente entre lucros e salários. Como determinar-seão as renda por hectare e a terra marginal, quando fornecemos um grau de liberdade ao sistema econômico, permitindo que a distribuição se altere? Precisamos, para isso, obter as diferentes ordens de eficiência para os 
diferentes posslveis valores das variáveis distributivas. Para este fim deveremos considerar as curvas w-r obtidas considerando-se cada terra como se fosse a terra marginal. Passemos, pois, a considerar esta questão.

Assumiremos, inicialmente, para fins de simplicidade, um sistema econômico como o descrito nas equacões abaixo, nas quais e utilizada a simbologia jâ definida anteriormente:

$$
\begin{aligned}
& \mathrm{Aa} \cdot \mathrm{pa} \cdot(1+r)+\mathrm{La} \cdot \mathrm{W}=\mathrm{A} \cdot \mathrm{pa} \\
& \mathrm{Az}(1) \cdot \mathrm{pa} \cdot(1+r)+\mathrm{Lz}(1) \cdot \mathrm{W}+\mathrm{T}(1) \cdot \mathrm{R}(1)=\mathrm{Z}(1) \\
& \mathrm{Az}(2) \cdot \mathrm{pa} \cdot(1+\mathrm{r})+\mathrm{Lz}(2) \cdot \mathrm{w}+\mathrm{T}(2) \cdot \mathrm{R}(2)=\mathrm{Z}(2)
\end{aligned}
$$

Portanto, hà uma so mercadoria industrial (mercadoria "a"), que e a unica mercadoria básica, e o cereal (que e 0 numerario, $\mathrm{pz}=1$ ) e produzido em duas terras de diferentes qualidades. Já vimos que, dada certa taxa de salärio, e posstvel definir uma ordem de eficiência para os tipos de terras conhecidos, que corresponde a ordem hipotetica de incorporação das terras quando a demanda por cereal estâ aumentando.

Agora estudaremos os efeitos causados por uma mudanca na taxa de lucro, na hipotese de que a quantidade de cereal a ser produzida \& uma varidvel independente 20 . A demanda por cereal serd um dado exógeno, que determinard, para cada valor da taxa de lucro, a terra marginal, bem 
como o total de terras que serd utilizado.

Para discutirmos 0 aparecimento da renda diferencial, consideraremos o caso em que a quantidade de cereal a ser produzida e tal que ambas as terras devem ser cultivadas, mas que, em qualquer caso, uma certa superflcie de uma das terras não sera cultivada. ou seja, a demanda por cereal poderd ser atendida sem que toda a terra dispontvel (que se resume às duas qualidades em questão, com quantidades conhecidas e determinadas) seja utilizada. Haverd, de um lado, uma terra escassa (totalmente ocupada) e, de outro lado, uma terra redundante (parcialmente ocupada) $^{21}$.

A terra escassa serd a terra de melhor qualidade e nela serd̂ posslvel obter-se renda. A escassez originar-se-d devido ao fato de a demanda por cereal não poder ser atendida com o cultivo de toda a terra de melhor qualidade.

Como vimos anteriormente, para obtermos a solucão do sistema acima (representada por uma relacão entre a taxa de salario-w e a taxa de lucro-r), deveremos admitir, alternativamente, que $R(i)=0$. ou seja, usaremos, lado a lado com a equação da mercadoria industrial, uma equacão de producão do cereal de cada vez. Observemos que, apesar de o cereal não ser uma mercadoria básica, sua equacão participa da solucão do sistema (afetando o valor das incognitas) porque este foi tomado como numerdrio. 
Para obtermos as expressões literais das relações $w-r$ e $r-R(i)$, deveremos isolar pa da equação de producão industrial e substituir a expressão obtida nas equacões de producão do cereal. Obteremos, assim, duas relações w-r, cuja formulação literal e dada por:

$w(i)=\frac{Z(i) \cdot[A-A a \cdot(1+r)]}{L z(i) \cdot A+(1+r) \cdot[A z(i) \cdot L a-L z(i) \cdot A a]}$

Com $i=1$ ou 2. Para obtermos a relação entre $R(2)$ e $r$, por exemplo, tomamos a relação $w(1)-r$ e substitulmos na equąão de producão do cereal na terra 2. Obteremos, assim fazendo, a seguinte expressão literal:

$R(2)=\frac{\left\{\begin{array}{l}\mathrm{Z}(2) \cdot[\mathrm{Lz}(1) \cdot A+(1+r) \cdot(\mathrm{La} \cdot \mathrm{Az}(1)-\mathrm{Lz}(1) \cdot \mathrm{Aa})]- \\ -\mathrm{Z}(1) \cdot[\mathrm{Lz}(2) \cdot \mathrm{A}+(1+\mathrm{r}) \cdot(\mathrm{La} \cdot \mathrm{Az}(2)-\mathrm{Lz}(2) \cdot \mathrm{Aa})]\end{array}\right\}}{\mathrm{T}(2) \cdot[\mathrm{Lz}(1) \cdot \mathrm{A}+(1+\mathrm{r}) \cdot(\mathrm{La} \cdot \mathrm{Az}(1)-\mathrm{Lz}(1) \cdot \mathrm{Aa})]}$

E fazemos o inverso para obtermos a relação entre $R(1)$ e $r$. Tomemos um exemplo numerico para discutirmos com mais detalhes as questões que levantamos no infcio desta seção. Admitamos que o sistema seja:

$$
\begin{array}{ll}
5 \cdot p a \cdot(1+r)+0,30 \cdot w & =10 \cdot p a \\
1 \cdot p a \cdot(1+r)+0,04 \cdot w+1 \cdot R(1) & =2,1 \\
2 \cdot p a \cdot(1+r)+0,50 \cdot w+1 \cdot R(2) & =6,5
\end{array}
$$


Verifica-se, por exemplo, que o produto llquido desta economia (em termos flsicos) serd de duas unidades da mercadoria industrial (10 unidades produzidas menos 8 unidades usadas como insumos) e 8,6 unidades de cereal (que não e utilizado como meio de produção).

Neste caso, poderemos obter os gráficos apresentados nas Figuras 4.1 e 4.2, a seguir, as quais passaremos a comentar ${ }^{22}$. As relações w-r serão lineares, côncavas ou convexas, conforme a proporção entre as quantidades de trabalho e da mercadoria "a" que entram na producão das duas mercadorias ${ }^{23}$.

A taxa maxima de lucro(r-max) e a mesma para ambas as relações, simplesmente porque hà só uma mercadoria básica. Neste caso, r-max e obtida exclusivamente da primeira equação fazendo-se $\mathrm{w}=0$. No exemplo, $\mathrm{r}-\max =(\mathrm{A}-$ Aa) $/ \mathrm{Aa}=1$.

Jd que estamos assumindo que a demanda por cereal não pode ser atendida com o cultivo de uma unica terra, a maxima taxa de salário desta economia será igual a 10,48 (unidades de cereal, que foi tomado como numerario). Isso porque, uma taxa de salário maior inviabilizard a producão na terra $2^{24}$.

Tomemos, agora, a taxa de lucro como um parâmetro (variàvel exógena, como prefere Sraffa). Neste caso, verificamos que, para $r$ entre 0,0 e 0,7 , na terra 1 e posslvel obter a maior taxa de salário (a produção na terra 


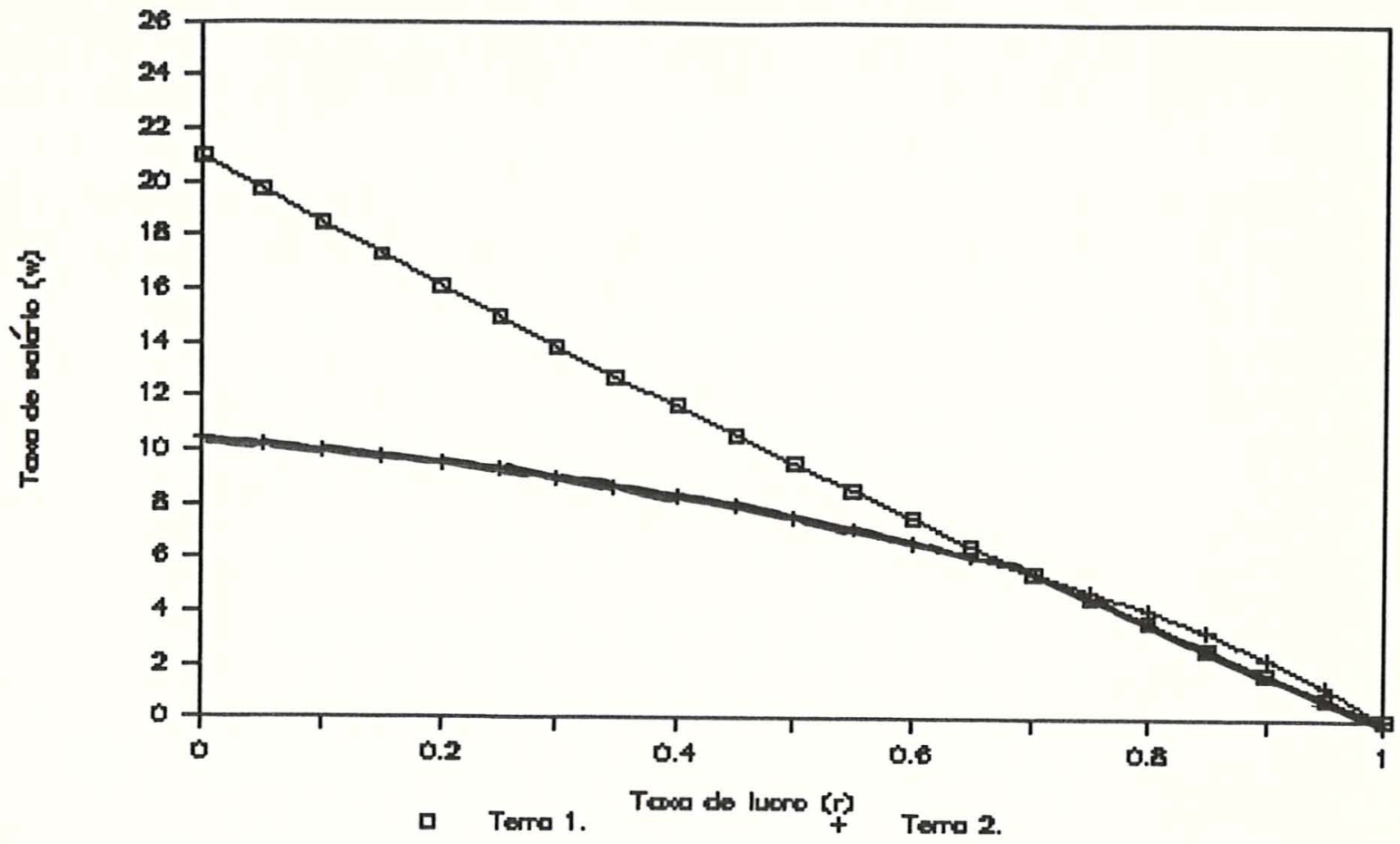

Figura 4.1 - A renda extensiva e as mudanças autônomas na distribuicão - cereal mercadoria não-błsica: curvas w-r.

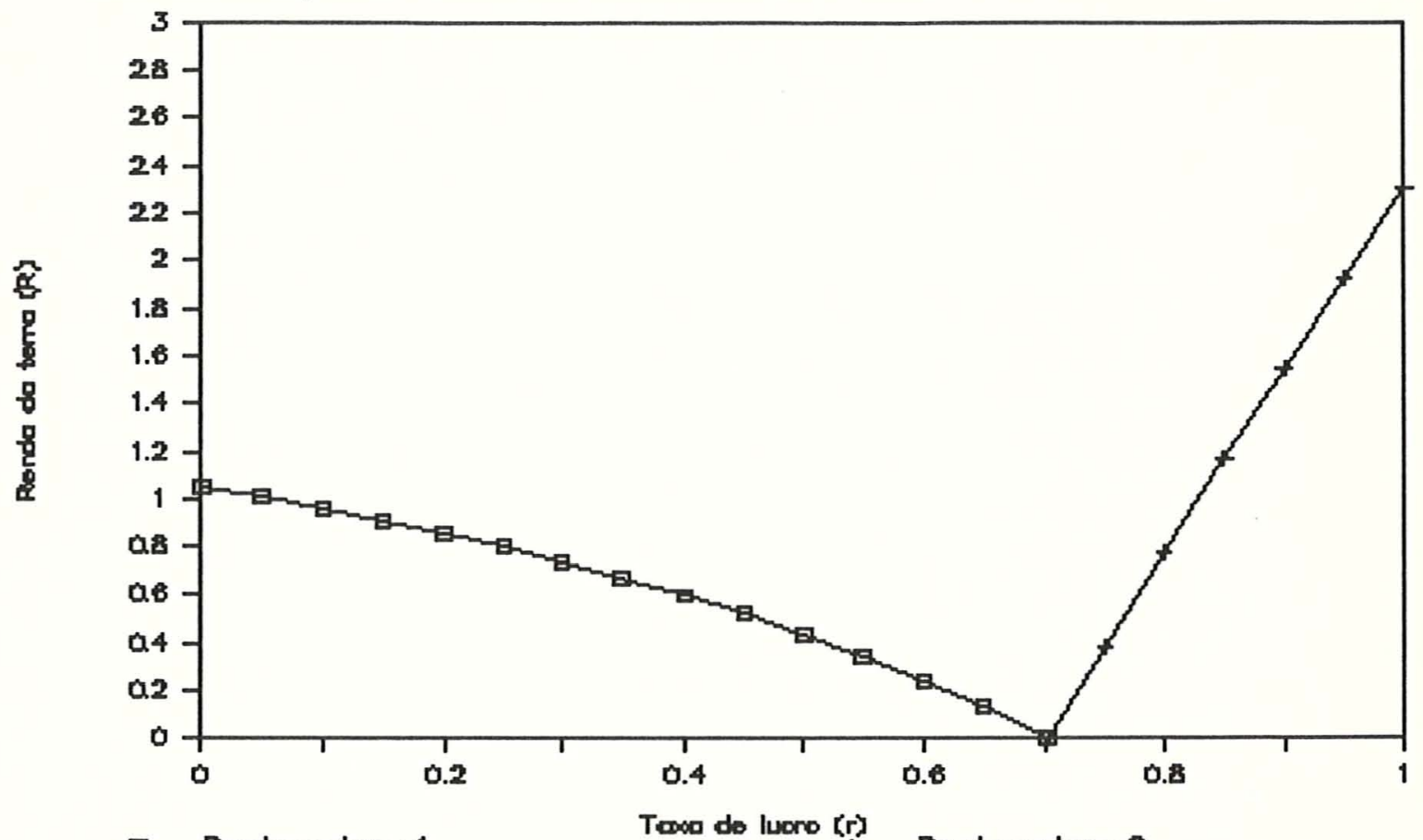

a Ponda na terra 1.

Renda na terro 2.

Figura 4.2 - A renda extensiva e as mudanças autônomas na distribuicão - cereal mercadoria não-bdsica : curvas R-r. 
1 e, neste caso, mais eficiente). Como a taxa de salario deve ser uniforme, devemos concluir que a mesma e dada pela relacão $\mathrm{w}-\mathrm{r}$ da terra 2 , neste intervalo. A maior eficiência da terra 1 fard com que seja necessârio que $R(1)$ seja maior que zero $^{25}$. o que pode ser conferido na Figura 4.2 .

Quando $r$ varia entre 0,7 e $r-\max =1$, ocorre o inverso, como vemos nas Figuras 4.1 e 4.2. Neste caso, a renda surge na terra 2 e a terra 1 serd, agora, a terra marginal $(R(1)=0)$.

Resta considerarmos o caso em que $r=0,7$. Neste ponto, as terras terão igual eficiência e nenhuma delas pagard renda da terra. Serão, portanto, igualmente redundantes.

Portanto, agora deve estar claro que a determinação da terra marginal (e, portanto, da escassez de uma dada qualidade de terra) depende da previa distribuicão do excedente econômico entre lucros e salarios, assim como da demanda por cereal.

Alem disso, fica claro, tambem, que a ordem de eficiência das terras pode alterar-se com a mudança na distribuicão da renda. Ou seja, tal ordem so e definida a partir do momento que fornecemos, exogenamente, a taxa de salario (ou de lucro).

Esta conclusão gerou criticas da teoria sraffiana às considerações de Ricardo quanto a uma ordem de 
"fertilidade" das terras "naturalmente" determinada. Se interpretarmos o termo "fertilidade" como querendo designar eficiência (como parece mais apropriado), haveremos de concluir que aquela ordem não e naturalmente determinada. Como afirma MONTANI(1975, p.77), "it is not possible to measure fertility in physical terms, because it does not depend merely on 'generosity of nature ' " 26 .

\section{A fronteira tecnologica deste sistema, sob} as hipoteses assumidas quanto ao atendimento da demanda por cereal, e dada pela curva em negrito na Figura 4.1 ${ }^{28}$.

4.2.4. A não coincidência das ordens de eficiência

29

e de rentabilidade das terras

E oportuno salientarmos que $\circ$ modelo simplificado utilizado para se chegar às conclusões acima, não invalida a generalização das mesmas para um modelo mais completo. Para isso, basta considerarmos, da mesma forma, o exemplo numerico abaixo, que representa um sistema mais completo e mais proximo da realidade:

$$
\begin{array}{ll}
(4 \cdot p a+1) \cdot(1+r)+0,50 \cdot w & =10 \cdot p a \\
(0,5 \cdot p a+2) \cdot(1+r)+0,15 \cdot w+1 \cdot R(1) & =4,2 \\
(2,5 \cdot p a+0,4) \cdot(1+r)+0,40 \cdot w+1 \cdot R(2) & =5,4
\end{array}
$$


Portanto, o produto llquido desta economia e composto 3 unidades da mercadoria industrial (10 unidades produzidas menos 7 unidades utilizadas como insumo) e 6,2 unidades de cereal $(9,6$ unidades produzidas menos 3,4 unidades usadas como insumos). Tal como procedemos anteriormente, podemos obter duas relaç̃es $w-r$. Essas relaçoes, assim como as relacões entre $R(i)$ e $r$, encontram-se nas Figuras 4.3 e 4.4, na proxima página ${ }^{30}$.

Se supusermos que a demanda por cereal e de tal ordem que pode ser atendida com o cultivo de apenas uma qualidade de terra, sem que esta seja totalmente cultivada, a fronteira tecnologica desta economia e dada pela curva $\mathrm{W}(1)-\mathrm{A}-\mathrm{R}(2)$. Isto porque, com a variação na distribuição da renda, utilizar-se-ão, alternativamente, as terras que proporcionarem o maior valor para a taxa de lucro (de salário) para uma dada taxa de salário (de lucro). No intervalo de variação de $r$ entre 0 e 0,476 a terra 1 e mais eficiente e serd cultivada exclusivamente. Para valores de $r$ entre 0,476 e $R(2)=0,97$ (aprox.) a terra 2 serd a cultivada.

Se, por outro lado, supusermos que a demanda por cereal não possa ser atendida com o cultivo de toda a terra dispontvel de uma dada qualidade, mas será atendida com o cultivo das duas qualidades de terras, haveremos de concluir (segundo o mesmo racioctnio anterior), que a fronteira tecnologica e dada pela parte mais interna das 


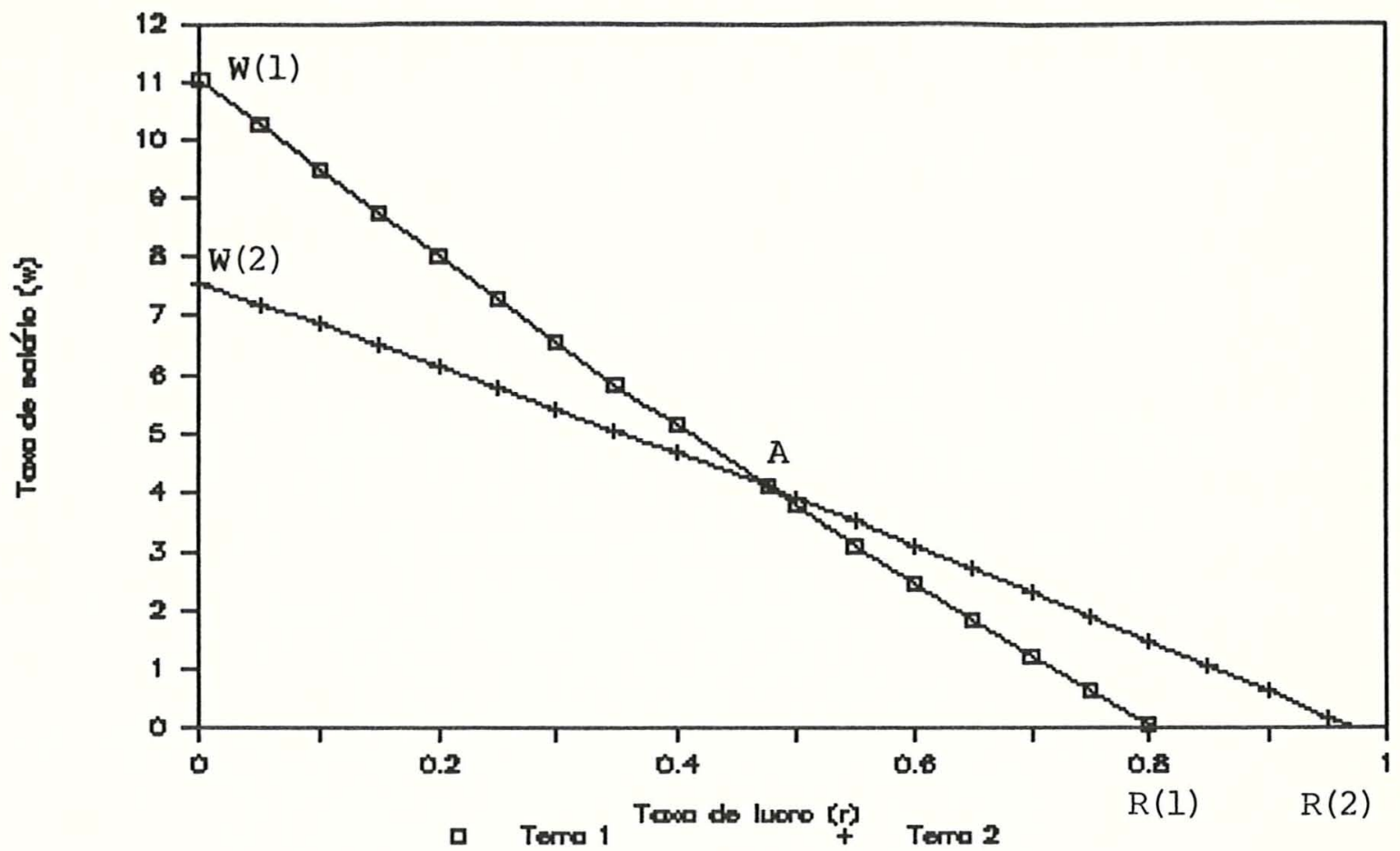

Figura 4.3 - A renda extensiva e as mudanças autônomas na distribuicão - cereal mercadoria basica : as curvas $w-r$.

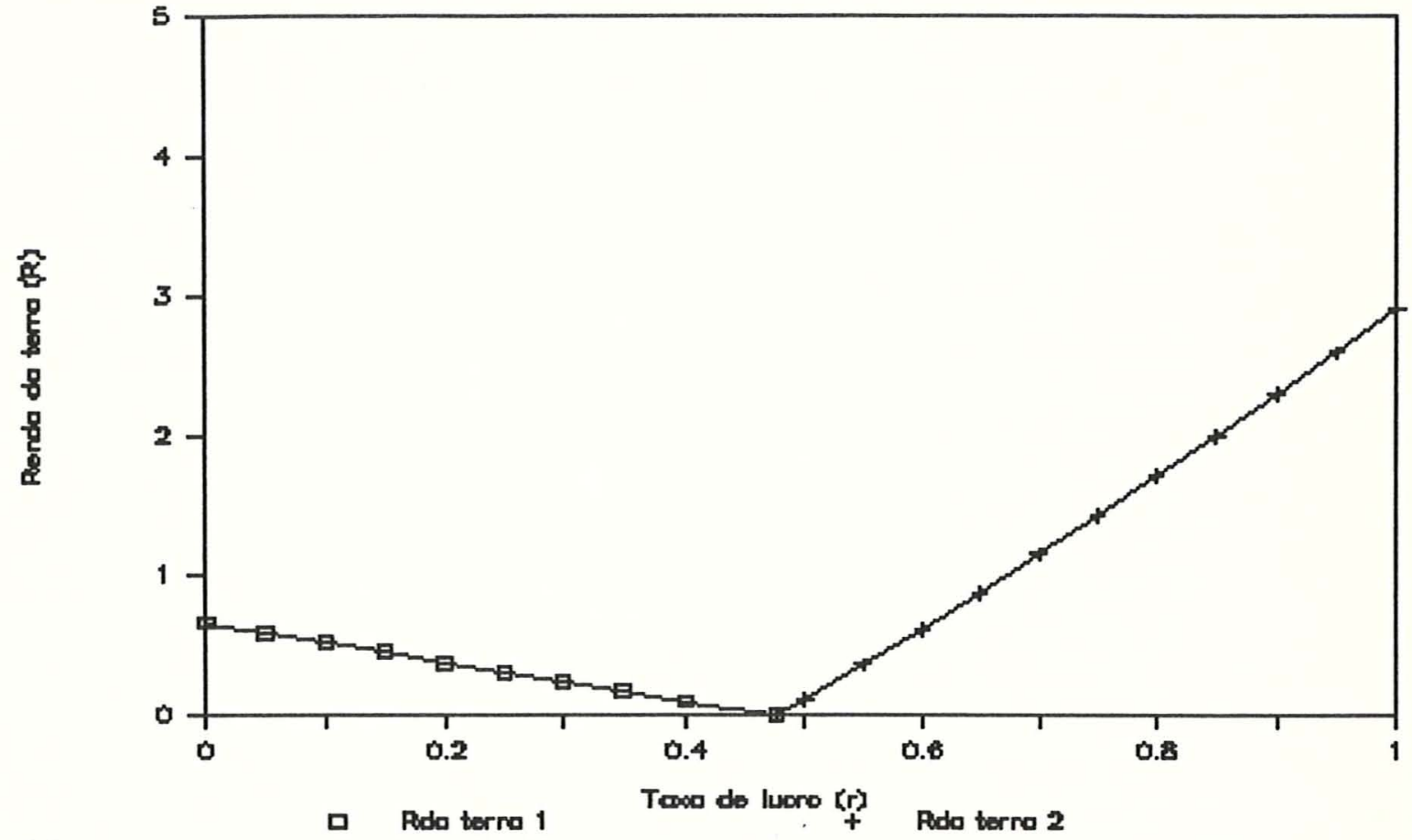

Figura 4.4 - A renda extensiva e as mudanças autônomas na distribuição - cereal mercadoria båsica : curvas $R-r$. 
relaçoes $w-r$, formando a curva $W(2)-A-R(1)$, na Figura 4.3 . A maior taxa de lucro desta economia serd dada por $r=R(1)$ $=0,80$ (aprox.). E a maior taxa de saldrio serd dada por $\mathrm{w}$ $=\mathrm{W}(1)=11,0435$ (em unidades de cereal, tomado como numerdrio).

Pela Figura 4.3, observa-se que, à medida que a taxa de lucro aumenta (a partir de zero), a terra 1 vai reduzindo a sua eficiência relativa e, em contrapartida, a terra 2 tem sua eficiência aumentada. Observando-se essa figura, pode-se concluir que a producão de cereal na terra 1 e mais intensiva em "capital", sendo mais eficiente, portanto, para valores menores da taxa de lucro. Em oposicão, a producão na terra 2 e mais intensiva em trabalho, sendo mais eficiente para valores mais elevados da taxa de lucro (que correspondem a valores mais baixos para a taxa de saldrio).

Se, agora, considerarmos um terceiro tipo de terra (em adicão ao sistema econômico anterior, mantendo as demais equações anteriores), verificaremos que a inclusão dessa terceira terra fard com que a inversão na ordem de eficiência das terras não mais coincida com a inversão da ordem de rentabilidade das mesmas. Assim sendo, não e correto afirmarmos que a ordem de eficiência das terras coincide com a ordem de rentabilidade das mesmas, para os diferentes valores da taxa de lucro.

Acrescentemos, pois, ao sistema anterior, a 
seguinte equação que representa a tecnica de producão do cereal em uma terceira qualidade de terra:

$$
(2 \cdot p a+1,5) \cdot(1+r)+0 \cdot 1 \cdot w+1 \cdot R(3)=3,8
$$

Com essa terceira equação, obteremos, da mesma forma como jd discorremos anteriormente, três relações w-r. Alem disso, tomando-se a relação $w-r$ da terra marginal e substituindo-a nas equacões de producão do cereal nas outras duas terras, obteremos as duas relações $R(i)-r$. As Figuras 4.5 e 4.6, na proxima pagina, referem-se a essas relações do sistema econômico acima descrito.

$$
\text { Observando-se essas figuras, constata-se }
$$

que, enquanto a inversão da ordem de eficiência das terras 1 e 2 ocorre para $r=0,476$ (como antes), a inversão da ordem de rentabilidade das mesmas ocorre para $r=0.115$ (aprox.). Isso ocorre porque, enquanto a eficiência e medida em termos de taxa de saldrio (dada a taxa de lucro), a rentabilidade el medida em termos de renda por área.

Expliquemos com mais detalhes essa questão. Se tomarmos $r=0,2$, por exemplo, a taxa de salário serd dada pela relação $w-r$ da terceira terra (como pode-se observar da Figura 4.5) e serd́ igual a 4,3721 unidades de cereal. A essa taxa de lucro a producão na terra 1 pode pagar uma taxa de salário de 8,00 unidades de cereal (com renda igual a zero), e a produção na terra 2 pode pagar uma taxa de salário de 6,1408. Portanto, a terra 1 e mais 


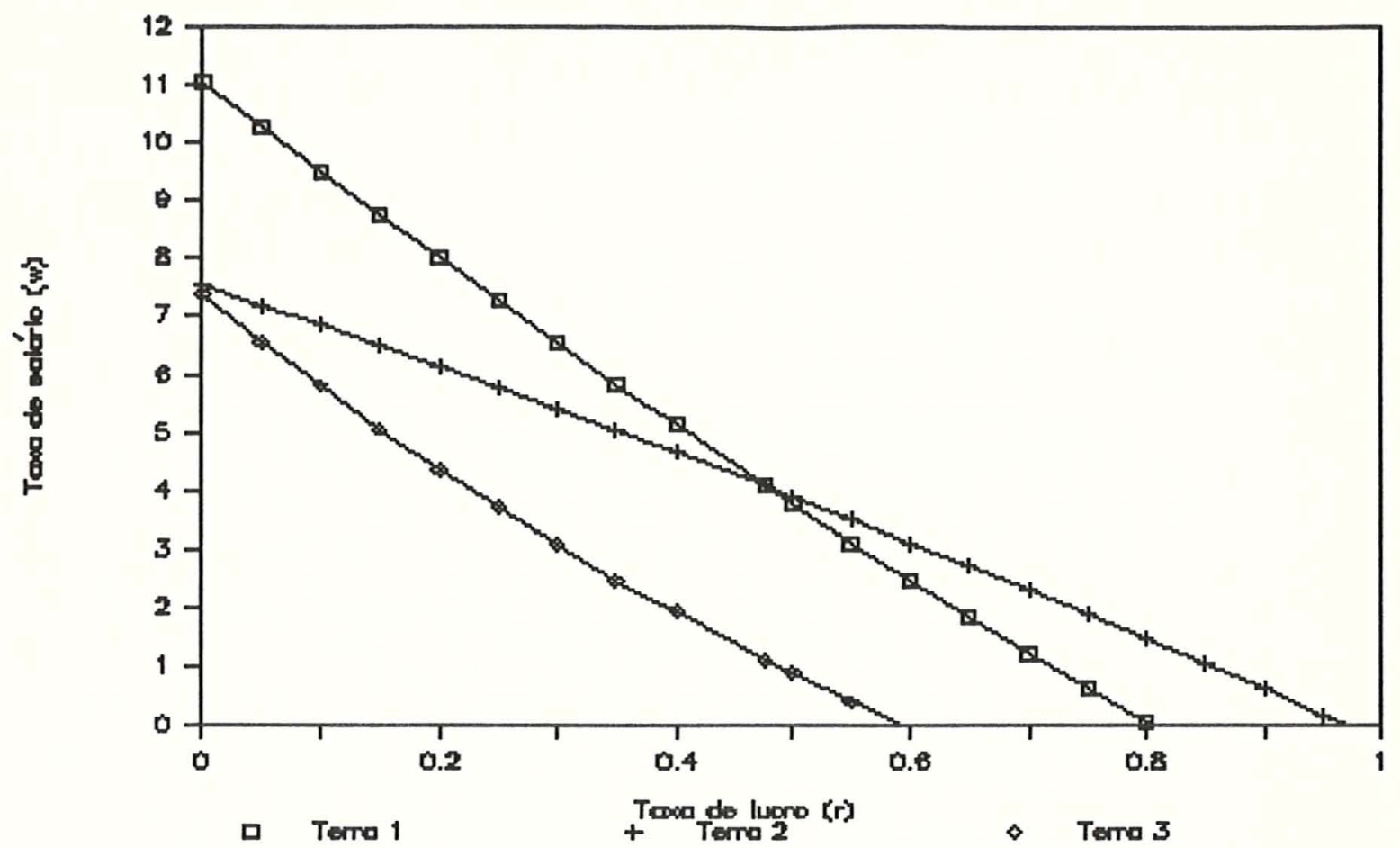

Figura 4.5 - A não coincidência das ordens de eficiência e de rentabilidade das terras : curvas $w-r$.

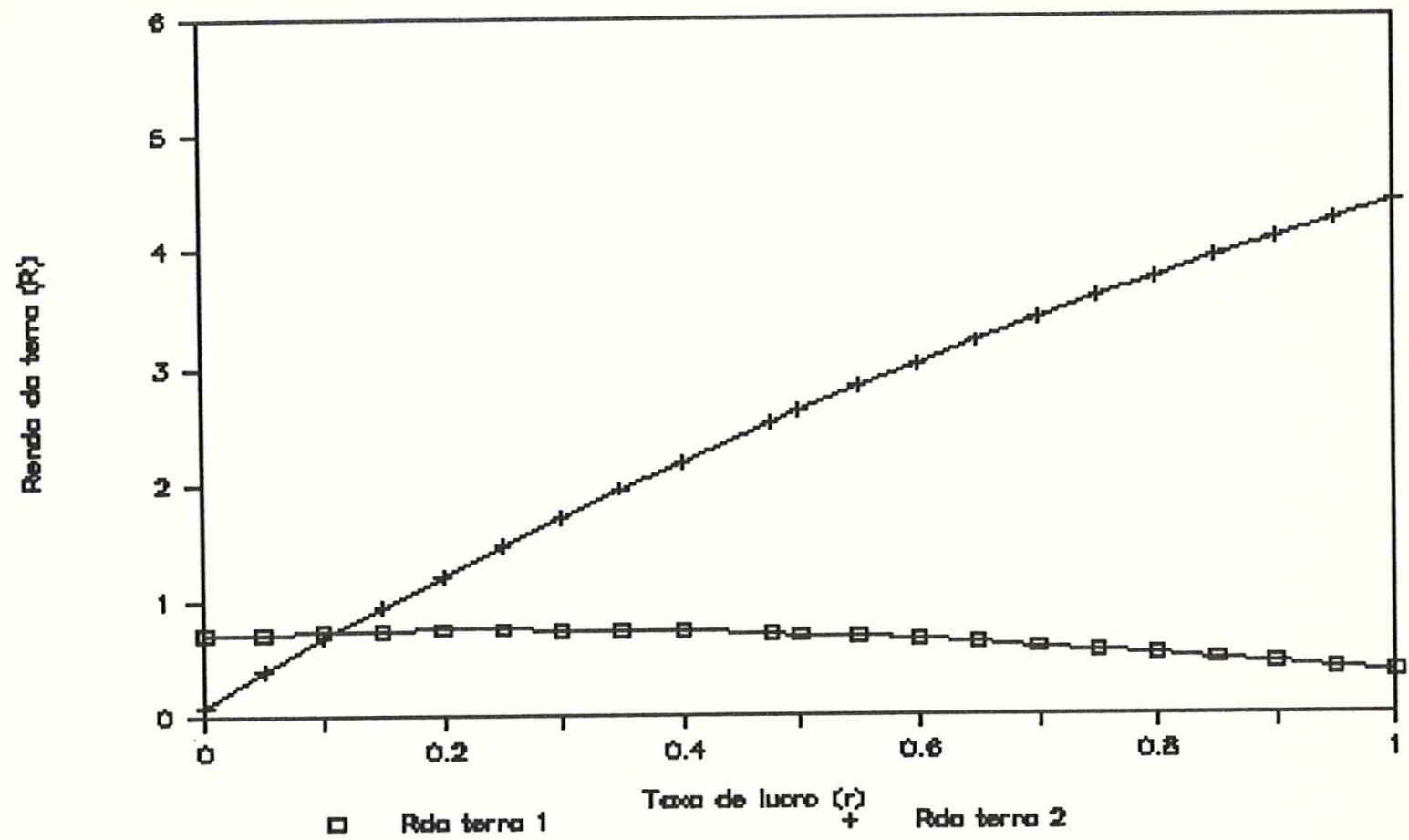

Figura 4.6 - A não coincidência das ordens de eficiência e de rentabilidade das terras : curvas $\mathrm{R}-\mathrm{r}$. 
eficiente que a terra 2. Agora, o resultado econômico da producão do cereal nas terras 1 e 2 que excede a 4,3721 (a taxa de salário da economia para $r=0,2)$ sera para o pagamento da renda da terra. No entanto, esse excedente serd maior na terra 2 pois essa emprega um maior volume de trabalho $(0,40$ unidades $)$ que a terra $1(0,15$ unidades). E por essa razão que as ordens de rentabilidade e eficiência das terras não coincide, necessariamente (ha, ainda, um efeito indireto atraves de pa). Entretanto, observando-se as Figuras 4.5 e 4.6, verifica-se que para $r$ menor que 0,11 (aprox.) as ordens de eficiência e rentabilidade das terras coincidem. Isso porque a maior eficiência da producão na terra 1 em relação à terra 2 passa a ser de tal magnitude que supera $\circ$ fato de a producão na terra 1 usar menos trabalho.

Podemos usar esse exemplo para ilustrar a andlise do processo de crescimento extensivo da producão agricola, discutida na seção 2.4.2, acima. Assim, se tomarmos a taxa de salário como um dado (como antes analisávamos) e admitirmos que $\mathrm{w}=5,00$ (unidades de cereal, que e o numerdrio), poderemos verificar que a terra 1 serd mais eficiente que a terra 2 (observando-se a Figura 4.5). Portanto, se a demanda por cereal for pequena o suficiente para ser atendida pelo cultivo parcial de uma unica terra, a terra 1 serd cultivada, sem o pagamento de uma renda e a taxa de lucro serd igual a 0,41 (aprox.). 0 
aumento da demanda pelo cereal fard com que a terra 2 seja incorporada ao cultivo. Nesse caso, haverd a possibilidade do pagamento de renda na terra 1 (veja Figura 4.3) e a taxa de lucro situar-se-d em torno de 0,35. Finalmente, um novo aumento na demanda pelo cereal fard com que a terra 3 seja cultivada, reduzindo a taxa de lucro para 0,15 (aprox.). No entanto, como pode-se observar na Figura 4.6 , \& a terra 2 que pagard uma maior renda da terra. Contrariando o pensamento de Ricardo e Marx, como ja havlamos comentado.

Ademais, como o cereal e o numerdrio e a taxa de saldrio esta fixada monetariamente (portanto, em termos de unidades de cereal), e recordando que o modelo de Ricardo considerava a taxa de salário como rlgida em termos de cereal, teremos a formalização matematica do modelo ricardiano, embora nem todas as conclusões de Ricardo se confirmem. Ainda sobre isso, observando-se as Figuras 4.4 e 4.6 verifica-se que as rendas das duas terras aumentaram com a introducão de uma terceira terra menos eficiente, em concordância, agora sim, com o pensamento ricardiano.

\subsubsection{Um ultimo exemplo ilustrativo}

Desejamos concluir a apresentação da renda extensiva do sistema econômico sraffiano considerando um ultimo exemplo ilustrativo construldo a partir de um sistema econômico que contemple duas mercadorias 
industriais e duas qualidades de terras. Aproveitaremos esse exemplo para tecermos alguns comentarios sobre a especificidade dos exemplos numericos discutidos, bem como para apresentarmos o fenômeno de "reswitching of technique", tambem presente na CONTROVERSIA DE CAMBRIDGE.

Consideremos, pois, o seguinte sistema econômico, jầ na forma de exemplo numerico:

$$
\begin{array}{ll}
(0,5 \cdot \mathrm{pa}+1) \cdot(1+\mathrm{r})+1 \cdot \mathrm{w} & =1,1 \cdot \mathrm{pa} \\
(0,05 \cdot \mathrm{pb}+1) \cdot(1+\mathrm{r})+10 \cdot \mathrm{w} & =1,1 \cdot \mathrm{pb} \\
(0,1 \cdot \mathrm{pa}+0,2) \cdot(1+\mathrm{r})+10 \cdot \mathrm{w}+1 \cdot \mathrm{R}(1) & =2,2 \\
(1 \cdot \mathrm{pb}+0,2) \cdot(1+\mathrm{r})+0,4 \cdot \mathrm{w}+1 \cdot \mathrm{R}(2) & =4
\end{array}
$$

Portanto, o produto l1quido da economia e constituldo por 0,5 unidades da mercadoria industrial "a", 0,05 unidades da mercadoria industrial "b" e 3,8 unidades do cereal.

Desse sistema, poderemos obter duas relações w-r referentes aos casos em que $R(i)=0$ para $i=1$ ou 2 , atraves de subsitituicões das expressões de pa e pb obtidas das duas primeiras equações, nas equações de produção do cereal. Para obtermos as relacões entre $R(1)$ e $r$, por exemplo, deveremos substituir no w da equação de produção do cereal na terra 1 a relação $w-r$ da terra 2 , admitindo que $R(2)=0$ (trata-se da terra marginal) e $R(1)$ e diferente de zero (e claro que esse procedimento so e válido para a faixa de variacão de $r$ em que a terra 2 e a 
terra marginal).

As Figuras 4.7 e 4.8 , a seguir, ilustram essas relações para o exemplo numerico acima discutido. Passemos, pois, a comentar essas figuras.

Observe-se, primeiramente, que ha, agora, duas interseções das relą̧ões $w-r$ das duas terras. Esse fenômeno, denominado de "reswichtinhg of technique", foi um dos aspectos discutidos na CONTROVERSIA DE CAMBRIDGE, uma vez que contrariava a teoria neoclássica do capital. Mas isso pouco nos interessa no momento.

E mais interessante observarmos que essa dupla interseç̧ão das relą̧ões $\mathrm{w}-\mathrm{r}$ corresponde a um sistema econômico um tanto peculiar. Se verificarmos os coeficientes das equacões do sistema que baseia essas figuras, observaremos que a producão na terra 1 so utiliza - insumo industrial "a" e a producão da terra 2 so utiliza o insumo industrial "b". Mais que isso; embora a producão do cereal na terra 1 utilize uma tecnologia trabalhointensiva, usa um meio de producão produzido com uma tecnologia capital-intensiva. E o inverso ocorre para a producão do cereal na terra 2. Portanto, trata-se de um caso muito particular.

E quanto aos exemplos anteriores? Apesar de se tratarem de exemplos artificialmente construldos, pretendem explicar o surgimento da renda diferencial extensiva dentro das premissas do sistema econômico 


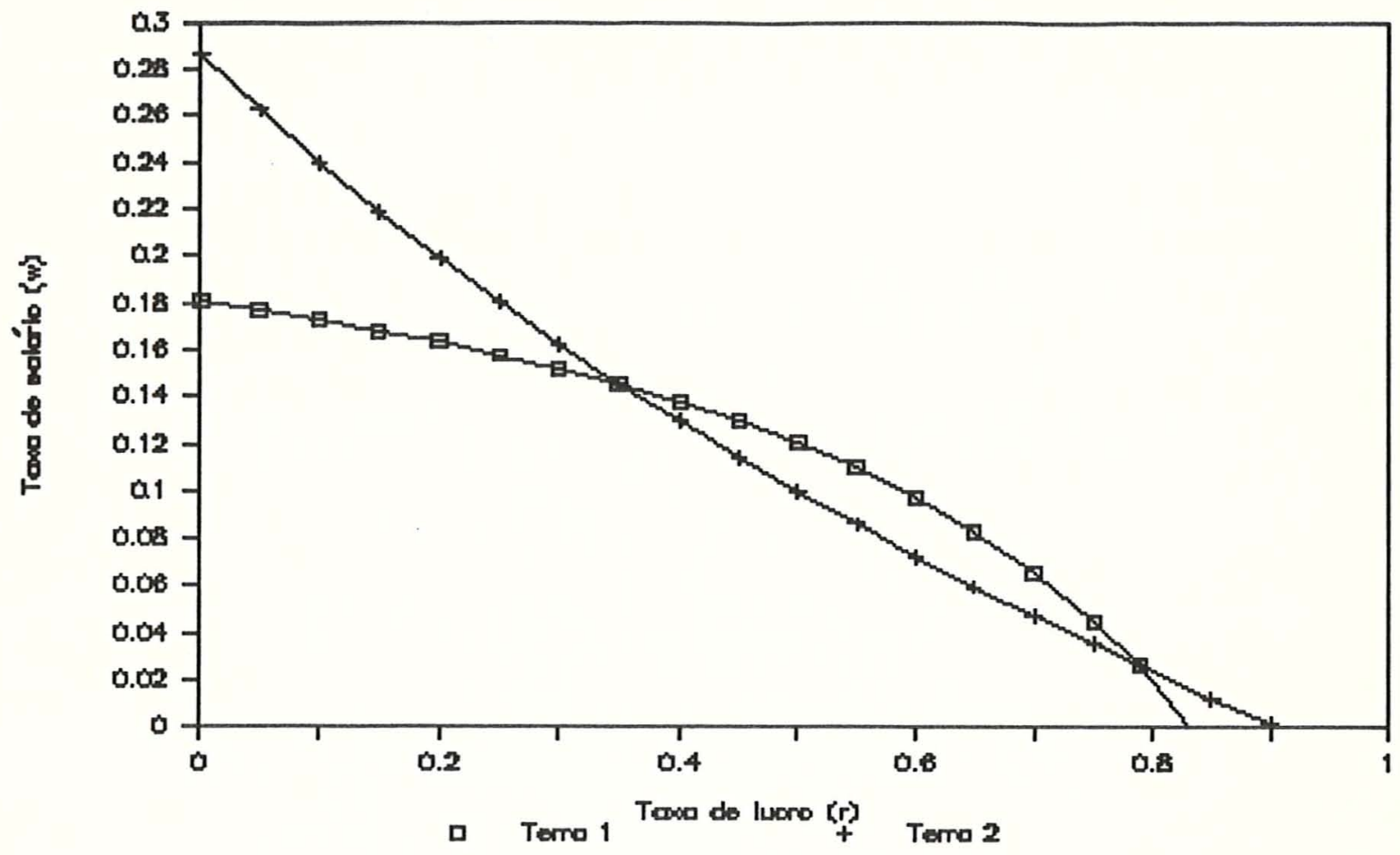

Figura 4.7 - O fenômeno de "reswichting of technique" : curvas $w-r$.

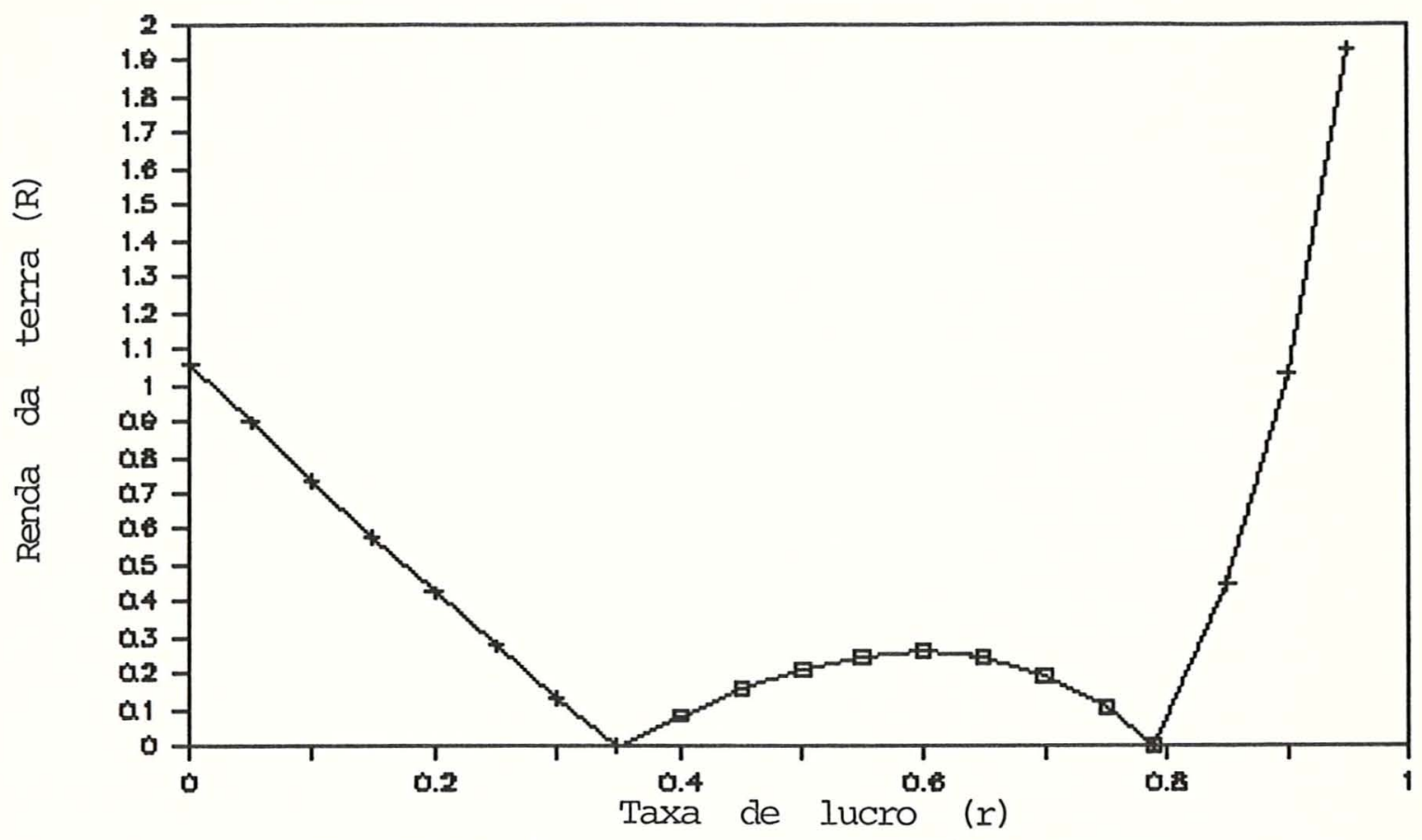

口 Rda terra $1+$ Rda terra 2

Figura 4.8 - O fenômeno de "reswichting of technique" : curvas $\mathrm{R}-\mathrm{r}$. 
sraffiano. ou seja, se na pratica ha uma terra gerando um resultado econômico maior que outra terra, a teoria sraffiana se presta para explicar tal fenômeno. Inclusive advertindo que uma mudanca na distribuicão de renda pode alterar a maior eficiência daquela terra. Assim, os demais exemplos numericos apresentados pretendem modular na teoria - que está ocorrendo na pratica. E claro, por fim, que resta operacionalizar a teoria sraffiana a fim de se buscar constatação emp1rica de suas assertivas.

Devemos, finalmente, explicar a Figura 4.8, uma vez que ela se origina de uma hipotese quanto ao atendimento da demanda. Assim, se supusermos que a demanda pelo cereal so possa ser atendida pelo cultivo de duas das qualidades de terras (uma sendo totalmente cultivada e a outra sendo parcialmente cultivada), obteremos a Figura 4.8 em correspondência com a Figura 4.7. Ou seja, para $r$ menor que 0,35 a terra 1 serd a terra marginal e pagar-se-d renda na terra 2. O inverso ocorrerd para valores de $r$ entre 0,35 e 0,8. Finalmente, para $r$ maior que 0,8 repete-se a situação inicial.

Se, por outro lado, a demanda puder ser atendida com o cultivo parcial da terra 2 (por ter maior produtividade) mas não puder ser atendida se apenas a terra 1 for cultivada, então a fronteira tecnologica dessa economia serł dada pela relação $\mathrm{w}-\mathrm{r}$ da terra 2 , para todos os valores posstveis de $r$, e apenas existird a curva $R(1)-r$ 
na Figura 4.8. Isso porque, quando a terra 2 e mais eficiente esta deverd ser cultivada exclusivamente, e não haverd renda da terra. A renda da terra aparecerd apenas quando o cultivo for mais eficiente na terra 1 . Como a demanda não poderầ ser atendida, a terra 2 deverâ ser cultivada parcialmente e serd posslvel pagar renda na terra 1.

4.3. A renda intensiva

\subsubsection{Introducão}

Passemos, agora, a considerar a renda da terra em um modelo onde hâ só uma qualidade de terra. Neste caso, como veremos a seguir, o aparecimento da renda da terra deve-se à coexistência de dois metodos de cultivo do cereal sobre a mesma qualidade de terra, cultivando-se toda a drea dispontvel. Como afirma SRAFFA(1983, p.238), "enquanto o caso de terras de qualidades diferentes serd facilmente reconhecido como o resultado de um processo de rendimentos decrescentes 'extensivos', pode ser menos óbvio que exista uma conexão similar entre o emprego de dois metodos de produzir cereal na terra de uma so qualidade e um processo de rendimentos decrescentes 'intensivos' ".

A renda intensiva relaciona-se, por um lado, com o que Marx chamou de Renda Diferencial II; uma renda 
vinculada à aplicacão de diferentes "doses de capital e trabalho" sobre a mesma qualidade de terra. David Ricardo tambem ja se referiu a essa variedade de renda, embora privilegiasse, no seu tratamento, a renda de carater extensivo $^{31}$. Entretanto, tanto em Ricardo quanto em Marx, a renda oriunda da aplicação de diferentes "doses de capital e trabalho" não correspondia a uma posição de equilıbrio (o que fica mais explicito na teoria marxista), como ja comentamos anteriormente.

De outra parte, como veremos a seguir, a renda intensiva do sistema sraffiano ocorre em situação de equilibrio. Alem disso, apesar de a renda intensiva sraffiana referir-se a um modelo de terra de uma so qualidade (onde se aplicam diferentes "doses de capital e trabalho"), trata-se, na verdade, de uma renda de monopolio, uma vez que surge quando ocorre a escassez da terra.

Finalmente, acreditamos que no modelo sraffiano fica mais expllcito o fato de que esses metodos (que aqui representam as diferentes doses de "capital" e trabalho) ocorrem em áreas diferentes da mesma qualidade de terra, o que não parece expl1cito nos modelos ricardiano e marxista, que parecem tratar de acrescimos dessas "doses" sobre o mesmo "talhão" de terra, donde não se pode explicar o surgimento da renda, em uma situação de equillbrio . 
Feitos estes comentårios iniciais, passemos, de imediato, ao modelo sraffiano da renda intensiva.

\subsubsection{Hipoteses e definicões}

De intcio, passaremos a considerar o modelo definido pelas equações abaixo:

$$
\begin{aligned}
& (\mathrm{Aa}+\mathrm{Ba} \cdot \mathrm{pb}+\ldots+\mathrm{Ka} \cdot \mathrm{pk}) \cdot(1+\mathrm{r})+\mathrm{La} \cdot \mathrm{W}=\mathrm{A} \\
& (\mathrm{Ab}+\mathrm{Bb} \cdot \mathrm{pb}+\ldots+\mathrm{Kb} \cdot \mathrm{pk}) \cdot(1+\mathrm{r})+\mathrm{Lb} \cdot \mathrm{W}=\mathrm{B} \cdot \mathrm{pb} \\
& (\mathrm{Ak}+\mathrm{Bk} \cdot \mathrm{pb}+\ldots+\mathrm{Kk} \cdot \mathrm{pk}) \cdot(1+\mathrm{r})+\mathrm{Lk} \cdot \mathrm{W}=\mathrm{K} \cdot \mathrm{pk} \\
& {[\mathrm{Az}(\mathrm{i})+\mathrm{Bz}(\mathrm{i}) \cdot \mathrm{pb}+\ldots+\mathrm{Kz}(\mathrm{i}) \cdot \mathrm{pk}] \cdot(1+r)+\mathrm{Lz}(\mathrm{i}) \cdot \mathrm{w}+} \\
& \mathrm{T}(\mathrm{i}) \cdot \mathrm{R}=\mathrm{z}(\mathrm{i}) \cdot \mathrm{pz} \quad \mathrm{com} i=1,2, \ldots, \mathrm{H} \text {. }
\end{aligned}
$$

Relembremos que $\mathrm{Kz}(\mathrm{i})$, por exemplo, corresponde à quantidade da mercadoria "k" que entra como meio de producão do cereal para produzir Z(i) unidades do mesmo, pelo metodo "i". Neste caso, o 1ndice "i" não mais se refere a diferentes qualidades de terras, mas a diferentes metodos de producão de cereal sobre a mesma qualidade de terra. Como se observa nas equações acima, não temos mais $R(i)$, mas sim $R$ apenas, que es a renda da terra (que obviamente serd a mesma em qualquer metodo, pois trata-se de uma unica qualidade de terra). Por enquanto, o cereal serd considerado uma mercadoria não-básica. o numerârio 
serd representado pela mercadoria "a" (portanto, pa = 1). $\mathrm{T}$ (i) corresponderd, agora, a areas da terra usadas com o metodo "i". Como antes, as $k$ primeiras equacões representam o setor industrial e as $\mathrm{H}$ Ultimas, representam - setor agricola, com diferentes metodos de cultivo para a mesma qualidade de terra.

\section{3}

4.3.3) A solucão do sistema de prę̧os

Tomando-se a taxa de saldrio como um dado exógeno, se dois metodos estiverem sendo operados, lado a lado, no cultivo do cereal sobre a mesma qualidade de terra, o sistema de precos acima estard determinado (não restando qualquer grau de liberdade). Isto porque, teremos $\mathrm{k}+2$ equações para solucionar as $\mathrm{k}+2$ incognitas do sistema (os k - 1 preços industriais, o preco do cereal, a taxa de lucro e a renda da terra) ${ }^{34}$.

Neste caso, deveremos supor que a terra e escassa (de forma que a renda obtida passa a ter uma natureza de renda de monopolio); caso contrario, haverd sempre um capitalista disposto a aplicar seu capital na parte não cultivada da terra, obtendo a taxa de lucro apenas, e oferecendo o cereal a um preco menor. No entanto, como afirma SRAFFA(1983, p. 239), "enquanto a escassez de terra proporciona assim o 'background' do qual surge a renda, a unica evidência dessa escassez que se 
encontra no processo de producão e a dualidade de metodos: se não houvesse escassez, apenas se utilizaria um metodo, o mais barato, sobre a terra, e não poderia existir renda". Na verdade, uma vez que, no sistema econômico que ora discutimos, o cereal não e uma mercadoria båsica, as $\mathrm{k}$ primeiras equacões (do sistema industrial) determinam os k - 1 preços industriais e a taxa de lucro. Os valores dessas incognitas são, então, inseridos nas equações de producão do cereal, obtendo-se o valor das ultimas duas incognitas: a renda da terra e o preço do cereal.

Para que, no entanto, não obtenhamos valores negativos para a renda da terra, devemos obedecer a restricão de que o metodo com maior producão por unidade de area (maior $\mathrm{Z}(\mathrm{i}) / \mathrm{T}(\mathrm{i})$ ) apresente o maior custo por unidade de produto, calculado a partir dos valores correntes dos precos e taxas de salario e de lucro. Vejamos isto mais de perto. O custo total de producão do metodo "i" e:

$C(i)=[A z(i)+B z(i) \cdot p b+\ldots+K z(i) \cdot p k] \cdot(1+r)+L z(i) \cdot w$

Neste caso, as duas equacões de produção do cereal seriam:

$$
\begin{aligned}
& \mathrm{Z}(1) \cdot \mathrm{pz}-\mathrm{T}(1) \cdot \mathrm{R}=\mathrm{C}(1) \\
& \mathrm{Z}(2) \cdot \mathrm{pz}-\mathrm{T}(2) \cdot \mathrm{R}=\mathrm{C}(2)
\end{aligned}
$$

Como o cereal e uma mercadoria não-básica, C(1) e C(2) são 
conhecidos e, portanto, apenas $\mathrm{R}$ e pz são incógnitas. Agora, a solução deste sistema requer que :

$$
\left|\begin{array}{ll}
\mathrm{Z}(1) & -\mathrm{T}(1) \\
\mathrm{Z}(2) & -\mathrm{T}(2)
\end{array}\right| \neq 0 \text {. }
$$

o que implica que $\mathrm{Z}(2) \cdot \mathrm{T}(1)-\mathrm{Z}(1) \cdot \mathrm{T}(2) \neq 0 ;$ ou seja, $\mathrm{Z}(2) / \mathrm{T}(2) \neq \mathrm{Z}(1) / \mathrm{T}(1)$ (as producões por unidade de ârea dos dois metodos devem diferir, para termos solucões). Das equacões acima, podemos ver que:

$$
R=p z \cdot[z(i) / T(i)]-C(i) / T(i)
$$

Agora, solucionando o sistema (1),(2), teremos:

$$
R=[Z(2) \cdot C(1)-Z(1) \cdot C(2)] /[Z(1) \cdot T(2)-Z(2) \cdot T(1)]
$$

Como, por hipotese, $\mathrm{Z}(2) / \mathrm{T}(2) \neq \mathrm{Z}(1) / \mathrm{T}(1)$, suponhamos que $\mathrm{Z}(2) / \mathrm{T}(2)>\mathrm{Z}(1) / \mathrm{T}(1)$. Neste caso, o denominador da expressão (4) serd negativo. Então, para $\mathrm{R}>0$ deveremos ter o numerador tambem negativo, o que implicard em $Z(1) \cdot C(2)>Z(2) \cdot C(1)$ e, portanto, $C(2) / Z(2)>C(1) / Z(1)$, como querlamos demonstrar. Recapitulando: o metodo com maior producão por unidade de area (o metodo 2, no caso) deverd ter o maior custo medio (custo total por unidade do produto) para que a taxa de renda seja positiva. A Figura 
4.9 , a seguir, ilustra o fato $^{35}$.

Pela equacão (3), podemos verificar que a renda e uma função linear do prę̧o do cereal. A inclinação da reta ${ }^{36}$ corresponde à producão por unidade de área em cada metodo, enquanto que, para $\mathrm{R}=0$, terlamos $\mathrm{pz}=$ C(i)/Z(i), o custo medio de producão em cada metodo (corresponde à interseção das retas com o eixo das abscissas) •

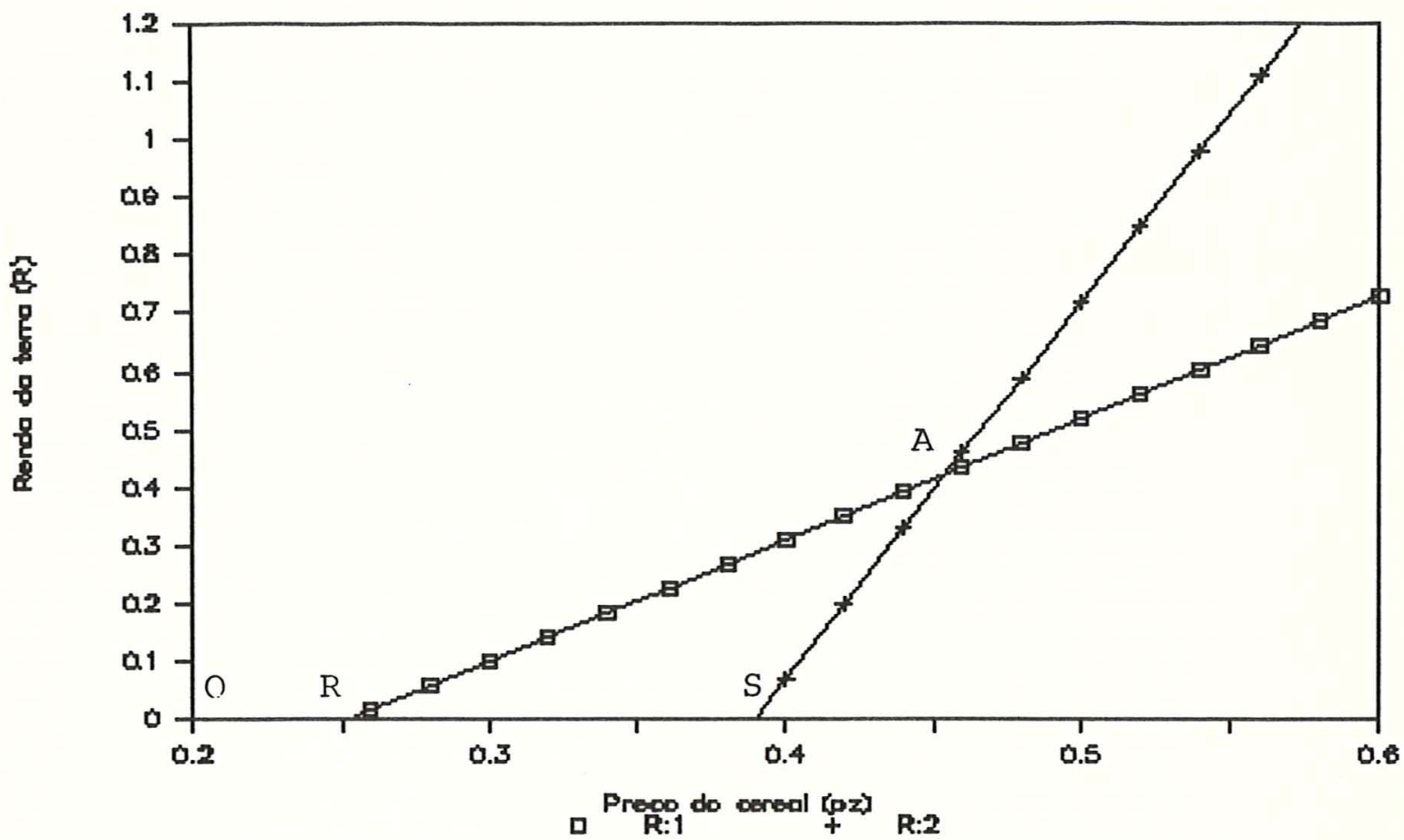

Figura 4.9 - A coexistência de dois metodos gerando renda positiva.

Observando, então, a Figura 4.9, vemos que quando o metodo com maior produção por unidade de área 
(reta mais inclinada) for tambem o de maior custo medio (OS>OR), ambos os metodos podem coexistir, lado a lado, gerando uma mesma renda (positiva), como mostra a interseção das duas retas no ponto A. E importante ressaltar, entretanto, que a posição dessas retas pode alterar-se para valores diferentes para a taxa de lucro (ou de salărio, conforme a variável escolhida como exógena). ou seja, a Fig. 4.9 e vallida para uma dada taxa de lucro. Voltaremos a comentar este importante aspecto quando nos referirmos às mudanças autônomas na distribuição.

4.3.4. O crescimento intensivo da producão agrlcola

Voltemos, agora, a analisar o processo de aumento da producão agricola devido à crescente demanda por cereal. Manteremos a pressuposicão (meramente didatica, a fim de introduzir $\circ$ assunto) de que $\circ$ cereal e uma mercadoria não-básica.

Suponhamos que existam três metodos de cultivo do cereal e que o metodo com maior producão por unidade de área é tambèm o que produz o cereal ao maior custo medio. Este custo, evidentemente, e obtido para uma dada taxa de salario (ou de lucro) monetariamente fixa, tomando-se a solucão do sistema de precos industriais. A Figura 4.10, abaixo, ilustra o que pretendemos discutir. Essa figura e obtida a partir do sistema 
econômico abaixo, para $r=0.5$ e pa $=1$.

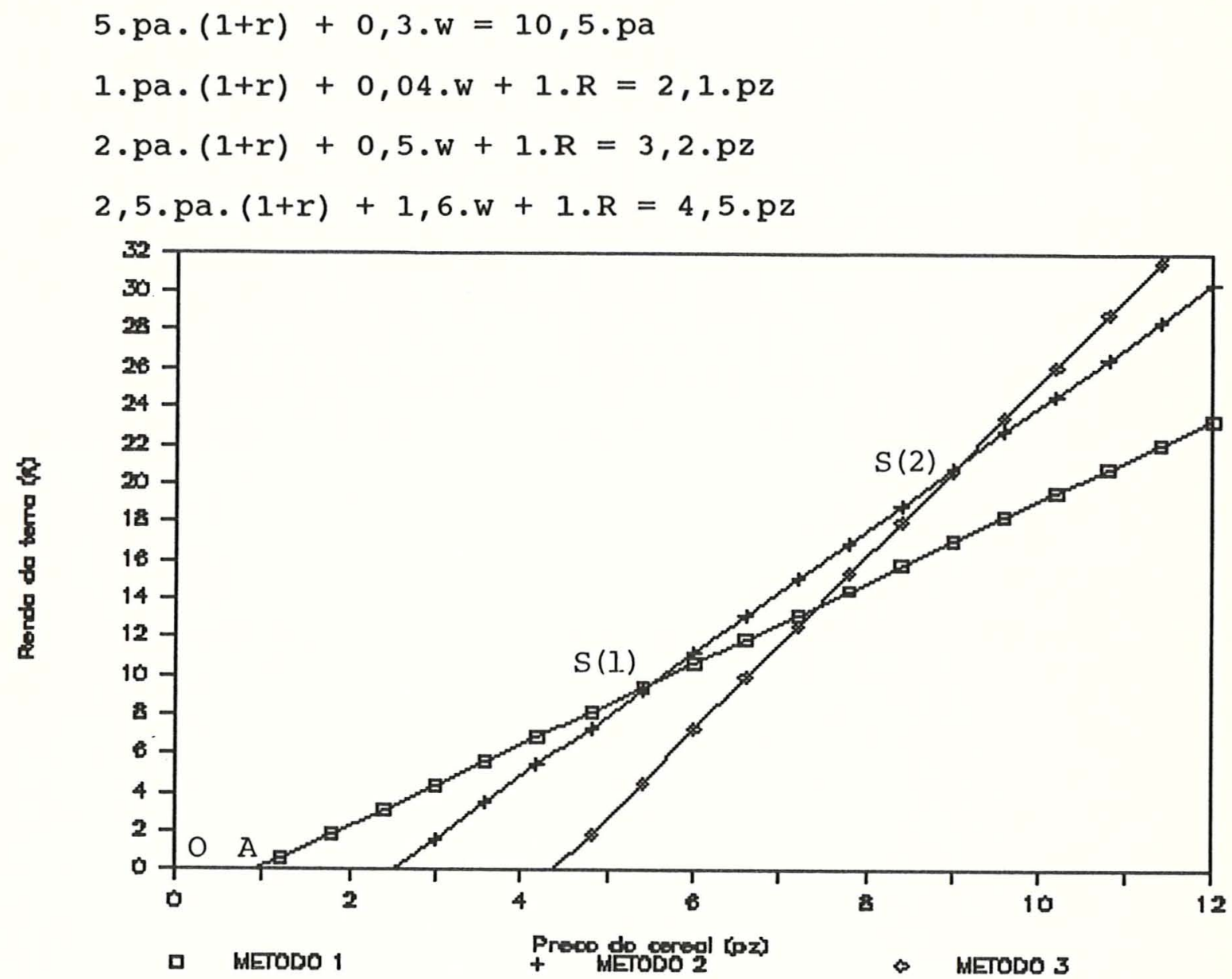

Figura 4.10 - o crescimento da producão e a substituicão dos metodos de cultivo.

Partamos do caso em que a demanda por cereal e suficientemente pequena, de tal forma que pode ser atendida com o cultivo de parte da terra total disponfvel (com qualquer metodo). Neste caso, como jd havlamos comentado acima, a terra não será escassa e $R=0$. 0 
metodo 1, que produz o cereal ao menor custo medio, serd empregado isoladamente. O preqo do cereal correspondera, assim, à medida do segmento OA na Figura 4.10.

Suponhamos que a demanda por cereal cresca ate o ponto em que o metodo 1 (com menor produção por unidade de área) não mais possa atendê-la, mesmo utilizando toda a terra dispontvel. Assim sendo, o preqo do cereal deverá subir (devido ao excesso de demanda), ate o ponto em que seja viável o cultivo pelo metodo 2 , lado a lado com o metodo 1. o novo pręo e a renda por unidade de area são as coordenadas do ponto $S(1)$ na Figura 4.10.

Um novo crescimento na demanda por cereal fard com que o segundo metodo substitua, paulatinamente, o primeiro, por toda a extensão da terra, uma vez que e mais produtivo. Enquanto isto acontece, o preço do cereal e a renda da terra permanecem constantes ao nivel anterior.

Apesar de a producão do cereal pelo metodo 2 ocorrer a um custo medio maior, não podemos esquecer que este metodo produz mais cereal por unidade de area. Assim sendo, verifiquemos o que esta ocorrendo, atraves dos seguintes calculos: No ponto $\mathrm{S}(1)$ temos $\mathrm{pz}=5,5$ (aprox.) e a taxa de salario sera igual a 10,0 (para $r=0,5$, obtida da equação de produção da mercadoria industrial) . Assim sendo, o custo medio de producão pelo metodo 1 serd igual a 0,904 (aprox.) e o do metodo 2 serd igual a 2,5. No entanto, enquanto a receita da producão total pelo metodo 1 
e igual a $11,55(2,1$ unidades produzidas vezes o preqo do cereal), a receita total obtida pelo metodo 2 e igual a 17,6 . Os calculos mostrarão que ambos os metodos, ao preqo do cereal igual a 5,5 (ponto $S(1)$ na Fig. 4.10), pagarão a mesma renda da terra por unidade de area ( $\mathrm{R}=9,6$, aprox.). Ou seja, o resultado econômico global da producão, a esse preço, \& igual em qualquer metodo. Portanto, \& indiferente ao capitalista qual metodo usar.

o metodo 2 deverd, então, substituir o metodo 1 a fim de que a demanda seja atentida. Fica claro, aqui, que a introdução de metodos "mais custosos" se viabiliza, apenas, com o crescimento da demanda pelo cereal (que acarreta um crescimento no preco do cereal).

Quando o crescimento da demanda fizer com que a mesma não possa mais ser atendida com o cultivo de toda a terra disponivel com o metodo 2, voltaremos a ter um crescimento no preço do cereal e, por conseguinte, na renda da terra. Quando o preqo do cereal atingir, aproximadamente, 0 valor 9,0 o terceiro metodo passa a ocupar parte da terra dispontvel, pagando uma renda da terra igual à obtida com o cultivo pelo metodo 2 (aproximadamente 20,8 ). E o processo continua com metodos que produzem mais por unidade de área a um custo medio maior. Como afirma SRAFFA(1983 pp. 238-9), "desse modo, o volume de produção pode aumentar continuamente, embora os metodos de producão sejam mudados de uma forma 
espasmodica".

Se tivermos infinitos metodos, poderemos obter uma curva envolvente, que representard as possiveis solucões de pz e R para o crescente nlvel de demanda. Um metodo, que não tenha qualquer segmento de sua equacão pertencendo à tal curva envolvente, não será utilizado a qualquer ntvel de demanda por cereal. Nesse caso, a substituicão dos metodos serd continua.

observa-se, portanto, que quanto mais

favoravel for a razão entre o aumento na produtividade da terra e o aumento no custo (ou seja, quanto mais proximas forem as interseções das funções com o eixo das abscissas, e quanto maior a diferença nas inclinações destas funcões), menor deverd ser o aumento do preco do cereal para que um metodo substitua outro.

Alem disso, devemos ressaltar que a posicão das retas na Fig. 4.10 altera-se para valores de $r$ diferentes, porque alteram-se os custos medios de producão de cada metodo, alterando o intercepto com 0 eixo das abscissas. Essas alterações podem fazer com que, por exemplo, o metodo com maior producão por unidade de area seja tambem o de menor custo medio. Nesse caso, este metodo sera utilizado isoladamente e não haverd renda da terra

Observe-se, tambem, que esse processo de crescimento intensivo da producão agricola atraves da 
introducão de metodos que produzem mais por unidade de area a um custo maior devido aos retornos decrescentes na agricultura. Nesse sentido, nesse processo, 0 aumento do preço do cereal e acompanhado do crescimento da renda da terra e da queda da taxa de salário (de lucro), dada a taxa de lucro (de salario).

Finalmente, preciso acrescentar que a andlise do processo de crescimento intensivo da produção agrlcola acima discutido não se altera, em essência, para o caso (real) de o cereal ser uma mercadoria basica. Na verdade, o que se modifica e o formato das relaçoes entre pz e R, que deixam de ser retas (a menos que escolhamos a taxa de salario como numerario), uma vez que, agora, mudanças em pz alteram a taxa de lucro. De forma que o custo medio de produção do cereal por um dado metodo não mais corresponde à interseção da relação pz-R com o eixo pz (como antes). Esse custo varia para diferentes valores de $\mathrm{pz}^{38}$.

Ate então mostramos apenas como se da o processo de substituicão dos metodos com a crescente demanda por cereal. Resta-nos considerar, nesse mesmo processo de crescimento intensivo da producão agricola, como se determinam as areas da terra cultivadas com cada metodo. A Figura 4.11 , a seguir, ilustra a determinacão das àreas utilizadas com dois metodos consecutivos, em função da demanda por cereal ${ }^{39}$. 
Definamos $g(i)=T(i) / Z(i)(0$ inverso da produtividade da terra, pelo metodo "i"). As retas decrescentes paralelas (em ângulo de 45 graus, em linha contInua na Fig. 4.11), representam os diferentes niveis de demanda (com $G(3)>G(2)>G(1))$. A linha decrescente pontilhada, por outro lado, representa a equacão $\mathbf{T}=$ $\mathrm{Z}(1) \cdot \mathrm{g}(1)+\mathrm{Z}(2) \cdot \mathrm{g}(2)$ (com $\mathrm{T}=\mathrm{T}(1)+\mathrm{T}(2)$, a drea total disponivel), ou $z(2)=T / g(2)-[g(1) / g(2)] \cdot z(1)$. Como 0 metodo 2, por hipotese, apresenta maior producão por unidade de area, $g(2)$ menor que $g(1)$, e essa reta terd inclinacão maior que as paralelas. A condicão de equillbrio entre a oferta e a demanda requer que $\mathrm{z}(1)+$ $\mathrm{Z}(2)=G(i)$ (o nlvel de demanda do cereal). Portanto, para um dado ntvel de demanda, a interseção da linha pontilhada com a linha correspondente a esse nlvel de demanda determinara a distribuicão da area pelos metodos de cultivo. com $\mathrm{z}(1)+\mathrm{z}(2)=\mathrm{G}$ ( 0 ntvel da demanda de cereal) como condicão de equilibrio entre oferta e demanda. ou seja, dado um nivel de demanda, a interseção da linha pontilhada com a linha correspondente a esse nivel de demanda determinara a distribuicão da area pelos metodos de cultivo.

Passemos, então, a interpretar a Fig. 4.11. Se $G=G(1)$, então $Z(2)=0$ e $Z(1)=0,8$. Se $G=G(2)$, teremos $\mathrm{Z}(1)=0,4$ e $\mathrm{Z}(2)=0,8$. Finalmente, se $\mathrm{G}=\mathrm{G}(3)$, $\mathrm{Z}(1)=0$ e $\mathrm{Z}(2)=1,6$. Ou seja, à medida que aumenta a 
demanda por cereal, o metodo que produz mais por unidade de area ( 0 metodo 2 , conforme hipoteses anteriores) deve substituir o metodo que produz menos por unidade de area, para $\circ$ atendimento da demanda. Enquanto a Fig. 4.10 representa o que ocorre com as varidveis econômicas (pz e R), a Fig. 4.11 representa o que ocorre, no mesmo processo, com as areas cultivadas com cada metodo.

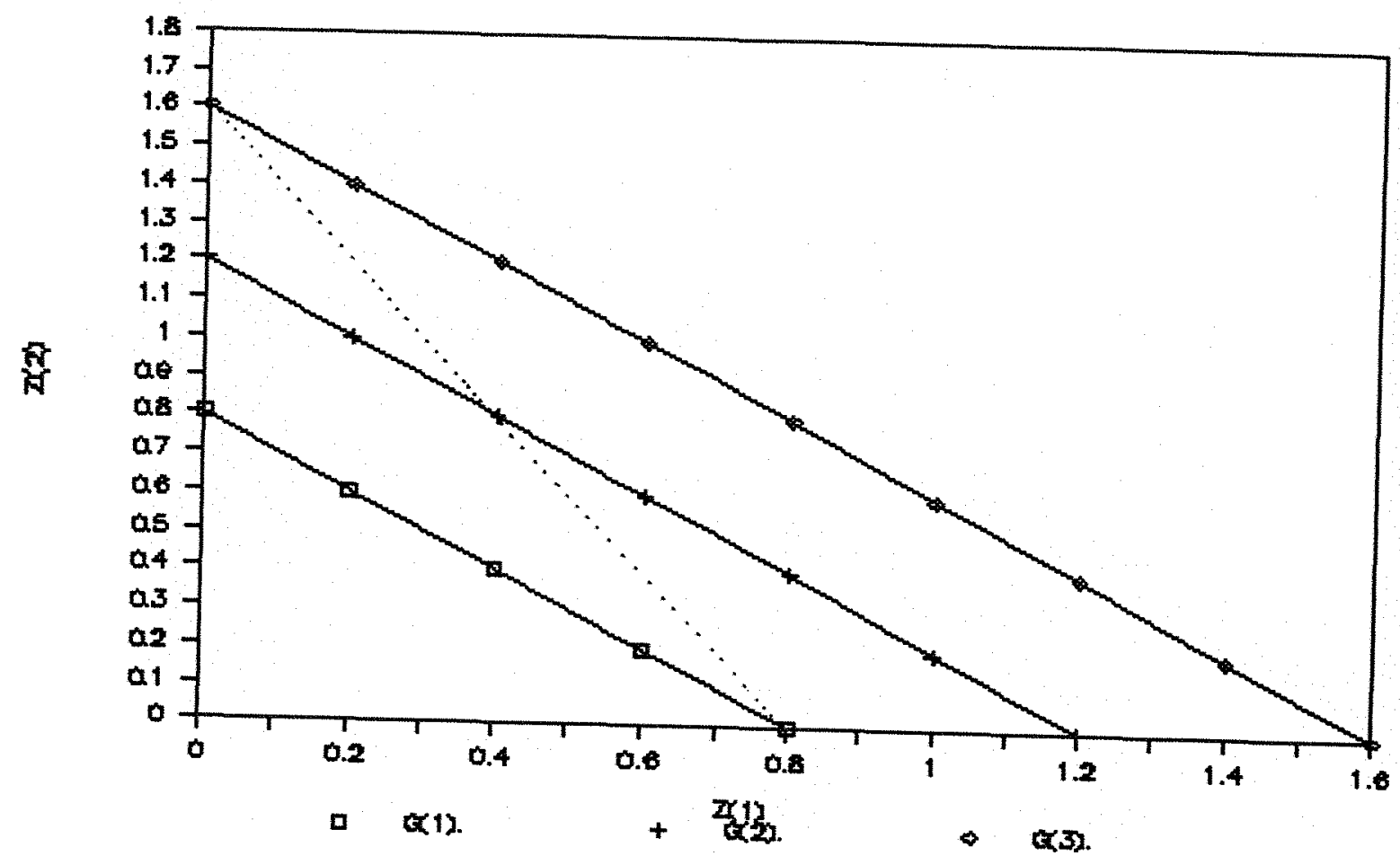

Figura 4.11 - A distribuicão dos metodos pela area dispontvel.

A seguir, quando analisarmos a renda intensiva frente às mudanças na distribuição da renda entre lucros e saldrios, observaremos o processo de crescimento 
intensivo da producão agricola nos casos em que o cereal e uma mercadoria não básica ou uma mercadoria básica, utilizando-se das curvas $w-r$. Assim, poderemos ver esse processo de uma maneira mais globalizada, frente aos diferentes posslveis valores de $r$, para um dado sistema econômico.

4.3.5. As mudanças autônomas na distribuicão e a
renda intensiva

Passaremos a estudar, como fizemos no caso da renda extensiva, os efeitos de mudanças autônomas na distribuição sobre a renda da terra e, portanto, sobre a escassez do meio de produção terra. Veremos que, dados certos metodos de producão do cereal em uma mesma qualidade de terra, a terra (ou qualquer meio de produção não produzido) tornar-se-à escassa em função das necessidades globais da economia pelo cereal e da distribuicão do excedente econômico entre lucros e salários. Um resultado, aliás, já constatado no caso da renda extensiva, ao determinarmos a terra marginal.

4.3.5.1) Introducão

Inicialmente, como introdução ao tema, consideraremos o seguinte sistema econômico: 


$$
\begin{array}{ll}
\mathrm{Aa} \cdot \mathrm{pa} \cdot(1+\mathrm{r})+\mathrm{La} \cdot \mathrm{w} & =\mathrm{A} \cdot \mathrm{pa} \\
\mathrm{Az}(1) \cdot \mathrm{pa} \cdot(1+\mathrm{r})+\mathrm{Lz}(1) \cdot \mathrm{w}+\mathrm{T}(1) \cdot \mathrm{R}=\mathrm{Z}(1) \cdot \mathrm{pz} \text { (metodo } 1) \\
\mathrm{Az}(2) \cdot \mathrm{pa} \cdot(1+\mathrm{r})+\mathrm{Lz}(2) \cdot \mathrm{w}+\mathrm{T}(2) \cdot \mathrm{R}=\mathrm{Z}(2) \cdot \mathrm{pz} \quad \text { (metodo 2) }
\end{array}
$$

A primeira equação representa a produção da mercadoria industrial (que $\notin$, por enquanto, a unica mercadoria básica), escolhida como numerario ( $\mathrm{pa}=1$ ). A fronteira tecnologica dessa economia e determinada, exclusivamente, a partir da equação de produção industrial, sendo a seguinte função linear:

$$
\mathrm{W}=\mathrm{A} / \mathrm{La}-(\mathrm{Aa} / \mathrm{La}) \cdot(1+\mathrm{r})
$$

Suponhamos que o método de producão do cereal representado pela terceira equacão do sistema (que chamaremos de metodo 2) produz mais por unidade de area que o outro (metodo 1). Portanto, $\mathrm{Z}(2) / \mathrm{T}(2)>\mathrm{Z}(1) / \mathrm{T}(1)$. Alem disso, suponhamos que a demanda por cereal não poderá ser atendida com o metodo 1 , mesmo que se cultive toda area dispon1vel, mas poderd ser atendida pelo metodo 2 sem 0 cultivo de toda area dispontvel ${ }^{41}$.

Ja vimos que, no caso em que dois metodos coexistam, e necessario que o metodo com maior produção por unidade de area tenha o maior custo medio de produção, para que a solução do sistema gere renda da terra positiva. Agora, no entanto, analisaremos esse processo diretamente 
atraves das relacões $w-r$, ao inves de nos reportarmos às relações entre $p z$ e $R$, porque consideraremos simultaneamente na andilise as variacões na distribuicão da renda.

Para esse primeiro caso particular, onde a fronteira tecnologica e determinada, exclusivamente, pela equąão de produção da mercadoria industrial, deveremos considerar a variacão dos custos medios em cada metodo, quando varia a distribuicão. Enquanto a Figura 4.12 , a seguir, apresenta a fronteira tecnologica, a Figura 4.13 mostra a variação dos custos medios frente a variaçóes na distribuição da renda.

Para o sistema econômico acima, a equação dos custos medios dos metodos e dada por:

$C(i) / Z(i)=\frac{\mathrm{Lz}(\mathrm{i}) \cdot \mathrm{A}}{\mathrm{z}(\mathrm{i}) \cdot \mathrm{La}}+\frac{[\mathrm{La} \cdot \mathrm{Az}(\mathrm{i})-\mathrm{Lz}(\mathrm{i}) \cdot \mathrm{Aa}]}{\mathrm{z}(\mathrm{i}) \cdot \mathrm{La}} \cdot(1+\mathrm{r})$

Uma relação linear crescente se La.Az(i) > Lz(i).Aa, e linear decrescente no caso contrario ${ }^{42}$.

As Figuras 4.12 e 4.13 baseiam-se no seguinte sistema econômico:

$$
\begin{aligned}
& 8 \cdot(1+r)+1 \cdot w=16 \\
& 4 \cdot(1+r)+0,25 \cdot w+1 \cdot R=5 \cdot p z \\
& 6 \cdot(1+r)+2 \cdot w+1 \cdot R=10 \cdot p z
\end{aligned}
$$




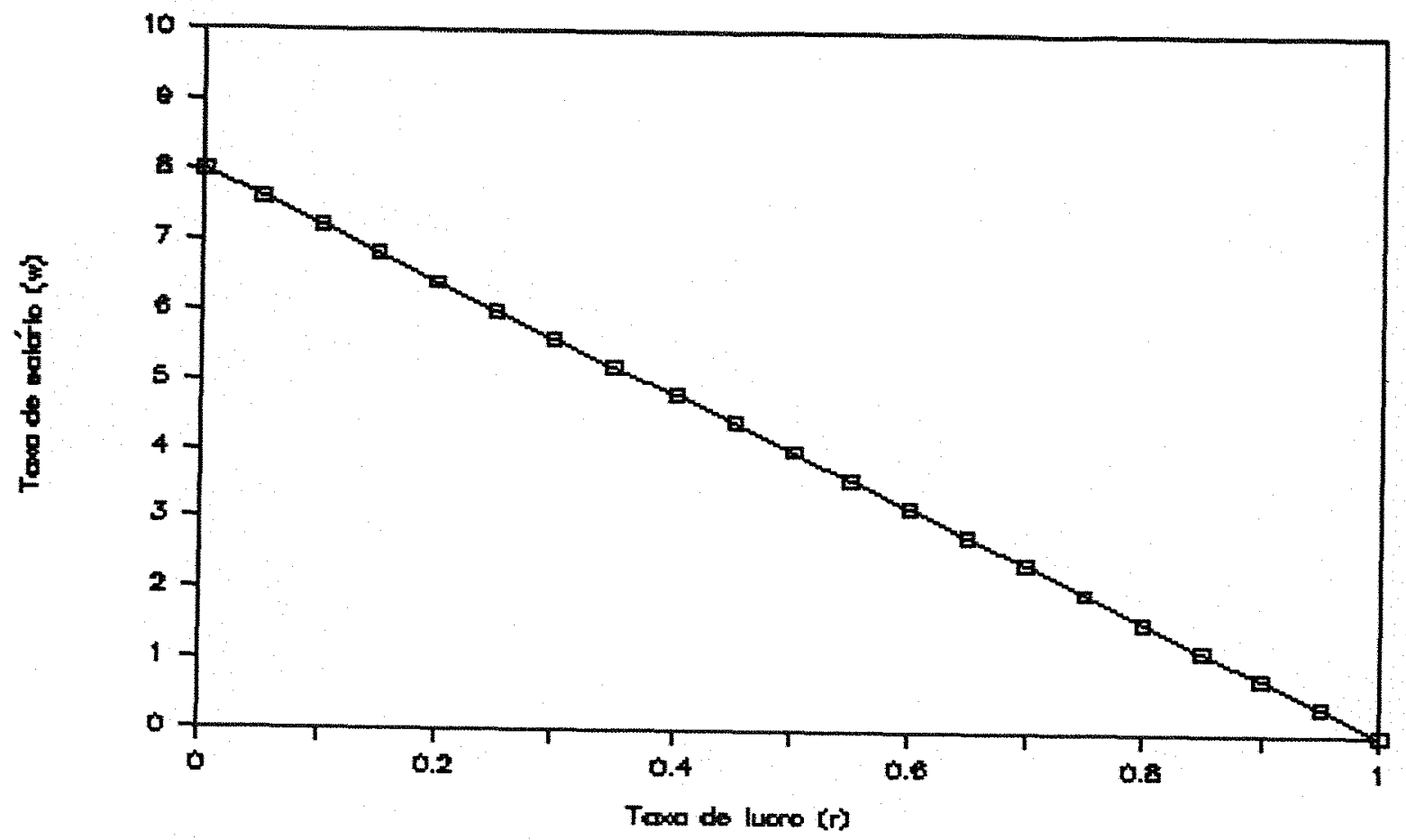

Figura 4.12 - A fronteira tecnologica.

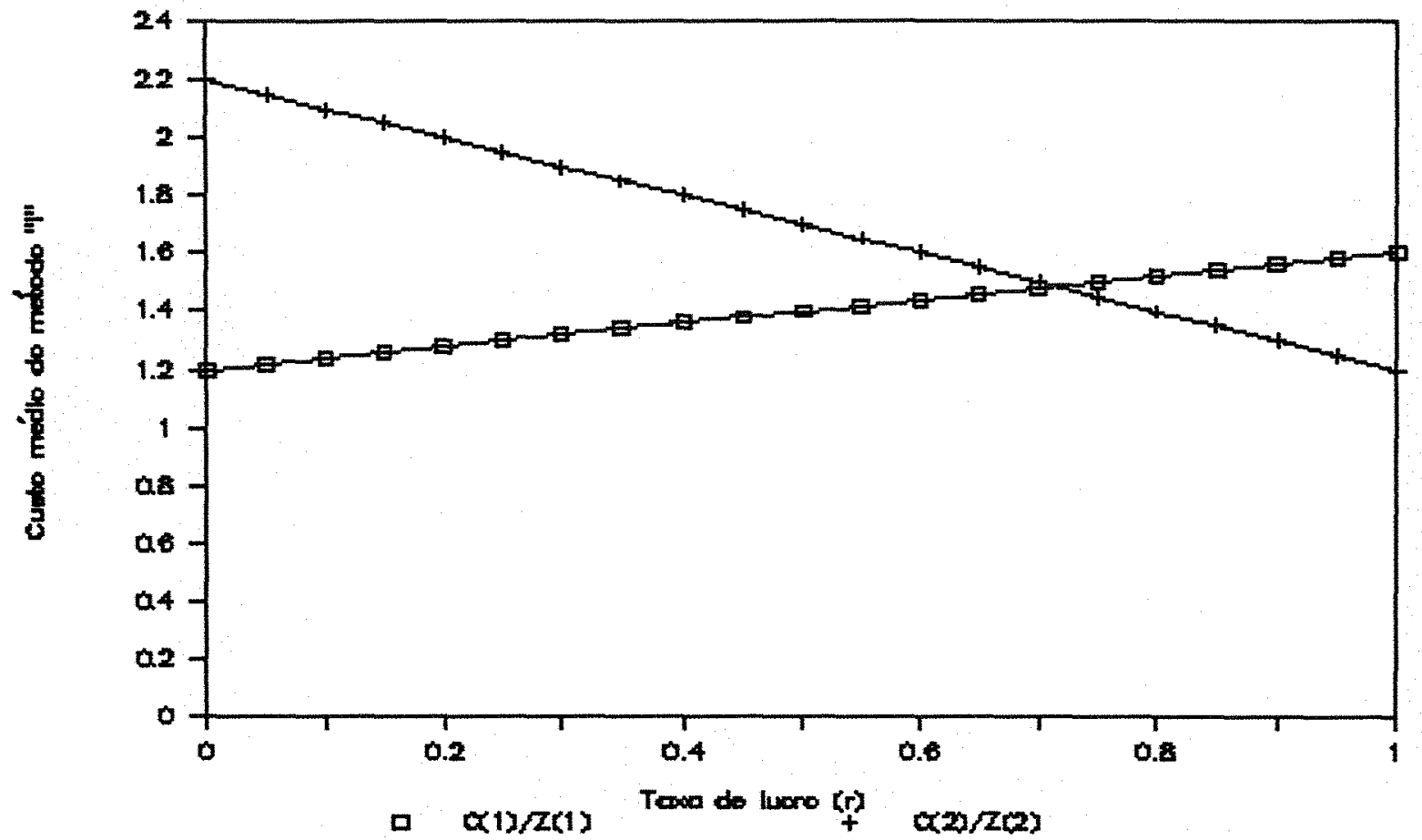

Figura 4.13 - o comportamento dos custos medios. 
Ao verificarmos as figuras, observamos que para valores de $r$ entre 0 e 0,7 (aprox.) a producão com 0 metodo 1 e mais eficiente (menor custo medio). Como a demanda não poder ser atendida (por hipotese), a terra tornar-se-d escassa, a renda serd, portanto, positiva, e os dois metodos coexistirão, lado a lado, no cultivo de toda area disponivel. Entretanto, para $r$ maior que 0,7 a producão serd mais eficiente com o metodo 2. Como a demanda poderd ser atendida com o cultivo parcial da terra disponivel se for usado o metodo 2 , a terra não será escassa enquanto $r$ for menor que 0,7 . Finalmente, para $r=0,7$, ambos os metodos terão igual eficiência, e a demanda por cereal serd atendida pelo cultivo parcial da terra disponfvel com o metodo 2, exclusivamente, ou com ambos $^{43}$. Neste caso, não haverd renda da terra.

Concluindo: quando o custo medio de producão do metodo de maior producão por unidade de area maior que - custo medio do metodo de menor producão por unidade de area, e posstvel a existência de renda da terra. A escassez da terra dependerd, portanto, de duas condicões: primeiramente, e necessario que haja pelo menos um metodo, entre os dispontveis, cuja produtividade tal que as necessidades globais de cereal não serão atendidas se toda a terra disponfvel for cultivada exclusivamente por este metodo. Em segundo lugar, e necessario que tal metodo tenha um custo medio de produção menor que o custo medio de 
produção de qualquer outro metodo de maior produtividade. Como esta ultima condição depende da previa distribuicão do excedente econômico entre lucros e salarios, fica claro que a escassez da terra não depende, exclusivamente, das necessidades globais da economia por cereal mas, tambem, da distribuicão do excedente econômico. Certamente, uma contribuição original da teoria sraffiana.

4.3.5.2. Relações entre taxas de lucro, salário e renda da terra

A fim de nos aprofundarmos no tema, passaremos a analisar mais detalhadamente as relações entre as taxas de lucro, de saldrio e da renda da terra. para este fim, passaremos a considerar o seguinte sistema econômico:

$$
\begin{array}{ll}
\mathrm{Aa} \cdot \mathrm{pa} \cdot(1+\mathrm{r})+\mathrm{La} \cdot \mathrm{w}=\mathrm{A} \cdot \mathrm{pa} & \\
\mathrm{Az}(1) \cdot \mathrm{pa} \cdot(1+\mathrm{r})+\mathrm{Lz}(1) \cdot \mathrm{W}+\mathrm{T}(1) \cdot \mathrm{R}=\mathrm{Z}(1) & \text { (metodo 1) } \\
\mathrm{Az}(2) \cdot \mathrm{pa} \cdot(1+\mathrm{I})+\mathrm{Lz}(2) \cdot \mathrm{W}+\mathrm{T}(2) \cdot \mathrm{R}=\mathrm{Z}(2) & \text { (metodo 2) }
\end{array}
$$

Apenas mudou-se, em relação ao sistema anterior, o numerario (que, agora, passa a ser o cereal). Neste caso, a fronteira tecnologica não mais podera ser obtida diretamente do sistema industrial e, assim, poderemos analisar a relação entre a renda da terra e as mudancas 
autônomas na distribuição da renda, diretamente a partir das curvas w-r. Manteremos, entretanto, as hipoteses sobre as produtividades dos metodos e os requisitos de atendimento da demanda por cereal.

Para analisarmos as relações entre as taxas de lucro, salario e renda da terra (alem de determinarmos a fronteira tecnologica), precisamos considerar, no mesmo grafico, as três posslveis relacões $w-r$ deste sistema econômico $^{44}$.

A primeira relação $w-r$ refere-se ao caso em que ambos os metodos são utilizados conjuntamente sobre toda a area dispontvel. Tal relação \& obtida, por substituicão, utilizando-se as três equações do sistema acima. Neste caso, tambem \& posslvel obter-se, alternativamente, a relação entre a taxa de lucro(r) e a taxa de renda( $R)$, uma vez que a renda da terra sera positiva.

Pode-se, ainda, obter a relação w-r correspondente ao caso em que o segundo metodo e utilizado isoladamente, sem o cultivo de toda a terra dispontvel. Assim, a terra ser redundante, $R=0$, e a relação $w-r$ e obtida substituindo-se a terceira equacão do sistema acima (referente ao metodo 2) na equação industrial.

Deveremos acrescentar, por fim, a relação w-r referente ao cultivo parcial da terra dispontvel, exclusivamente com o metodo 1 . Embora isto nunca 
acontecerd (pois, por hipotese, a demanda por cereal não seră atendida), sera necessario incluirmos essa relação para analisarmos o que pretendemos, como veremos abaixo. Tal relação, e obtida das duas primeiras equacões do sistema, com $\mathrm{R}=0$.

Para essas três relações, teremos a mesma taxa maxima de lucro ( $r$-max, para $w=0)$, pois ha so uma mercadoria básica. Neste caso, $r-\max =(A-A a) / A a$. As Figuras 4.14 e 4.15, a seguir, ilustram um caso posstvel. Essas figuras correspondem a um sistema econômico igual ao descrito logo acima, em termos numericos, como abaixo:

$$
\begin{array}{ll}
5 \cdot \mathrm{pa} \cdot(1+\mathrm{r})+0,30 \cdot \mathrm{w} & =10 \cdot \mathrm{pa} \\
1 \cdot \mathrm{pa} \cdot(1+\mathrm{r})+0,04 \cdot \mathrm{w}+1 \cdot \mathrm{R}=2,1 & \\
2 \cdot \mathrm{pa} \cdot(1+\mathrm{r})+0,50 \cdot \mathrm{w}+1 \cdot \mathrm{R}=6,5 & \text { (metodo 1) }
\end{array}
$$

Façamos variar $r$ entre 0 e $r$-max $(=1,00)$, para estudarmos as relacões que pretendemos . Primeiramente, como observa-se na Fig. 4.14 , verificamos que o metodo 1 e mais eficiente (menor custo medio) que o metodo 2, para valores de $r$ entre 0 e 0,7 . Como a demanda não podera ser atendida, serd necessario que ambos os metodos operem lado a lado, acarretando no aparecimento da renda da terra (como mostra a Fig. 4.15). Portanto, nesta faixa de variação da taxa de lucro, a relação w-r relevante serd a correspondente à mais interna relação $w^{-r}$ na Fig. 4.14, em negrito. 


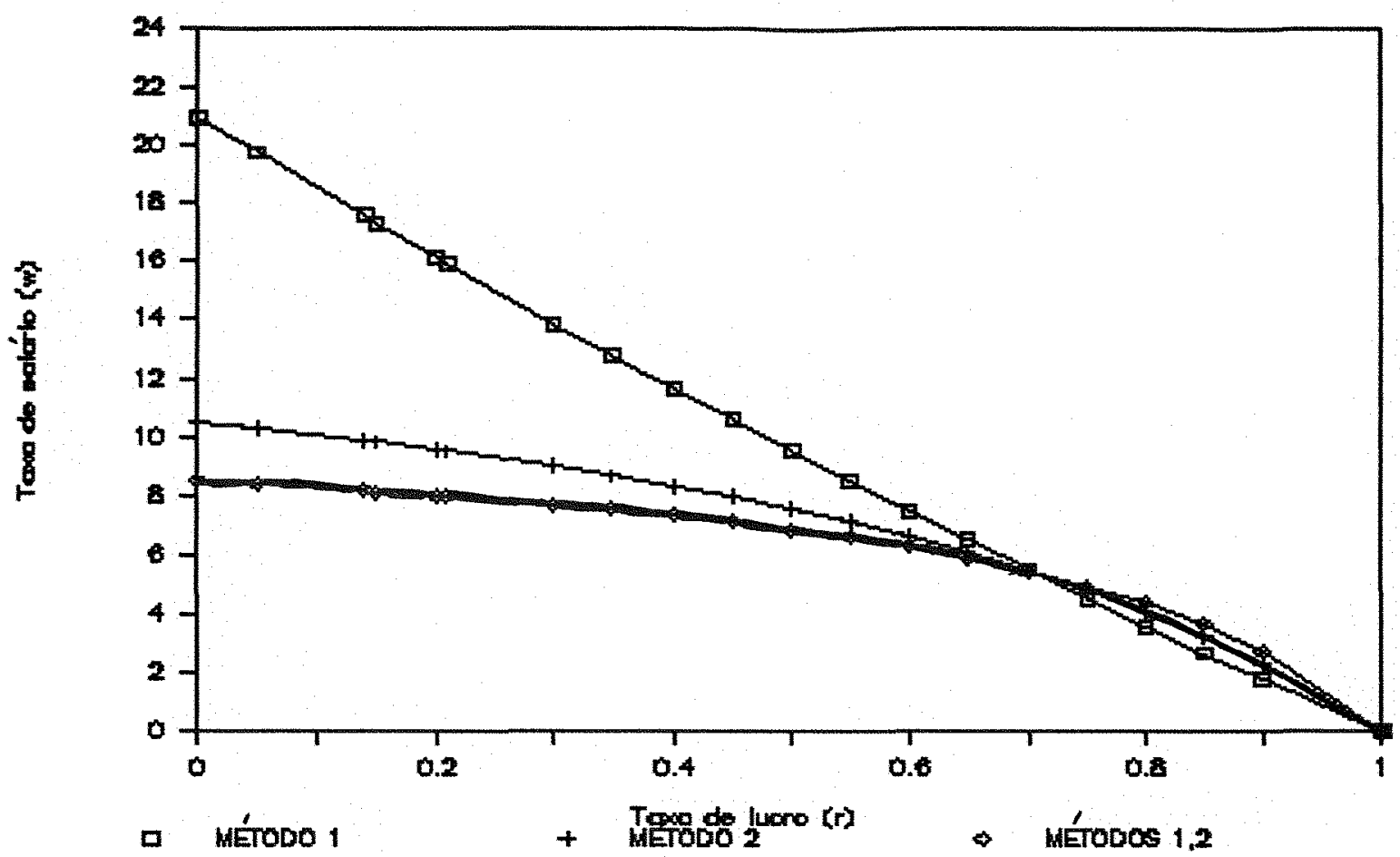

Figura 4.14 - A renda intensiva e as mudanças autônomas na distribuicão: curvas w-r.

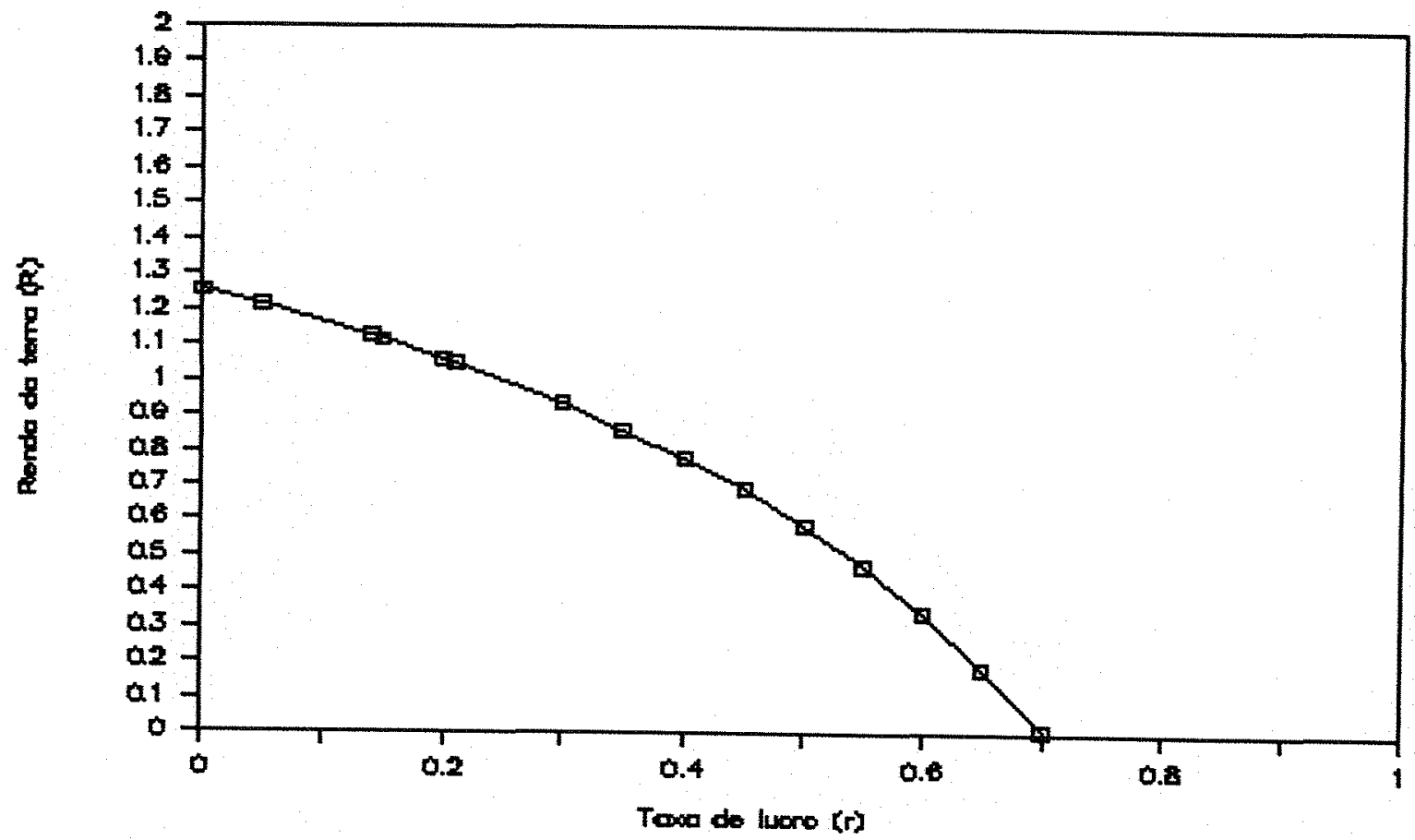

Figura 4.15 - A renda intensiva e as mudanças autônomas na distribuição: curva $R-r$. 
Quando $r$ varia entre 0,7 e 1,0 (r-max), podemos observar na Fig. 4.14 que o metodo 2 passa a ser mais eficiente que o metodo 1. Assim, parte da terra não serd cultivada, a terra serd redundante e não haverd, portanto, renda da terra. o metodo 2 serd utilizado na parte cultivada da terra. A relação $\mathrm{w}-\mathrm{r}$ relevante para este intervalo de variacão de $r$ édada, dessa vez, pela curva intermediaria (operação isolada do metodo 2), tambem em negrito na Fig. 4.14 .

Para $r=0,7$, finalmente, ambos os metodos terão igual eficiência, a terra serd parcialmente cultivada com o metodo 2 ou com ambos, como ja havlamos comentado anteriormente. A fronteira tecnologica desta economia corresponderd, portanto, à curva em negrito na Figura 4.14, sendo a maxima taxa de salario posstvel igual a 8,5 (aprox.)

Finalmente, poderemos observar o processo de crescimento intensivo da produção agrlcola, discutido na seção 4.3.4, considerando, diretamente, as relações $w-r$. Voltemos, pois, a observar a Fig. 4.14. Se a demanda por cereal for pequena e puder ser atendida pelo cultivo com - metodo 1 , não haverd renda da terra, enquanto $r$ for menor que 0,7 . o crescimento da demanda por cereal (para $r$ menor que 0,7$)$ tornard necessaria a introducão de um metodo que produza mais cereal por unidade de area. Como vimos, inicialmente ambos os metodos operarão simultaneamente, ate 
que 0 metodo 2 substitua (com o crescimento da demanda) totalmente, 0 metodo 1 . A Fig. 4.10 da seç̧ão 4.3 .4 corresponde à situação em que $r=0,5$, na Fig.4.14. A Figura 4.14, de outra parte, abrange a andlise para qualquer valor de $r$.

4.3.5.3) A possibilidade de uma relação $w-r$ crescente: a indeterminação para uma dada taxa de salario

Passaremos, agora, a analisar o interessante fenômeno representado pela indeterminação causada para uma dada taxa de saldrio. Este caso ocorrerd, como veremos, quando tivermos uma relação $w-r$ crescente, gerando uma fronteira tecnologica tambem crescente, embora para uma dada faixa de variação de $r$, apenas.

Passemos, pois, a discutir tal caso. Para este fim consideraremos o seguinte sistema econômico ${ }^{47}$ ja na forma de exemplo numerico:

$$
\begin{aligned}
& (8 \cdot \mathrm{pa}+1 \cdot \mathrm{pz}) \cdot(1+\mathrm{r})+1 \cdot \mathrm{w}=16 \cdot \mathrm{pa} \\
& (2 \cdot \mathrm{pa}+2 \cdot \mathrm{pz}) \cdot(1+\mathrm{r})+0,05 \cdot \mathrm{w}+1 \cdot \mathrm{R}=6 \cdot \mathrm{pz} \\
& (1 \cdot \mathrm{pa}+2 \cdot \mathrm{pz}) \cdot(1+\mathrm{r})+1,5 \cdot \mathrm{w}+1 \cdot \mathrm{R}=8 \cdot \mathrm{pz}
\end{aligned}
$$

Observa-se, portanto, que o cereal passa a ser uma mercadoria bdsica. Fazendo-se $p z=1$ (cereal sera 
- numerario), podemos obter as três relações entre $w$ e $r$, conforme se utilize os metodos 1 e 2 isoladamente, ou simultaneamente. Essas relações aparecem na Figura 4.16, a seguir. A Figura 4.17 mostra a relação entre a renda da terra e a taxa de lucro.

Uma primeira diferenciação que ocorrera, como pode-se verificar nas Figuras 4.16 e 4.17 , \& que não ha mais uma mesma taxa maxima de lucro para as três posslveis relações $w-r$ (porque ha mais de uma mercadoria bdsica).

Hd, no entanto, uma diferenca mais importante. Qual seja: a relação $w-r$ crescente quando ambos os metodos são operados conjuntamente. Ha que se salientar, entretanto, que tal relação podera ser decrescente, para outros valores dos coeficientes tecnicos do mesmo sistema econômico.

Vejamos isto mais de perto: se observarmos a primeira equação do sistema acima, verificaremos que, para que haja um crescimento simultâneo em w e $r$, e preciso que haja, tambem, um crescimento de pa. ora, se agora observarmos as duas equações de produção do cereal, verificaremos que quando $R=0,0$ aumento simultâneo destas três variatveis imposstvel ( $\mathrm{com} p z=1)$. Conclutmos, portanto, que tal fenômeno so ocorrerd quando $\mathrm{R}$ for diferente de zero (pois al a queda em $\mathrm{R}$ poderd compensar 0 aumento simultâneo em $w, r$ e pa). Ou seja, apenas a relação $w-r$ correspondente à operação conjunta dos dois metodos 
poderd ser crescente.

Vejamos, agora, como obter a fronteira tecnologica para esta economia (em negrito na Fig. 4.16) e a indeterminacão que caracterizara um conflito distributivo entre capitalistas e proprietarios de terras. Manteremos as pressuposicões quanto ao atendimento da demanda. ou seja o cultivo do cereal pelo metodo 1 , que produz o menor produto l1quido por unidade de area, não podera atender a demanda, dada a área dispontvel. Por outro lado, o cultivo do cereal pelo metodo 2 resulta em um produto llquido suficiente para o atendimento da demanda, sem o cultivo de toda a terra disponivel. Reportemo-nos, portanto, à Fig. 4.16, abaixo, tomando-se a taxa de saldrio exogenamente $e$ variando-a dentro do intervalo relevante.

observando-se a Fig. 4.16, verifica-se que, para valores de $w$ entre 12,5 e 2,35 (aprox.) seria posslvel, à primeira vista, produzir o cereal operando ambos os metodos 1 e 2 conjuntamente (e obtendo-se uma taxa de lucro maior que 0,50$)$. No entanto, nessa faixa de variação da taxa de salario, obterlamos uma taxa de renda negativa, pela operacão dos dois metodos. Portanto, essa situação não e possivel.

Por outro lado, neste intervalo de variacão da taxa de salario, o metodo 1 seria o mais eficiente e os capitalistas tentariam introduzi-10, causando a escassez da terra e propiciando a cobranca de renda da terra por parte 


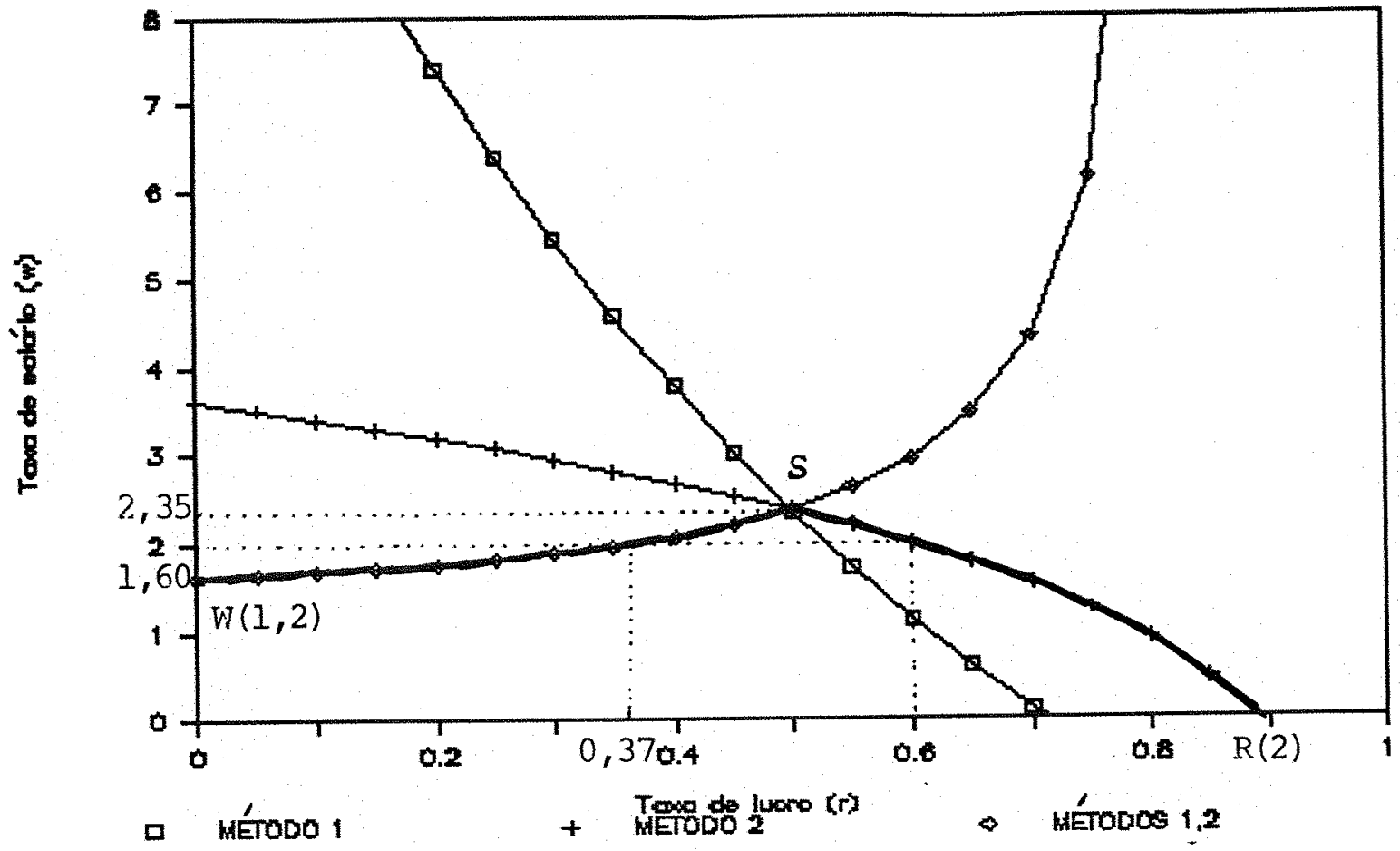

Figura 4.16 - A relação w-r crescente.



Figura 4.17 - o comportamento da renda da terra. 
dos proprietarios da terra. A competicão entre os capitalistas faria com que a taxa de lucro se reduzisse a zero, uma vez que a taxa de salario estaria fixada e o metodo 2 não seria eficiente para esta taxa de saldrio. Portanto, devemos concluir que $w=2,35$ (aprox.) serd a maxima taxa de salario desta economia.

Agora, para $w$ entre 2,35 (aprox.) e 1,6 (aprox.) surgird uma indeterminacão na solucão do sistema, uma vez que ha duas solucões posslveis. Neste caso, a solucão não se resumira a aspectos meramente econômicos, passando a depender de questões pollticas de luta de classes, por exemplo. Se, por exemplo, tomarmos $w=2$, verificamos que uma solução consiste em cultivar parte da terra com o metodo 2 , exclusivamente, obtendo-se $r=0,6$ e $\mathrm{R}=0$. Outra solução posslvel consiste em cultivar toda a terra disponivel com ambos os metodos, com uma taxa de lucro menor $\left(0,37\right.$, aprox.), mas $\operatorname{com} R>0\left(1,4\right.$, aprox. $^{49}$.

No entanto, se tomarmos a taxa de lucro como um dado exógeno e variarmo-la na faixa posstvel, não teremos qualquer indeterminacão. Seguindo o mesmo racioclnio que ja vinhamos desenvolvendo, e facil verificar que a fronteira tecnologica correspondera à curva $W(1,2)-S-$ $R(2)$, em negrito na Fig. 4.16. E claro que a fronteira \& a mesma nos doịs casos, restando, apenas, escolhermos a variavel exogena. Observe-se, finalmente, que a fronteira tecnologica e crescente para uma dada faixa de variacão de 
$r$ (ou de $w)$, o que até então não ocorria.

Finalmente, tambem aqui podemos analisar o processo de crescimento intensivo da produção agrlcola, diretamente nas relaçoes $w-r$. Nesse caso, lembremos que o cereal e uma mercadoria básica.

Assim sendo, novamente, se a demanda pelo cereal for suficientemente pequena, para valores de $r$ menores que 0,5 , esta poderd ser atendida pelo metodo 1 . Um aumento na demanda tornara necessaria a introducão do metodo 2. Nesse caso, para valores de $r$ menores que 0,5 , ambos os metodos operarão lado a lado, cultivando toda a terra, com renda da terra positiva. Se, no entanto, $r$ for maior que 0,5 , o metodo 2 serd utilizado, sem que se passe (nesse processo) pelo metodo 1 .

\subsubsection{Um outro tipo de indeterminação}

Nesta seção, consideraremos um novo tipo de indeterminação para uma dada faixa de variação na taxa de salario. Essa indeterminacão difere-se da discutida logo acima porque duas soluções posstveis (para um dado $w$ ) correspondem a valores positivos da renda da terra.

Consideremos, pois, $0_{50}$ seguinte sistema econômico, na forma de exemplo numerico : 


$$
\begin{array}{lr}
(0,5 \cdot \mathrm{pa}+1 \cdot \mathrm{pz}) \cdot(1+\mathrm{r})+0,1 \cdot \mathrm{w}=1 \cdot \mathrm{pa} & \text { (industria "a") } \\
(0,05 \cdot \mathrm{pb}+1 \cdot \mathrm{pz}) \cdot(1+\mathrm{r})+1 \cdot \mathrm{w}=1 \cdot \mathrm{pb} & \text { (industria "b") } \\
(0,1 \cdot \mathrm{pa}+0,2 \cdot \mathrm{pz}) \cdot(1+\mathrm{r})+1 \cdot \mathrm{w}+1 \cdot \mathrm{R}=3 \cdot \mathrm{pz} & \text { (metodo 1) } \\
(1 \cdot \mathrm{pb}+0,2 \cdot \mathrm{pz}) \cdot(1+\mathrm{r})+0,02 \cdot \mathrm{w}+1 \cdot \mathrm{R}=4,6 \cdot \mathrm{pz} & \text { (metodo 2) }
\end{array}
$$

Temos, agora, duas mercadorias industriais e dois metodos de cultivo do cereal. Alem disso, trata-se de um sistema muito particular, onde o metodo agricola 1 corresponde a uma tecnologia trabalho-intensiva (em reląão ao metodo 2) e utiliza uma mercadoria industrial produzida com uma tecnologia capital-intensiva (em relacão à outra mercadoria industrial). 0 inverso ocorre com o metodo 2. Essa particularidade e importante para obtermos a indeterminacão que iremos discutir.

Fazendo-se pa $=1$, poderemos obter, como anteriormente, três relações $w-r$ a relação entre $r$ e $R$, quando os dois metodos são operados conjuntamente. A Figura 4.18 , a seguir, representa as relaçoes $w-r$. Logo abaixo, a Figura 4.19 representa a relacão entre $r$ e $R$.

Como se pode observar na Fig. 4.18 , a relação $w-r$ referente ao cultivo do cereal com a operacão simultânea dos dois metodos e inicialmente decrescente e posteriormente crescente. Mantendo-se as hipoteses anteriores quanto ao atendimento da demanda pelo cereal, obteremos, para uma pequena faixa de valores de $w$ três posslveis soluções, que refletirão, novamente, um conflito 


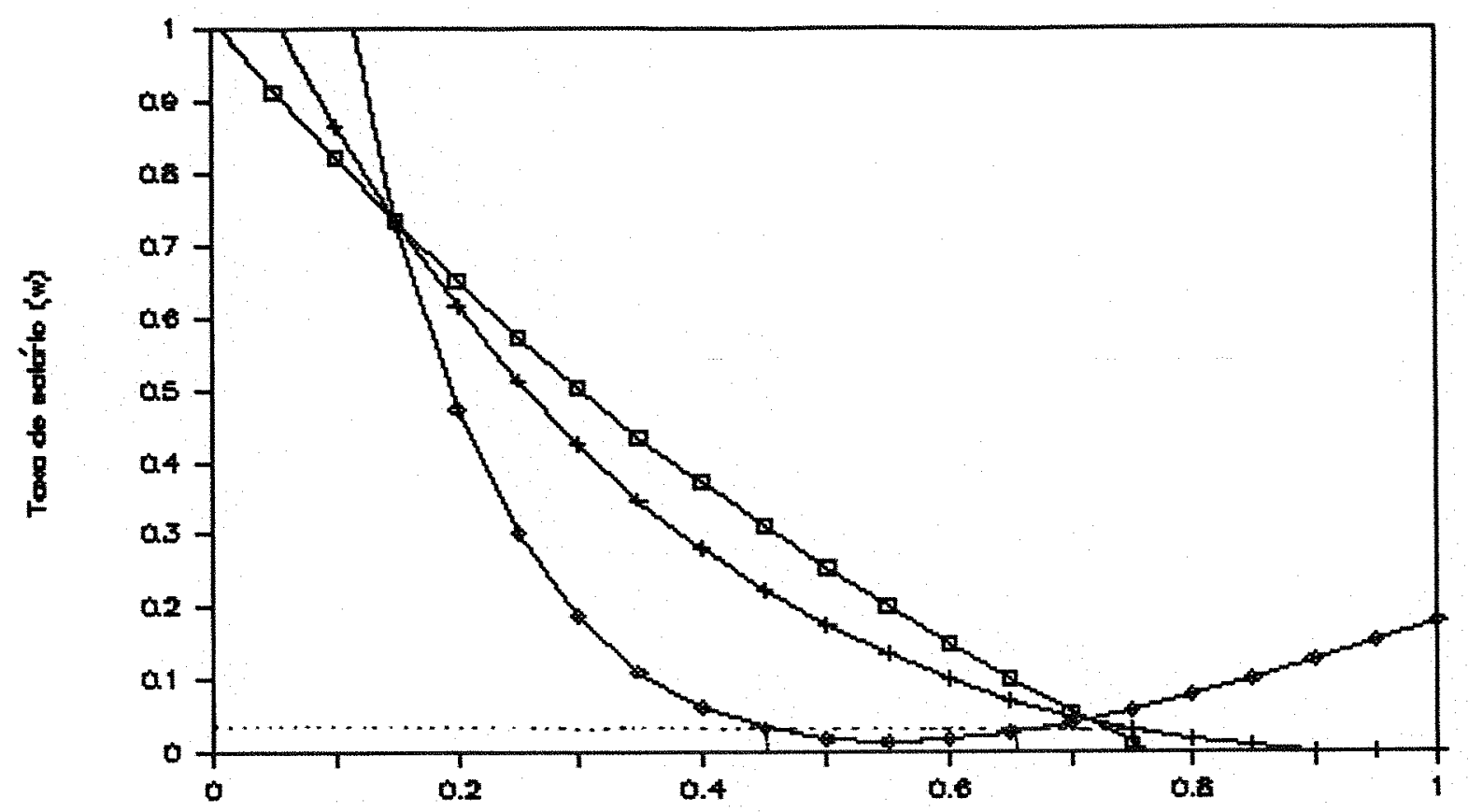

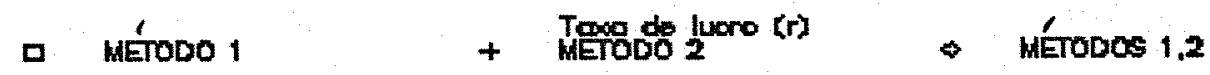

Figura 4.18 - Um novo tipo de indeterminação: curvas $w-r$.

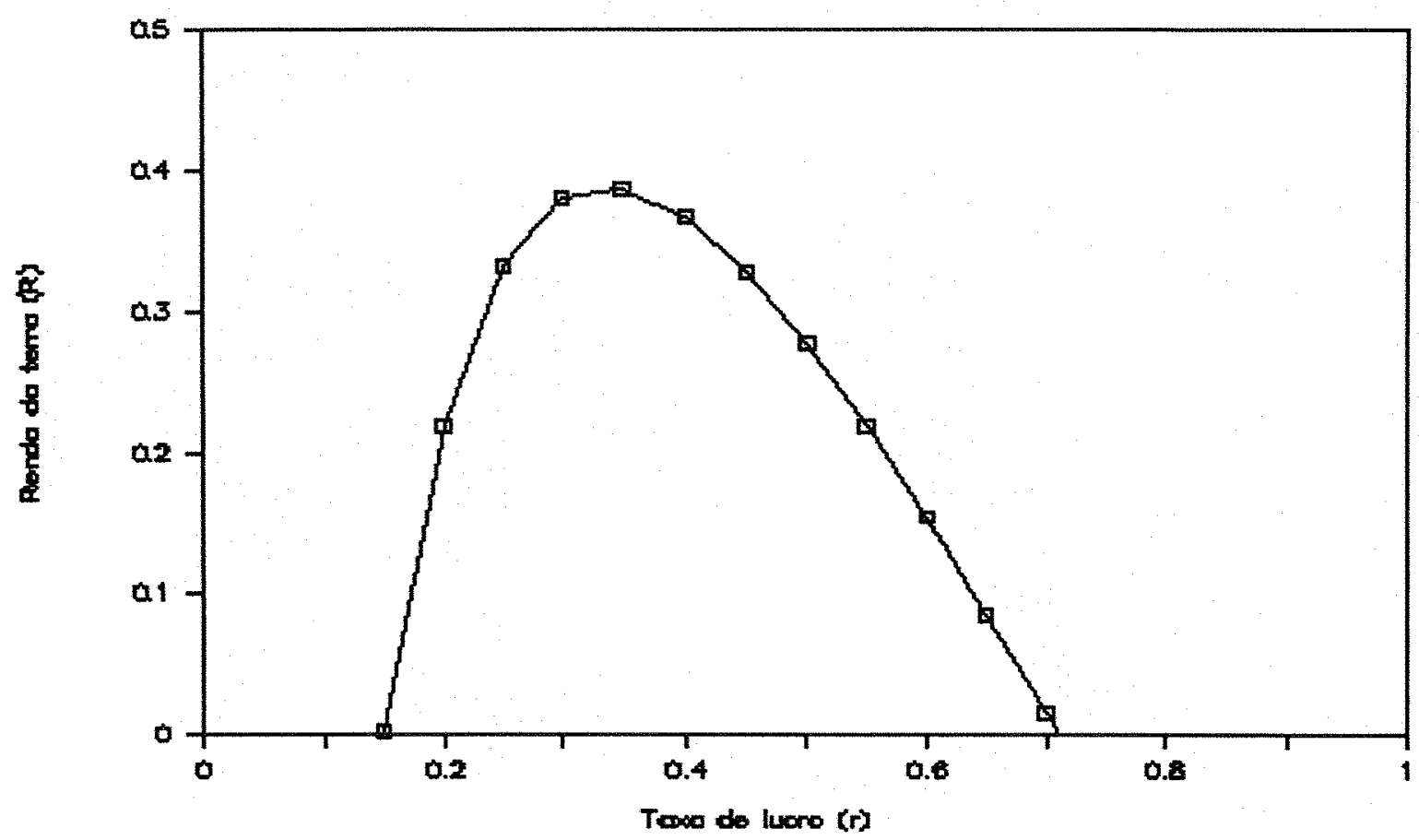

Figura 4.19 - Um novo tipo de indeterminação: curva r-R. 
distributivo entre capitalistas e proprietarios da terra (se houver separacão de classes). No entanto, diferentemente do caso discutido na seção anterior, duas das posslveis soluções correspoderão a valores positivos (e diferentes) da renda da terra, como se pode observar na Fig. 4.19 .

Se fossemos obter as relações entre o preço do cereal ( $\mathrm{pz}$ ) e a renda da terra (R), como obtivemos anteriormente quando discutlamos o processo de crescimento intensivo da producão agrlcola, obterlamos duas interseç̧ões das duas relações correspondentes aos dois metodos de cultivo do cereal. No caso então discutido isso não ocorria porque o cereal era uma mercadoria não-błsica e obtinhamos retas. Nesse caso, como 0 cereal e uma mercadoria básica, obteremos curvas que poderão interceptar-se em dois pontos ${ }^{51}$. 4.3.5.4. A indeterminação e a inexistência de uma
solução para uma dada taxa de lucro

Finalmente, discutiremos um ultimo tipo de indeterminação ainda não considerado. Nesse caso, a indeterminação ocorre quando tomamos a taxa de lucro (e não a de salario, como nos dois casos acima) como um dado exogeno (surgindo, agora, um "inesperado" conflito distributivo entre trabalhadores e proprietarios da terra). 
Alem disso, veremos que, embora seja possivel obter soluqões positivas para $w$ e $R$ (sistemas economicamente vidveis), a partir de um dado valor de $r$ não mais encontraremos soluções de equiltbrio, fazendo com que a fronteira tecnologica não seja definida em todo o espectro posslvel de valores para a taxa de lucro.

Consideremos, para isso, o seguinte sistema econômico, na forma de exemplo numerico ${ }^{53}$ :

$$
\begin{array}{ll}
0,1 \cdot \mathrm{pz} \cdot(1+\mathrm{r})+1,0 \cdot \mathrm{w}=1 \cdot \mathrm{pa} & \text { (producão de ferro) } \\
0,6 \cdot \mathrm{pz} \cdot(1+\mathrm{r})+1,0 \cdot \mathrm{w}=1 \cdot \mathrm{pb} & \text { (producão de carvão) } \\
(0,1 \cdot \mathrm{pa}+0,4 \cdot \mathrm{pb}+0,1 \cdot \mathrm{pz}) \cdot(1+\mathrm{r})+1,0 \cdot \mathrm{w}+1 \cdot \mathrm{R}=1 \cdot \mathrm{pz} \\
(0,1 \cdot \mathrm{pa}+0,1 \cdot \mathrm{pb}+0,3 \cdot \mathrm{pz}) \cdot(1+\mathrm{r})+2,2 \cdot \mathrm{w}+1 \cdot \mathrm{R}=1 \cdot \mathrm{pz} \\
(0,1 \cdot \mathrm{pa}+0,1 \cdot \mathrm{pb}+0,4 \cdot \mathrm{pz}) \cdot(1+\mathrm{r})+1,0 \cdot \mathrm{w}+1 \cdot \mathrm{R}=1 \cdot \mathrm{pz}
\end{array}
$$

Hd, portanto, duas mercadorias industriais e três metodos de produção do cereal sobre a mesma qualidade de terra. As mercadorias industriais não são meios de produção do setor industrial, mas são meios de producão do setor agrlcola. 0 cereal, por outro lado, e meio de producão de ambos os setores.

Pressupomos, ainda, que a demanda final pelas três mercadorias e constitulda pelo seguinte vetor de produto I1quido: 90 unidades de ferro, 60 unidades de carvão e 19 unidades de cereal. Finalmente, admitimos que existam, apenas, 100 hectares de terra dispontveis ao 
cultivo $^{54}$

Tomando-se o cereal como numerdrio $(p z=1)$, deste sistema podemos obter 6 relações $w-r$, quais sejam: a produção das mercadorias industriais lado a lado com o cultivo da terra, isoladamente, com cada um dos três metodos (sem renda da terra), e a producão das mercadorias industriais lado a lado com o cultivo de toda drea dispontvel com uma combinacão (das três posstveis) de dois metodos em cultivo. No entanto, dados os requisitos de demanda final, apenas três relações interessar-nos-ão. Esssas relações estão apresentadas na Figura 4.20. A Figura 4.21, por sua vez, mostra-nos as relações $r-R$. Após essas figuras, encontram-se as tabelas dos posstveis valores das variáveis econômicas para diferentes valores de $r$, exibidas para que o leitor possa acompanhar os calculos que justificarão a obtenção da fronteira tecnologica desta economia.

Passemos, pois, a explicar os fenômenos da multiplicidade de solucões e da inexistência de uma solução, para $r$ exogeno. Tomemos, por exemplo $r=0,05$. Para esse valor de $r$ (e para todos os valores entre 0 e $0,11)$, podemos verificar que a relação que compord a fronteira tecnologica serâ a relação $w-r$ correspondente à produção de cereal conjuntamente com os metodos 1 e 3 . Isto porque, se tomarmos as solucões referentes à outra relação vidavel, neste intervalo (referente à producão de 
cereal exclusivamente com o metodo 1), e inserirmos na equacão do metodo 3 , veremos que este serd introduzido. Senão vejamos: as soluções da relação $W(1)$, para $r=0,05$, seriam (conforme tabelas, apos as figuras): $w=0,4061$, pa $=0,5111 \mathrm{e} \mathrm{pb}=1,0361$. Agora, inserindo-se esses valores na equação do metodo 3 , teremos :

$(0,1 * 0,5111+0,1 * 1,0361+0,4) *(1,05)+1 * 0,4061=0,9885$

que, totalizando menos que a unidade, caracteriza a maior eficiência do metodo 3. Portanto, o metodo 1 não serd utilizado isoladamente no cultivo da terra. A solução de equilibrio e representada pela relacão $W(1,3)$, que constituira a fronteira tecnologica, para este intervalo de variação de $r$.

Passemos a considerar o intervalo de variacão de $r$ entre 0,11 e 0,47 (aprox.). Neste intervalo, surge uma nova relação viável, qual seja, a que corresponde à producão de cereal conjuntamente com os metodos 1 e 2 . Veremos agora, pelo mesmo racioclnio, que existirão duas solucões de equilibrio para um mesmo valor de $r$, caracterizando a indeterminacão ate então ausente no sistema econômico com renda da terra, para $r$ exógeno.

Para isso, tomemos $r=0,2$. Neste caso, as solucões para o sistema em que o cereal e produzido com os metodos 1 e 3 serão: $w=0,28, R=0,072, p a=0,4$ e $p b=$ 


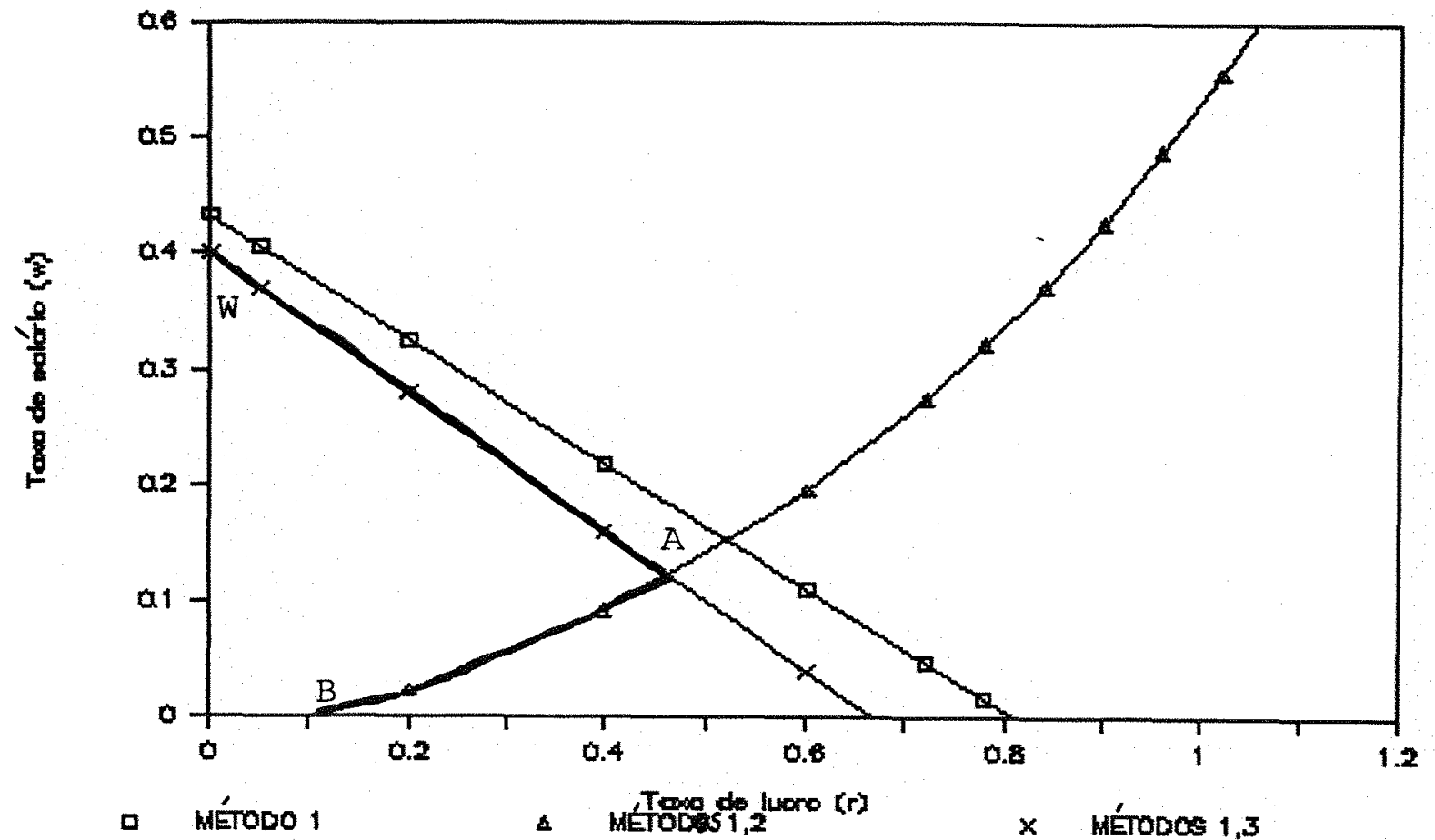

Figura 4.20 - A indeterminacão para $r$ exógena : curvas $w-r$.

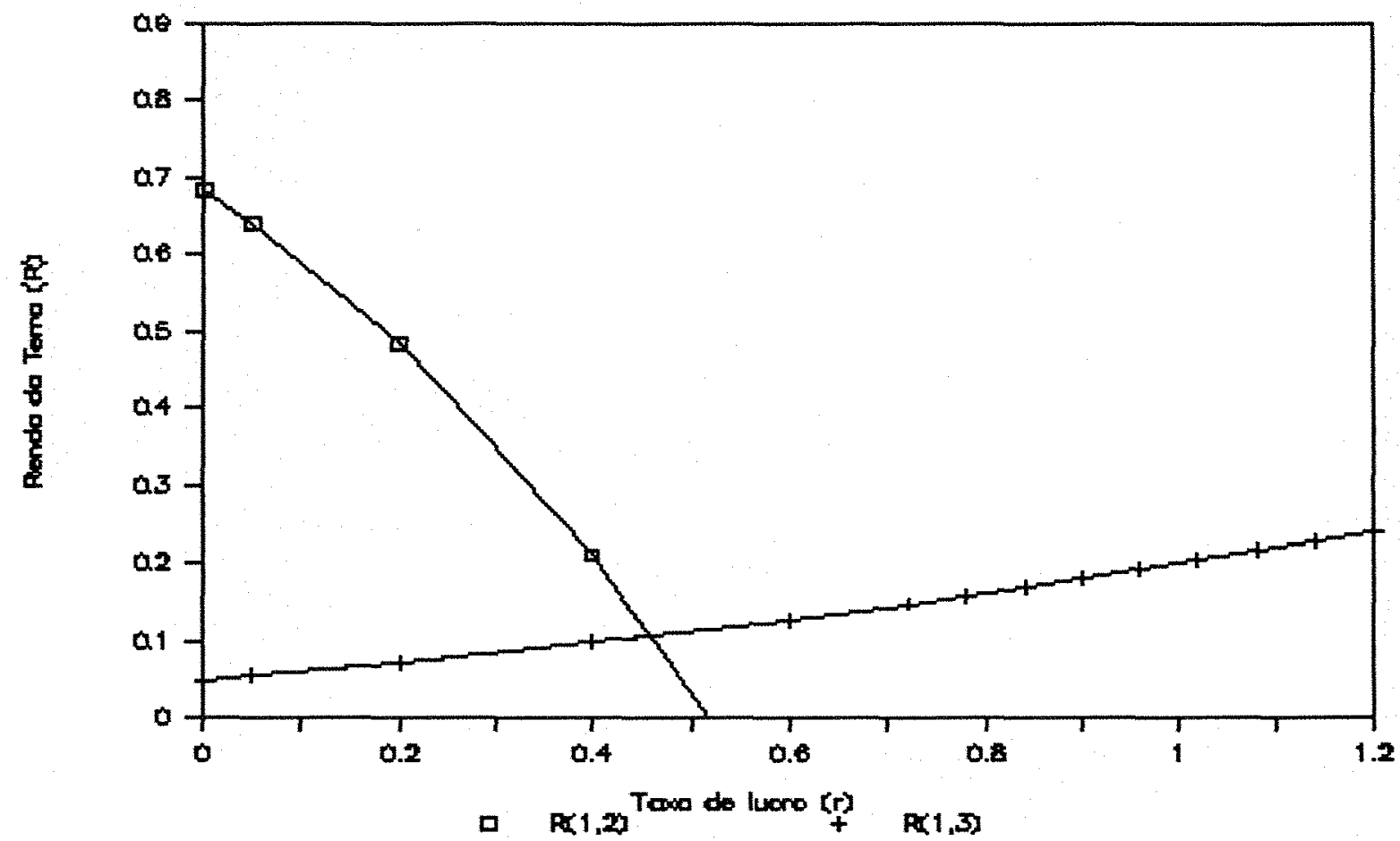

Figura 4.21 - A indeterminacão para $r$ exógena : curvas $r-R$. 
SOLUCOES DO SISTEMA ECONOMICO - SEÇAO 4.3.5.5

Tabela 1. Valores das taxas de salário.

\begin{tabular}{lrrrrrr}
\hline Tx. lucro & W(1) & W(2) & $W(3)$ & $W(1,2)$ & $W(1,3)$ & $W(2,3)$ \\
\hline 0,000 & 0,433 & 0,262 & 0,441 & $-0,022$ & 0,400 & 0,083 \\
0,050 & 0,406 & 0,252 & 0,415 & $-0,013$ & 0,370 & 0,087 \\
0,200 & 0,325 & 0,220 & 0,338 & 0,022 & 0,280 & 0,100 \\
0,400 & 0,217 & 0,178 & 0,236 & 0,093 & 0,160 & 0,116 \\
0,600 & 0,111 & 0,135 & 0,136 & 0,195 & 0,040 & 0,133 \\
0,800 & 0,005 & 0,091 & 0,039 & 0,338 & $-0,080$ & 0,150 \\
0,900 & $-0,047$ & 0,068 & $-0,009$ & 0,428 & $-0,140$ & 0,158 \\
1,000 & $-0,100$ & 0,046 & $-0,057$ & 0,533 & $-0,200$ & 0,166 \\
1,100 & $-0,152$ & $0,023-0,104$ & 0,655 & $-0,260$ & 0,175 \\
1,200 & $-0,204$ & 0,000 & $-0,151$ & 0,798 & $-0,320$ & 0,183 \\
& & & & & & \\
\hline
\end{tabular}

Tabela 2. Valores das rendas.

\begin{tabular}{lrrr}
\hline TX. lucro & $R(1,2)$ & $R(1,3)$ & $R(2,3)$ \\
\hline 0,000 & 0,683 & 0,050 & 0,430 \\
0,050 & 0,639 & 0,055 & 0,396 \\
0,200 & 0,483 & 0,072 & 0,295 \\
0,400 & 0,211 & 0,098 & 0,153 \\
0,600 & $-0,152$ & 0,128 & 0,004 \\
0,800 & $-0,632$ & 0,162 & $-0,150$ \\
0,900 & $-0,927$ & 0,180 & $-0,231$ \\
1,000 & $-1,266$ & 0,200 & $-0,313$ \\
1,100 & $-1,656$ & 0,220 & $-0,397$ \\
1,200 & $-2,106$ & 0,242 & $-0,482$ \\
\hline
\end{tabular}


SOLUÇOES DO SISTEMA ECONOMICO - SECYAO 4.3.5.5

Tabela 3. Valores dos preqos - mercadoria "a".

Tx. lucro pa(1) pa(2) pa(3) pa(1,2) pa(1,3) pa(2,3)

$\begin{array}{lllllll}0,000 & 0,533 & 0,362 & 0,541 & 0,077 & 0,500 & 0,183 \\ 0,050 & 0,511 & 0,357 & 0,520 & 0,091 & 0,475 & 0,192 \\ 0,200 & 0,445 & 0,340 & 0,458 & 0,142 & 0,400 & 0,220 \\ 0,400 & 0,357 & 0,318 & 0,376 & 0,233 & 0,300 & 0,256 \\ 0,600 & 0,271 & 0,259 & 0,296 & 0,355 & 0,200 & 0,293 \\ 0,800 & 0,185 & 0,271 & 0,219 & 0,518 & 0,100 & 0,330 \\ 0,900 & 0,142 & 0,258 & 0,180 & 0,618 & 0,050 & 0,348 \\ 1,000 & 0,100 & 0,246 & 0,142 & 0,733 & 0,000 & 0,366 \\ 1,100 & 0,057 & 0,233 & 0,105 & 0,865 & -0,050 & 0,385 \\ 1,200 & 0,015 & 0,220 & 0,068 & 1,018 & -0,100 & 0,403\end{array}$

Tabela 4. Valores dos preços - mercadoria "b".

$\mathrm{Tx}$. Iucro $\mathrm{pb}(1) \quad \mathrm{pb}(2) \quad \mathrm{pb}(3) \quad \mathrm{pb}(1,2) \quad \mathrm{pb}(1,3) \quad \mathrm{pb}(2,3)$

\begin{tabular}{lllllll}
\hline 0,000 & 1,003 & 0,862 & 1,041 & 0,577 & 1,000 & 0,683 \\
0,050 & 1,036 & 0,882 & 1,045 & 0,616 & 1,000 & 0,717 \\
0,200 & 1,045 & 0,940 & 1,058 & 0,742 & 1,000 & 0,820 \\
0,400 & 1,057 & 1,018 & 1,076 & 0,933 & 1,000 & 0,956 \\
0,600 & 1,071 & 1,095 & 1,096 & 1,155 & 1,000 & 1,093 \\
0,800 & 1,085 & 1,171 & 1,119 & 1,418 & 1,000 & 1,230 \\
0,900 & 1,092 & 1,208 & 1,130 & 1,568 & 1,000 & 1,298 \\
1,000 & 1,100 & 1,246 & 1,142 & 1,733 & 1,000 & 1,366 \\
1,100 & 1,107 & 1,283 & 1,155 & 1,915 & 1,000 & 1,435 \\
1,200 & 1,115 & 1,320 & 1,168 & 2,118 & 1,000 & 1,503 \\
\hline
\end{tabular}


1,0. Se, agora, substituirmos esses valores na equação do metodo 2 , teremos:

$$
(0,1 * 0,4+0,1 * 1+0,3) *(1,2)+2,2 * 0,28+1 * 0,072=1,216
$$

- que mostra que o metodo 2 não serd introduzido, se os metodos 1 e 3 estiverem sendo utilizados conjuntamente. Por outro lado, se imputarmos as solucões do sistema em que o cereal e cultivado conjuntamente pelos metodos 1 e 2 na equação do metodo 3, veremos que, tambem, esse metodo não serd introduzido. Haverd, portanto, duas solucões de equilibrio e, novamente, qual serd a solucão adotada e uma questão a ser respondida por informą̧óes exogenas ao modelo. Haverd, desta vez, um conflito distributivo entre trabalhadores e proprietarios de terras (ou capitalistas, se não houver separacão de classes entre esses e os proprietarios de terras), na disputa por uma parte maior do produto Ilquido da economia, uma vez que a solução que corresponde a uma maior taxa de salârio, corresponde, simultaneamente, a uma menor taxa de renda, e vice-versa.

Por fim, procedendo da mesma forma, pode-se verificar que, para valores de $r$ maiores que 0,47 (aprox.), não havera solução de equilfbrio, no sentido de que, sempre (para os metodos que atendem à demanda final) o cultivo de cereal com um metodo (ou com uma combinação de metodos) 
forçard a introducão de um novo metodo.

Podemos, portanto, concluir que a fronteira tecnologica desta economia corresponde à curva $W-A-B$, em negrito na Fig. 4.20. A multiplicidade de solucões deriva, inicialmente, da existência de uma relação $w-r$ crescente .

4.4. Alguns desenvolvimentos do modelo sraffiano da renda da terra

4.4.1. Introdução

Ate aqui, consideramos o modelo sraffiano da renda da terra apresentado em SRAFFA(1983) e aprimorado pelos trabalhos mencionados ao longo do texto. Esse modelo, na sua forma original, trata da renda da terra no caso em que se considera diferentes qualidades de terras (renda extensiva) e no caso em que ha uma unica qualidade de terra e varios metodos de produção do cereal (renda intensiva).

Os modelos até aqui desenvolvidos apresentam 56 caracteristicas essencialmente estaticas . Entretanto, alguns trabalhos têm sido desenvolvidos analisando o problema da renda da terra sob uma perspectiva dinâmica, considerando aspectos correlatos à acumulação de capital e à mudanca tecnologica. Veja, sobre isso, QUADRIOCURZIO $(1975,1986)$. 
Alem disso, jt comentamos que em SALVADORI (1986) encontra-se uma formalizacão matematica dos modelos acima considerados, englobando os casos de renda extensiva e intensiva no mesmo modelo, alem de formalizar os calculos das quantidades, ate então considerados apenas implicitamente nos modelos (quando dizemos que a producão pelo metodo " $x$ " - ou na terra " $x$ " - não atendem a demanda). Alem de mostrar a formalização matematica de um modelo geral, o autor desenvolve a demonstracão de um algoritmo que poderia solucionar o modelo, sob determinadas hipoteses. Acreditamos que um exemplo numerico poderia esclarescer melhor a questão.

Finalmente, devemos salientar que o modelo sraffiano da renda da terra pode analisar o problema da renda da terra, quando mais de uma mercadoria agrlcola e produzida. o proprio sraffa tece alguns comentarios introdutorios a esse respeito, em seu curto cap1tulo sobre a terra. Tambem em SALVADORI(1986) encontramos alguns comentarios a esse respeito. Veja 0 trabalho de D'AGATA (1983b), para um tratamento desse tema especifico, para o modelo da renda extensiva.

\subsubsection{A renda singular}

o artigo de SALVADORI(1983) considera um novo tipo de renda, que o autor denominou de renda singular. 
Essa renda surgiria em um modelo onde ha so uma qualidade de terra e só um metodo de produção do cereal, quando toda a terra disponfvel e cultivada. Portanto, um caso bastante particular. Nesse caso, o problema da escolha de tecnicas, ate aqui sempre presente, deixa de existir.

Nesse modelo, o autor considera, explicitamente, que o vetor que compõe a demanda final não e um vetor de quantidades fixas. Diferentemente do que tem sido considerado até então, assume-se que as classes sociais (trabalhadores, capitalistas e proprietarios de terras) não consomem as mesmas mercadorias, nas mesmas proporcões. Assim sendo, quando varia a distribuição de renda, tambem varia o vetor de demanda final.

Alem disso, no modelo da renda singular não mais se requer que o numero de processos produtivos seja igual à soma do numero de mercadorias produzidas e do numero de qualidades de terra que pagam renda, como ocorria ate então.

A solução do modelo e obtida quando se considera, alem das equacões de producão e das restricões de disponibilidade de terra e trabalho (que tambem ate então não foram formalmente consideradas), as hipoteses quanto ao consumo das mercadorias pelas diferentes classes sociais, que compõem o vetor de demanda final. Finalmente, hd que se acrescentar uma restrição que determina que a renda serd positiva apenas quando toda a terra for 
cultivada.

Evidentemente, estabelecer-se-ão conflitos distributivos entre as três classes, conforme a hipotese quanto ao consumo das mercadorias e a escassez da terra. Assim, por exemplo, se partirmos da hipotese de que o cereal e consumido apenas pelos trabalhadores e a mercadoria industrial e consumida pelos capitalistas e proprietarios da terra, quando a terra e totalmente cultivada, o conflito distributivo dar-se-d entre capitalistas e proprietarios da terra. Isto porque a produção do cereal estara determinada, determinando a taxa de salario (uma vez que assume-se que todo o produto Ilquido e consumido), e deixando o conflito entre capitalistas e proprietarios de terras, por um maior consumo da mercadoria industrial.

Ainda nesse exemplo, no caso em que a terra não for escassa (com renda igual a zero), o conflito passa a se dar entre trabalhadores e capitalistas, uma vez que uma maior producão de cereal (levando a uma maior taxa de saldrio) implicard em uma menor producão da mercadoria industrial ( $j$ d que ha uma restrição de disponibilidade de trabalho), redundando em menor consumo capitalista.

Ao considerarmos outras hipotese quanto à composição do consumo das mercadorias pelas diferentes classes sociais, teremos outras soluções e outros conflitos distributivos. 
A formalizacão matematica do modelo da renda singular permite concluir que, se as classes sociais consomem mercadorias em proporções diferentes, uma mudança na distribuição de renda alterara a composição da demanda final. Como consequência, se a terra escassa, uma nova restrição, relacionando a composicão da demanda final e as variàveis econômicas, deve ser introduzida, a fim de solucionarmos o sistema.

Por outro lado, se as classes sociais consomem as mercadorias em proporções fixas ou, de maneira mais restrita, se o vetor de demanda final e invaridvel frente às mudanças na distribuição do excedente econômico, preços e renda da terra tornam-se indeterminados e, de fato, variam dentro de uma dada faixa, neste modelo.

Finalmente, gostartamos de observar que 0 modelo da renda singular contempla, tambem, casos de multiplicidade de soluções, tanto para a taxa de salario como dado exogeno, como para taxa de lucro exogena.

4.4.3. A renda intensiva externa

Se considerarmos um sistema onde a mercadoria industrial possa ser produzida atraves de dois metodos de producão e o cereal produzido em terras de diferentes qualidades, poder surgir uma nova variedade de renda, ate então não considerada: a renda intensiva externa. Neste 
caso, a escolha de tecnicas tambem ocorrerd para a mercadoria industrial, um caso ainda não considerado neste texto.

Assim sendo, suponhamos que existam dois processos para produzir a mercadoria industrial (os processos 1 e 2 ), sendo que o processo 2 utiliza, na sua producão, menos cereal por unidade produzida (em relação ao processo 1). Suponhamos, ainda, que existam dois processos de produção do cereal (os processos I e II), em terras de diferentes qualidades. Teremos, então, quatro relacões $w-r$ no caso em que não hâ renda da terra. Suponhamos, finalmente, que à uma dada taxa de lucro, exogenamente determinada, obtenhamos as seguintes taxas de saldrios nas diferentes curvas, com renda igual a zero:

$$
\mathrm{w}(1, I)>\mathrm{w}(2, I)>\mathrm{w}(2, I I)>\mathrm{w}(1, I I)
$$

ou seja, a maior taxa de salário e obtida pela operação dos processos 1 (industrial) e I (agrlcola), e a menor taxa de saldrio el obtida pela operação dos processos 1 (industrial) e II (agricola).

Se a demanda final (que e um vetor de quantidades fixas do produto l1quido, por hipotese) não puder ser atendida pela operação dos processos 1 e I, sozinhos, surgira a seguinte complicação: nem os processos $(2, I)$, nem, tampouco, os processos $(2, I I)$ poderão ser 
operados, uma vez que, aos precos assim determinados ( $w=$ $w(2, I), \quad e w=w(2, I I))$, o processo 1 serd mais eficiente, sendo introduzido. A economia tambem não poderd operar com os processos $(1, I, I I)$, pagando renda na terra $I$, porque, aos precos assim determinados $(\mathrm{W}=\mathrm{W}(1, \mathrm{II}))$, o processo 2 sera introduzido, por ser mais eficiente. A unica solucão possivel serd operar a economia com os processos $(1,2, I)$, pagando uma renda intensiva na terra $I$, de forma que a producão na terra II seja ineficiente, aos precos assim determinados. Nesse caso, a introdução do processo 2 ( que e, por hipotese, menos intensivo na utilização de cereal) ao lado do processo 1 , reduziu a demanda final por cereal, possibilitando que a produção ocorresse, exclusivamente, na terra I. A essa nova variedade de renda, denominou-se de renda intensiva externa. 
NOTAS

(1) Em particular, um meio de producão não produzido. 0 que the faculta certas peculiaridades $e$, consequentemente, um estudo em separado. QUADRIO-CURZIO(1980) argumenta que a terra representaria os demais "non-produced means of production".

(2) O termo "fertility" tem sido muito usado na literatura sobre o assunto para expressar a rentabilidade (ou lucratividade) da producão agricola em uma determinada terra. Como o termo "fertilidade" tem uma conotacão, digamos, "flsica" (edafologica), seu uso no sentido acima referido tem causado algumas controversias de interpretacão de um fenômeno essencialmente econômico. Cf. CANDELA (1978) e VIDONNE $(1977,1978)$ sobre essa controversia, quanto à interpretacão do pensamento ricardiano sobre a renda da terra. Na verdade, acreditamos que o melhor termo para se referir a este fenômeno econômico seja eficiência, termo usado por QUADRIO-CURZIO(1980). Isto porque os termos "rentabilidade" e "lucratividade" seriam confundidos com renda e lucros, sendo que uma terra mais eficiente pode gerar lucro e renda da terra. Por outro lado, o termo "qualidade da terra" deve, em nossa opinião, ser reservado para expressar caractertsticas edafoclimaticas (e/ou de localizacão, como veremos adiante). Por esta razão, referimo-nos à eficiência de uma técnica, no capttulo anterior (e não à lucratividade de uma tecnica, como aparece em PASINETTI(1977)) .

(3) Cf. SRAFFA(1983, cap. XI).

(4) 0 trabalho pioneiro foi 0 de QUADRIO-CURzIO, A. "Rendita e distribuzione in un modello economico pIurisettoriale" Giuffre:Milano,1967. Náo tivemos acesso a esse trabalho. Os demais trabalhos serão citados ao longo deste capltulo.

(5) Cf. QUADRIO-CURZIO (1987, pp. 120-1)

(6) Neste texto serão consideradas apenas as teorias ricardiana e marxista, uma vez que os desenvolvimentos marginalistas do tema seguem uma linha microeconômica, alheia à abordagem classica dos problemas econômicos, retomada por sraffa.

(7) O termo "qualidade" da terra envolve, como comentamos na NOTA 2, aspectos edafoclimaticos e de localização em relacão aos mercados de insumos e produtos. Desta forma, uma terra de otimas condições edafoclimaticas, pode ser de mesma qualidade que outra com condicóes edafoclimaticas menos favoráveis, mas mais próxima ao mercado. Observe-se que estamos ampliando o sentido "fisico" do termo "qualidade", englobando as condicões climaticas da região onde essa terra se encontra. Assim sendo, uma terra 
edafologicamente fertil, pode não ser de boa qualidade se - clima da região não for favordvel ao cultivo.

(8) O termo "capital" não e adequado quando nos referimos ao sistema econômico sraffiano, como comentamos no capltulo anterior. Neste contexto, o termo resume a expressão "valor dos meios de produção", que são totalmente utilizados no processo produtivo.

(9) Cf. SALVADORI (1986) para a formalização matematica de um modelo completo, para determinação de preços e quantidades, assumindo mais de uma mercadoria agricola, mais de um processo para a producão de cada mercadoria industrial, alem de incluir os dois tipos de renda, indiscriminadamente, no mesmo modelo. o autor demonstra, ainda, um teorema que soluciona este modelo, sob certas hipoteses.

(10) Ha uma discussão em LIPIETZ(1978) sobre o fato de o termo $R(i) . T(i)$ não ser multiplicado por $(1+r)$. LIPIETZ(1978) argumenta que isso causaria uma inconsistência no modelo de sraffa quanto a situacão da terra como meio de produção ou "parâmetro de reparticão". Pensamos que, qualquer que seja a formulacão, a terra (assim como o trabalho) corresponde, simultaneamente, à meio de producão e a "parâmetro de repartição". A formulação de Sraffa apenas implica que a renda é paga no final do processo produtivo.

(11) Cf. discussão sobre este aspecto no cap1tulo anterior. Posteriormente tomaremos a taxa de lucro como um dado exogeno, para analisarmos outros aspectos do problema. (12) Esta equação e dada por $\mathrm{R}(1) * \mathrm{R}(2) * \ldots * \mathrm{R}(\mathrm{H})=0$, com apenas um $R(i)=0$.

(13) Se, por um acaso, essa demanda por cereal so puder ser atendida com o cultivo de toda drea de terras disponlveis (inclusive a terra marginal), então o numero de processos operados menor do que a soma das mercadorias e qualidades de terra que pagam renda. Neste caso, precos, rendas e taxa de lucro não podem ser completamente determinados, variando dentro de uma dada faixa limitada. Cria-se, nesté caso, um novo grau de liberdade para relacionarmos a "renda de monopolio" na terra marginal, ao excesso de demanda.

(14) Aqui ja e possivel verificar que a determinação da taxa de lucro envolve todos os setores da economia (menos aqueles que não produzem mercadorias bdsicas), em contraste com a teoria ricardiana que considera a taxa de lucro determinada no setor agricola, e em contraste com a teoria de Marx que considera a mesma determinada no setor industrial.

(15) A demonstracão el extra1da de MONTANI (1972, pp. 226-7). (16) Basta observarmos que a producão de cereal em terra de menor eficiência (ou com um metodo menos eficiente, como veremos no caso da renda intensiva), tornard o cereal mais caro, relativamente as mercadorias industriais (jd que nada 
ocorreu, por hipotese, na producão destas, que as produzissem menos eficientemente).

(17) Aqui est implicito que a terra e propriedade privada. LIPIETz(1978) enfatiza o fato de que a renda da terra no modelo sraffiano apenas se relacionaria com o fato de a terra ser escassa, não se considerando a importância do fato de que ela deva ser de propriedade privada. Pensamos que esse tipo de crltica não tem sentido, uma vez que esse tipo de questão ja foi considerada por Marx, de forma explicita. Não se pode argumentar que a propriedade da terra \& mais importante para explicar a renda do que a escassez. Ambas são igualmente importantes. Sraffa apenas deixa impllcito um fato ja considerado por Marx.

(18) Estas considerą̧̃es baseiam-se em QUADRIO-CURZIO (1980, pp. $230-2)$. Se e verdade que a agricultura perde importância com o desenvolvimento econômico, e discutivel que esta perda seja tão grande se incluirmos o setor agroindustrial dentro do conceito de setor agrlcola.

(19) Essa seção baseia-se, essencialmente, em MONTANI (1975, pp. 71-4). O termo "mudancas autônomas" na distribuição e usado por QUADRIO-CURZIO $(1980,1987)$, para designar as mudancas na distribuicão do excedente econômico (valor do produto Ilquido, ou renda nacional, se o sistema econômico representar uma nação) entre lucros e salários, de forma exogena ao modelo. A partir daqui, a teoria sraffiana da renda extensiva passa a considerar um contexto diferente de Ricardo e Marx, acrescentando elementos à teoria da renda da terra, ao partir para uma abordagem alternativa para a distribuição da renda.

(20) Jd que no sistema econômico sraffiano não hà equações de demanda (veja capltulo anterior, sobre este aspecto), estuda-se a determinacão de preços e varidveís distributivas, para cada diferente vetor de quantidades produzidas.

(21) Neste momento e oportuno salientar que o conceito de escassez de um recurso (a terra, no caso), refere-se à abordagem classica de considerar a escassez frente às necessidades globais da economia, divergindo, portanto, da abordagem neoclassica de considerar a escassez frente à proporq̣ão dos fatores de produção. Cf. MONTANI(1975, pp $68-9)$.

(22) Esse exemplo numerico, assim como os graficos, encontram-se, originalmente, em MONTANI(1975, pp. 93-5). (23) Cf. GAREGNANI(1970, pp.407-36) para discussão deste aspecto, detalhadamente. Esse trabalho e tambem um dos que compõem a CONTROVERSIA DE CAMBRIDGE.

(24) Na verdade, a maior taxa de salario devera ser menor que 10,48 pois, neste caso, a taxa de lucro anular-se-ia, não havendo capitalista interessado em aplicar seu capital na producão das mercadorias. A maior taxa de salario possivel dependerd, portanto, da menor taxa de lucro 
"aceitavel" pelos capitalistas. Por outro lado, se admitirmos que a parte de subsistência do saldrio esta inclula nos coeficientes tecnicos das equacões de producão, efetivamente, a maior taxa de lucro posstvel corresponderd ao ponto em que $w=0$.

(25) Como estamos considerando um modelo de determinacão da renda diferencial, não podemos pressupor (como faz MONTANI(1975)) que haja separaça de classes entre capitalistas e proprietarios de terras, uma vez que sempre haverd uma terra parcialmente cultivada, sem o pagamento de um renda. Neste caso, a terra marginal so seria cultivada se o seus proprietarios investissem seus capitais nas proprias terras, obtendo a taxa de lucro vigente na economia.

(26) A propósito deste aspecto, CANDELA(1978) defende o pensamento ricardiano, ao mostrar que a mudança na distribuicão da renda so altera a ordem de "fertilidade" (no sentido de eficiência econômica) das terras, quando não for posstvel ordend-las no sentido flsico. Quando a ordenacão em bases "flsicas" e posslvel, mostra CANDELA (1978), as curvas $w-r$ não se interceptam, caindo no caso classico (Ricardo $e$ Marx) onde a mudanca na distribuição não altera a ordem de eficiência das terras. (27) Veja, no capltulo anterior, quando nos referimos aos deslocamentos dos metodos de produçấo (escolha de tecnica), - conceito de fronteira tecnologica em um sistema econômico sraffiano.

(28) Devemos ressaltar, aqui, que a andlise que procedemos refere-se, meramente, à andlise de deslocamentos dos metodos de produção, introduzida no cap1tulo anterior. Assim sendo, $o$ ponto $r=0,7$ refere-se a um ponto de mudanca de técnica. Veremos, adiante, que no caso da renda intensiva, a andlise torna-se um pouco mais complicada, às vezes requerendo calculos para determinarmos a fronteira tecnologica.

(29) Os exemplos numericos dessa seção e da seguinte foram originalmente desenvolvidos por nós.

(30) Não colocamos as expressões literais desse exemplo por acharmos desnecessario, jà que $o$ procedimento para obtê-las ja foi descrito anteriormente.

(31) A partir da teoria ricardiana da renda intensiva, os marginalistas (principalmente atraves de wicksteed) desenvolveram a teoria neoclássica da distribuicão. Segundo QUADRIO-CURZIO(1987, p. 119) o caso da renda extensiva foi negligenciado pelos neoclassicos, porque não requer, necessariamente, variacão na proporcão dos fatores de produção.

(32) Aqui, por outro lado, a teoria marginalista tambem parece mais explicita quanto a esse aspecto, ao considerar a construcão da funcão de produção a partir de experimentos com doses crescentes em talhões diferentes de uma mesma 
qualidade de terra.

(33) Esta seção, assim como as seguintes (quando não houver outra observacão), baseia-se nos trabalhos de KURZ (1980) e MONTANI (1972,1975).

(34) Como afirma SRAFFA (1983, p.238), "se toda a terra e de mesma qualidade e sua oferta e escassa, isso torna posstvel que dois processos ou metodos diferentes de cultivo sejam utilizados coerentemente, lado a lado, em terras similares, determinando uma renda uniforme por acre".

(35) A Fig. 4.9 baseia-se no exemplo numerico discutido na seção 4.3 .5 .2 .

(36) No caso em que o cereal for uma mercadoria basica, em geral, não mais teremos uma reta (a menos que tomemos a taxa de salario como numerario, como faz D'AGATA(1983a)), tambem poderemos obter uma reta dependendo dos coeficientes tecnicos do modelo)

(37) Isso não invalida o racioclnio apresentado, pois podera exisitir (ou serd produzido pela pesquisa cient1fica) um quarto metodo com producão por unidade de area ainda maior, porem com maior custo medio. $\mathbf{E}$, na verdade, 0 que acontece frequentemente na pratica. A teoria sraffiana ressalta, outrossim, que o custo de producão e uma variłvel que assume valores diferentes quando muda a distribuição de renda entre lucros e salarios.

(38) Veja em KURZ(1980) e MONTANI(1972) a determinação do custo medio $e$ a andise do crescimento intensivo da produção agricola para o caso de o cereal ser uma mercadoria básica. Analisaremos esse processo, adiante, quando nos referirmos às curvas $w-r$.

(39) Essa figura baseia-se em KURZ(1980, pp. 29). Cf. MONTANI(1972, pp. 233-5) para um outro tratamento, desse mesmo aspecto.

(40) Esta seção, em particular, baseia-se em MONTANI (1975, pp. 80-93), essencialmente.

(41) Fazemos essa hipotese para analisarmos o surgimento da renda intensiva. ou seja, veremos que a renda serd positiva se a produção do cereal for mais eficiente pelo metodo 1 , que não atende a demanda, tornando necessaría a introdução do metodo 2 lado a lado com o metodo 1 .

(42) As Figs. 4.12 e 4.13 mostram um caso possivel. Na verdade, 0 caso que pretendemos discutir. observe-se que 0 coeficiente angular das funcões representadas na Fig. 4.13 reflete a comparação entre as intensidades relativas de "capital" e trabalho dos metodos agricolas frente ao metodo industrial (algo como o conceito marxista de "composicão orgânica do capital"). De acordo com a Fig 4.13, o metodo 2 e mais intensivo em "capital" do que o metodo industrial. Este, por sua vez, e mais intensivo do que o metodo 1 , pois a reta $e$ decrescente. Assim sendo, elaro que o aumento em $r$ aumenta o custo de producão do metodo 2 , ao mesmo 
tempo que diminui o custo de producão do metodo 1. o exemplo numerico que baseia essas figuras foram desenvolvidos por nos.

(43) Se os capitalistas tentarem introduzir o metodo 1 , a terra tornar-se-d escassa, possibilitando a obtenção de uma mesma taxa de renda que o cultivo com o metodo 2 apenas se venderem o cereal a uma preco superior (o que não e compativel com a pressuposicão de competicão, vigente na economia). Matematicamente terlamos:

$C(1) / Z(1)+[T(1) / Z(1)] R=p z \quad e$

$C(2) / Z(2)+[T(2) / Z(2)] R=p z$

como $C(1) / Z(1)=C(2) / Z(2)$ e $Z(2) / T(2)>Z(1) / T(1)$ (o que implica que $T(2) / Z(2)<T(1) / Z(1))$. Para um mesmo $R$, precisarlamos ter um pz maior na primeira equacão; o que não el aceitâvel.

(44) Cf. MONTANI (1975) para a obtenção das relações $w-r$ e $R-r$, em termos literais, partindo do sistema discutido nesta seção.

(45) Poderlamos fazer a mesma andlise tomando a taxa de salario como um dado exogeno (como faz Montani). Neste caso, no entanto, e indiferente tomarmos $w$ ou $r$ como dados exogenos. Logo a seguir mostraremos que, conforme se tome uma ou outra, as conclusões não mais serão as mesmas.

(46) Veja em MONTANI(1975, p.88) outro caso posstvel, quando $R$ cresce para valores crescentes de $r$. 0 autor mostra, inclusive, exemplos numericos. As Fig. 4.19 e 4.20 referm-se a um exemplo numerico de MONTANI (1975, apêndice, exemplo 2). Ainda, 0 fato de o cereal náo ser uma mercadoria básica não afeta as principais conclusões que extralmos deste caso simplificado. Adiante trataremos de um modelo mais completo, quando poderão surgir algumas complicações.

(47) Novamente, esse exemplo numerico foi desenvolvido por nos. Cf. MONTANI(1975, pp.89-93). Veja o exemplo 5 , no apêndice desse trabalho, para um outro exemplo numerico. $\mathbf{E}$ oportuno salientarmos que e possivel obter uma relacão $\mathrm{w}-\mathrm{r}$ crescente (para a operação conjunta dos dois metodos), para - caso de o cereal ser uma mercadoria não-básica.

(48) Quando o cereal passa a ser uma mercadoria bdsica, devemos obter o produto 11 quido resultante do cultivo da terra com cada um metodos para verificarmos qual o metodo "e mais produtivo" para o atendimento da demanda 11quida por cereal. Para obtermos essa ordenação deveremos lançar mão da construção de subsistemas, a partir do sistema inicial com cada um dos metodos individualmente, que produzem apenas o cereal. Cf. SRAFFA (1983, apêndice Á). (49) No entanto, se não houver separação de classes entre capitalistas e proprietarios de terras, o conflito 
dar-se-d entre os capitalistas agricolas e os capitalistas industriais, uma vez que, enquanto estes buscarão uma maior taxa de lucro, aqueles desejarão uma maior renda da terra. (50) Tambem esse exemplo numerico foi desenvolvido por nos. (51) Na verdade, mesmo nesse caso poderemos obter uma reta, dependendo dos coeficientes tecnicos escolhidos (embora, em geral, a relação seja uma curva), como ja comentamos.

(52) Esta seção baseia-se em D'AGATA (1983a).

(53) Trata-se do exemplo 2 do artigo de D'agata.

(54) Na verdade, esta-se definindo (explicitamente) o vetor de demanda final e a trea de terra disponivel, para podermos determinar, atraves de calculos, quais os metodos que atendem a esses requisitos (o que ate então foi feito implicitamente). Veja no APENDICE - Sobre o calculo das quantidades, ao final dessas NOTAS, quais os calculos que devemos proceder para obter as combinacões de metodos que atendem àqueles requisitos, selecionando-se as relacões $w-r$ das combinacōes que poderão constituir a fronteira tecnologica.

(55) Cf. D'AGATA(1983a) para um exemplo em que ha três posstveis soluções de equillbrio, para um dado intervalo de $r$ Veja, tambem, explicação alternativa que 0 autor utiliza para esclarescer os fenômenos que discutimos. Em outro trabalho (Veja D'AGATA (1983b)), o autor mostra que esses mesmos fenômenos podem ocorrer no caso de renda extensiva, quando hd mais de uma mercadoria agricola.

(56) Com as ressalvas apresentadas por POSSAS (1982), conforme ja havlamos comentado.

(57) Cf. SALVADORI (1983, pp. 82-4) para outros exemplos de mudanca na composicão da demanda final e os efeitos na determinacão das variaveis econômicas. 0 autor tambem mostra a formalização matematica do modelo da renda singular.

(58) Esta seção baseia-se em SALVADORI(1986, pp. 97-8). De fato, a apresentação de salvadori trata-se de um resumo do tema. Apesar de acreditarmos que esse resumo é suficiente para entendermos 0 aparecimento da renda intensiva externa, $e$ conveniente que o leitor interessado dirija-se aos seguintes trabalhos, que trataram originalmente do assunto: 1) Abraham-Fois G.,Berrebi,E. "Rentes Rarete Superprofit", Economica, Paris,1980. 2) Saucier, $P$. "Le choix des techniques en situation de limitations de ressources",mimeo, Paris II, 1981 . Estes trabalhos, que não tivemos acesso, foram citados no artigo de SALVADORI (1983). 
APENDICE- Sobre o calculo das quantidades

Mostraremos, neste apêndice, por que, no exemplo citado na seção 4.3.5.5 desse texto, a economia não poderá ser operada com o cultivo do cereal com o metodo 3, isoladamente. Este exemplo servird para mostrar o procedimento geral que se deve percorrer para que determinemos quais subsistemas (combinacão de metodos de um sistema, relacionado às curvas $w-r$ ) serão vidveis, no sentido de atendimento de um dado vetor de demanda final por parte de cada subsistema (respeitando a restricão de area dispon (vel).

Em primeiro lugar, devemos obter a matriz de coeficientes tecnicos do subsistemas que desejamos. No exemplo, esta matriz e dada por:

$$
A=\left[\begin{array}{lll}
0,0 & 0,0 & 0,1 \\
0,0 & 0,0 & 0,6 \\
0,1 & 0,1 & 0,4
\end{array}\right]
$$

Para solucionarmos o problema pela equacão de Leontief $\left(x=(I-A)^{-1} \cdot y\right.$, onde $x$ \& vetor de intensidades dos processos, I a matriz identidade, A a matriz tecnologica e $y$ e o vetor de demanda final) deveremos transpor a matriz A, acima, uma vez que as equações do sistema sraffiano são definidas de forma "inversa" às 
equações do sistema de Leontief. Ou seja, a matriz tecnologica de Leontief corresponde a $A^{\prime}$ (a transposta de A). Assim sendo,

$$
A^{\prime}=\left[\begin{array}{lll}
0,0 & 0,0 & 0,1 \\
0,0 & 0,0 & 0,1 \\
0,1 & 0,6 & 0,4
\end{array}\right] \quad e^{\prime}
$$

então, apos alguns calculos, obteremos:

$x=1,8868 \cdot\left[\begin{array}{lll}0,54 & 0,06 & 0,10 \\ 0,01 & 0,59 & 0,10 \\ 0,10 & 0,60 & 1,00\end{array}\right] \cdot\left[\begin{array}{c}90,0 \\ 60,0 \\ 19,0\end{array}\right]$

ou seja, $x=\left(I-A^{\prime}\right)^{-1} \cdot y \cdot$ Portanto,

$$
x=\left[\begin{array}{l}
102,07 \\
72,07 \\
120,75
\end{array}\right] \text {, }
$$

valores que representam, respectivamente, os nlveis de atividade dos processos produtivos do ferro, carvão e cereal (c/ metodo 3, exclusivamente). Portanto, seriam necessarios 120,75 ha de terra, para atender a demanda de cereal. Como so estão disponlveis 100 ha, por hipotese, este subsistema (cereal produzido exclusivamente com metodo 
3), não e viável e, portanto, sua relação $\mathrm{w}-\mathrm{r}$ e exclulda, "a priori", da posterior obtenção da fronteira tecnologica. 
5- UMA SINTESE

Pretendemos concluir este trabalho listando os principais aspectos em que a teoria sraffiana difere das teorias anteriores, ressaltando a evolucão que aquela teoria representaria no corpo da teoria da renda da terra. Alem disso, salientaremos algumas de suas posstveis limitacões e sugeriremos posstveis trabalhos que deêm continuidade a essa teoria. Passemos, pois, a essa sintese, enumerando os principais aspectos.

1. A teoria sraffiana da renda da terra, ao formalizar matematicamente o pensamento ricardiano, evidenciou algumas deficiências da teoria ricardiana e contribuiu para o esclarecimento de questões não colocadas pela teoria ricardiana, como a explicacão da renda de monopolio. As deficiências referem-se, principalmente, à constatação de uma posstvel inversão na ordem de eficiência das terras, de forma que não e legltimo considerar, irrestritamente, uma ordem naturalmente determinada para a "fertilidade" das terras. Tambem quanto à poss1vel inversão na ordem de rentabilidade das terras, quando muda a distribuicão da 
renda entre lucros e salarios (ou com a incorporação de uma terra menos eficiente). Alem disso, a presenca de um modelo formalizado permite andises mais precisas do progresso tecnico na agricultura, sendo essa, aliás, uma possivel linha de pesquisa dentro da teoria sraffiana da renda da terra (atraves de simulaçóes de valores para os coeficientes tecnicos). Assim como a teoria marxista, a teoria sraffiana da renda da terra pode explicar o surgimento da renda em várias situações, enquanto a andlise ricardina e por demais restrita.

2. A teoria sraffiana parte de uma abordagem alternativa do problema da distribuicão da renda, recusando a andlise classica de manter o salario ao nlvel de subsistência e aproximando-se mais do caso real que contempla o conflito distributivo permanentemente presente na sociedade capitalista. Assim fazendo, a teoria sraffiana da renda da terra permite a andlise das diferentes posstveis solucões de preços e de renda da terra, frente a constantes mudanças nas varidveis distributivas ( $w$ e $r$ ). Assim sendo, foi posslvel concluir que a terra marginal não e obtida considerando-se apenas a demanda pelo cereal e as produtividades (e disponibilidades) das terras em cultivo mas, tambem, considerando-se as mudanças na distribuicão de renda. E este aspecto, no modelo de renda intensiva, evidenciou que a escassez de uma unica qualidade de terra 
tambem e função da distribuicão de renda.

3. A critica (pertinente) de FLICHMAN(1977) quanto à conceituação da renda diferencial I em Marx (ou, apenas renda diferencial em Ricardo) no que concerne à exigência de que iguais capitais apliquem-se em terras desiguais (par explicar essa renda), não se aplica ao modelo sraffiano de renda extensiva. Isso porque, como vimos, essa teoria não requer que iguais capitais apliquem-se em terras desiguais, para explicar o surgimento da renda diferencial extensiva. A teoria sraffiana parte, simplesmente, das equacões de producão do cereal nos diferentes tipos de terra, que correspondem, por hipotese, a "doses" otimas de "capitais" aplicados em cada terra, como recomenda FLICHMAN(1977).

4. No que se refere à andlise do processo de crescimento intensivo da produção agrlcola, acreditamos que o modelo da renda intensiva da teoria sraffiana e superior (quanto à sua consistência logica) às considerações de Ricardo e Marx. Em primeiro lugar, porque a teoria sraffiana torna explicito (ao considerar as diferentes equacões que correspondem aos metodos de cultivo do cereal sobre a mesma qualidade de terra) 0 fato de que esses diferentes "capitais" aplicam-se em "talhões" diferentes da mesma qualidade de terra. Como vimos, as andlises ricardiana e marxista consideravam esse aspecto, no maximo, 
implicitamente. Na verdade, pareciam tratar de acrescimos dessas "doses" de capitais sobre a mesma area. Se abstrairmos (como fazemos frequentemente em modelos teoricos) e considerarmos que existe um unico hectare de terra disponfvel para o cultivo, e acrescentarmos "doses" de capitais a esse hectare, não poderemos explicar o surgimento de renda, simplesmente dizendo que as "doses" marginais têm menor produtividade e as primeiras "doses" receberiam uma renda devido à maior produtividade. Por outro lado, vimos que as considerações de Marx sobre a renda diferencial II não são compatlveis com condicões de equiltbrio, embora sejam compatlveis com casos reais de desigualdade de distribuicão do capital e acesso às melhores tecnicas. O modelo sraffiano de renda intensiva, de outra parte, explica o surgimento da renda quando diferentes "doses de capitais" (que correspondem aos diferentes metodos de produção) são aplicadas em uma mesma qualidade de terra (e nesse sentido que a renda intensiva sraffiana aproxima-se da renda diferencial II de Marx e da renda "intensiva" ricardiana), em condicões de equillbrio.

5. No que concerne à renda de monopolio, pensamos que a teoria sraffiana da renda intensiva consiste em uma explicação inedita para o caso. Nesse sentido, acreditamos ser impreciso associar a renda intensiva sraffiana (uma renda de monopolio) com a renda absoluta marxista. Essa 
ultima pretende explicar a renda na terra marginal baseando-se em pressuposto questionavel (e historicamente mutável) da menor composição orgânica do capital na agricultura (e Marx afasta, ele proprio, a pecuaria de sua andlise - que, suspeitamente, corresponderia a uma maior composicão orgânica do capital - porque "ao tratar da renda, tomamos por determinante a parte do capital agricola que produz o alimento vegetal decisivo, o principal meio de subsistência dos povos civilizados"(MARX, 1985, p.881)). Alem disso, a teoria da renda absoluta parte do pressuposto de que ha uma nitida separação de classes entre capitalistas e proprietarios de terras. Por outro lado, a teoria sraffiana explica a posslvel existência de uma renda de monopolio em uma dada qualidade da terra (que pode ser a terra marginal), se existirem dois metodos de producão do cereal sendo operados lado a lado nessa terra, de tal forma que o metodo mais produtivo produza o cereal a um custo medio maior que o metodo menos produtivo. Ainda, a renda singular tambem explicaria a determinacão de uma renda de monopolio em uma dada terra, considerando apenas um metodo de produção do cereal e variações na demanda final das mercadorias, devidas a variações na distribuição de renda.

6. O modelo sraffiano da renda intensiva tambem se presta, como vimos, à andlise dos conflitos distributivos entre as classes sociais, de uma maneira mais abrangente que as 
teorias marxista e ricardiana. Tambem o modelo da renda singular contempla esses conflitos. Assim sendo, a andilise sraffiana prevê vărios casos em que não posslvel obter as soluções do modelo econômico considerando apenas aspectos econômicos. As indeterminações que consideram um conflito entre terra e capital ilustram a importância de um tratamento especlfico à renda da terra.

7. Como salientamos no cap1tulo 3 desta dissertaça, quando a antlise sraffiana aborda 0 problema da escolha de tecnicas (aspecto central da teoria sraffiana da renda da terra), devemos pressupor rendimentos constantes à escala nos diferentes processos produtivos da economia, 0 que torna a teoria sraffiana da renda da terra condicionada à validade desse pressuposto.

8. $\mathbf{E}$ preciso salientar, alem do mais, que a teoria sraffiana foi usada, em princlpio, para analisar aspectos de teoria econômica pura. como discutimos no capitulo 3, Sraffa propunha-se a explicar uma maneira alternativa de determinacão dos preços e sua relação com as varidveis distributivas. Operacionalizar o modelo sraffiano da renda da terra visando a constatacão emplrica de suas assertivas e, pois, um desafio a ser transposto. 


\section{REFERENCIAS BIBLIOGRAFICAS}

BARKAI,H. Ricardo's second thoughts on rent as a relative share. Southern Economic Journal, Chapel Hill, $32(3)$ : $285-93,1966$.

BIRD. R. E. A reinterpretation of ricardian rent theory. The American Economist, New York, 19(2):69-73, 1975.

CANDELA, G. Une presentation critique de la rente ricardienne: un amendment. Revue Economique, Paris, $\underline{29}(2): 395-401, \operatorname{mar} .1978$.

D'AGATA, A. The existence and unicity of cost-minimizing systems in intensive rent. Metroeconomica, Bologna, (35): $73-85,1983 a$.

D'AGATA,A. Molteplicitd di merci agricole e renditta diferenziale estensiva. Catania, 1983b. (mimeo)

DOBB,M. Teorias do valor e distribuicão desde Adam Smith. Portugal, Editorial Presenca, 1973a. 339p.

DOBB,M. The sraffa system and critique of the neoclassical theory of distribution. In: HUNT,E.K. \& SCHWARTZ,J.G, ed. A critique of economic theory, Hardmonsworth, Penguin Books, 1973b. p 205-21. 
FLICHMAN, G. Sobre a teoria da renda fundiaria. Estudos CEBRAP, Petropolis, (20): 29-73, abr.-jun. 1977.

GAREGNANI, P. Heterogeneous capital, the production function and the theory of distribution. The Review of Economics Studies, Oxford, (37): 407-36, 1970.

HOFFMANN, R. Comentarios a respeito da nota de Robert Nicol sobre a tendência à queda na taxa de lucro em Ricardo. Revista de Economia Polftica, São Paulo, 5(2): 115-17, abr.-jun. 1985.

JOHNSON, H.G. An error in Ricardo's exposition of his theory of rent. Quarterly Journal of Economics, New York, 62(5): 792-3, nov. 1948.

KURZ,H.D. Rent theory in a multisectoral model. Oxford Economic Papers, Oxford, 30(1): 16-37, 1980.

LACKMAN, C. The modern development of classical rent theory. The American Journal of Economics and Sociology, New York, 36(1): 51-63, jan. 1977 .

LENZ,M.H. A categoria econômica renda da terra. Porto Alegre, 1980. 134 p. (Mestrado-Faculdade de Ciências Econômicas-UFRGS) •

LIPIETZ, A. Terre, rente et rarete. Revue d'Economie Politique, Paris, (5): 746-54, sept.-oct., 1978. 
MARX, K. O Capital: Critica da economia polltica. 4.ed. São Paulo, DIFEL, 1985. Livro 3, v. 6. 375 p.

METCALFE,J.S \& STEEDMAN, I. Reswitching and primary imput use. The Economic Journal, Cambridge, (82), 1972.

MONTANI, G. La teoria ricardiana della rendita. L'Industria, Milano, $(3,4): 221-43,1972$.

MONTANI, G. Scarce natural resources and income distribution. Metroeconomica, Bologna, 27(1): 68-101, jan.-abr. 1975 .

MURRAY,R. Value and theory of rent: part one. Capital \& Class. Bulletin of the conference of socialist Economists, London, (3): 100-22, 1977.

MURRAY,R. Value and theory of rent: part two. Capital \& Class, Bulletin of the conference of socialist Economists, London, (4): 11-33, 1978 .

NAPOLEONI, C. Smith, Ricardo e Marx: consideracões sobre a historia do pensamento econômico. Rio de Janeiro, Graal, $1978.239 \mathrm{p}$.

NICOL, R. Uma nota sobre a tendência secular à queda na taxa de lucro em Ricardo. Revista de Economia Polftica, Petrópolis, 4(4): 53-61, out.-dez., 1984. 
PASINETTI, L.L. Lectures on the theory of production. Nova York, Columbia University Press, 1977. $285 \mathrm{p}$.

PASINETTI, L.L. Essays on the theory of joint production. Nova York, Columbia University Press, 1980. 243 p.

PINHEIRO,F.A. A renda e o preço da terra; uma contribução à and̆lise da questão agrâria brasileira. Piracicaba, 1980, 277 p. (Livre-docência - Escola superior de Agricultura "Luiz de Queiroz"/USP).

POSSAS, M. Valor, preço e concorrência. Revista de Economia Polltica, São Paulo, $2(4): 71-110$, out./dez., 1982 .

QUADRIO-CURZIO, A. Accumulazione del capitale e rendita. Bologna, Il Mulino, 1975.

QUADRIO-CURZIO, A. Rent, income distribution, and orders of efficiency and rentability. In: PASINETTI, L.L. Essays on the theory of joint production. Nova York, Columbia University Press, 1980. p. 218-40.

QUADRIO-CURZIO, A. Technological scarcity: an essay on productio and techical change. In: BARANZINI, M. \& SCAZZIERI, R., eds. Foundations of economics. Oxford, Basil Blackwell, 1986. 
QUADRIO-CURZIO, A. Land rent. In: EATWELL, J.;

MILGATE,M.; NEWMAN,P., eds. The new palgrave dictionary of economics. London, The Macmillan Press Limited, 1987. v. 3, p. $118-21$.

RICARDO, D. Princlpios de economia polltica e tributacão. São Paulo, Abril Cultural, 1982. 286 p.

ROBINSON, J. Prelude to a critique of economic theory. In: HUNT, E.K \& SCWARTZ, J.G. A critique of economic theory. Hardmonsworth, Penguin Books, 1973. p. 197204 .

ROBINSON,J. \& EATWELL,J. Introdução à economia. são Paulo, Livros Tecnicos e Cient1ficos, 1979. $416 \mathrm{p}$.

RONCAGLIA, A. Sraffa and the theory of prices. Chichester, John willey and Sons, $1978.176 \mathrm{p}$.

SALVADORI, $N$. On a new variety of rent. Metroeconomica, Bologna, (35): 73-85, 1985.

SALVADORI, N. Land and choice of techniques within the Sraffa framework. Australian Economic Papers, Adelaide, $25(46): 94-105,1986$. 
SAMUELSON,P.A. A modern treatment of the ricardian economy: I. The pricing of goods and of labor and land services. The Quarterly Journal of Economics, New York, $73(1): 1-35$, feb., 1959.

SILVA,S.S. Valor e renda da terra; o movimento do capital no campo, São Paulo, Polis, 1981. 159 p.

SRAFFA, P. As leis dos rendimentos sobre condicões de concorrência. Literatura Econômica, Rio de Janeiro, $4(1): p \cdot 13-34,1982$.

SRAFFA, P. Producão de mercadorias por meio de mercadorias. São Paulo, Abril Cultural, 1983. p. $173-258$

SRAFFA, P. Relacões entre custo e quantidade produzida. Campinas, Hucitec, $1989.88 \mathrm{p}$.

SWEEZY,P.M. Teoria do desenvolvimento capitalista. São Paulo, Abril Cultural, 1983. 288 p.

VIDONNE, $P$. Une presentation critique de la rente ricardienne. Revue Economique, Paris, 28(2): 227-39, mar., 1977.

VIDONNE, P. Reponse de P. Vidonne. Revue Economique, Paris, 29(2): 402-4, mar., 1978 . 